Cahiers Charlevoix

Cahiers Charlevoix

Études franco-ontariennes

\title{
Les Paroisses de l'Ontario français 1767-2000
}

\section{Gaétan Gervais}

Volume 6, 2005

URI : https://id.erudit.org/iderudit/1039332ar

DOI : https://doi.org/10.7202/1039332ar

Aller au sommaire du numéro

\section{Éditeur(s)}

Société Charlevoix

Presses de l’Université d’Ottawa

ISSN

1203-4371 (imprimé)

2371-6878 (numérique)

Découvrir la revue

Citer cet article

Gervais, G. (2005). Les Paroisses de l'Ontario français 1767-2000. Cahiers

Charlevoix, 6, 99-194. https://doi.org/10.7202/1039332ar

\section{Résumé de l'article}

Gaétan Gervais s'intéresse au réseau paroissial franco-ontarien. Outil de survivance ou institution sociale, la paroisse fut, avec l'école, cet appareil polyvalent qui fédéra les élites canadiennes-françaises, au temps où langue française et religion catholique fusionnaient, et qui marqua profondément, sur les plans culturel, social, éducatif et économique, la vie des Franco-Ontariens. Le survol historique de deux siècles et demi et le balayage géographique que l'auteur propose font plus que " montrer la concomitance entre une carte des églises du réseau franco-ontarien de paroisses catholiques et les régions de peuplement franco-ontarien ». Car, si cette problématique paraît aller de soi, les instruments de recherche pour la démontrer étaient jusqu'ici inexistants. Le tableau qu'il brosse constitue précisément un outil de recherche par lequel il dénombre, répertorie et localise par diocèse, en datant leur fondation, chacune des 258 paroisses qu'il a recensées entre 1767 et 2000 , et qu'il a représentées par une série de dix-huit tableaux et d'autant de cartes qu'il a fait préparer. Alors, les relations entre l'expansion démographique de ce peuple, qui se déploie au gré des activités de travail (commerce des fourrures, colonisation, exploitations forestières, agricoles, minières, ferroviaires et industrielles), et l'établissement des paroisses apparaissent clairement. Ce texte, qui définit le cadre dans lequel s'agitent les questions religieuses et nationales (paroisses françaises et paroisses bilingues), est aussi le prélude à un répertoire complet des paroisses franco-ontariennes auquel notre collègue travaille depuis quelques années.
Ce document est protégé par la loi sur le droit d'auteur. L’utilisation des services d'Érudit (y compris la reproduction) est assujettie à sa politique d'utilisation que vous pouvez consulter en ligne.

https://apropos.erudit.org/fr/usagers/politique-dutilisation/ 


\section{Les Paroisses}

\section{DE L'ONTARIO FRANÇAIS}

1767-2000

Gaétan Gervais

Département d'histoire

Université Laurentienne, Sudbury

Cahiers Charlevoix 6, 2004, p. 99-194 


\section{SOMMAIRE}

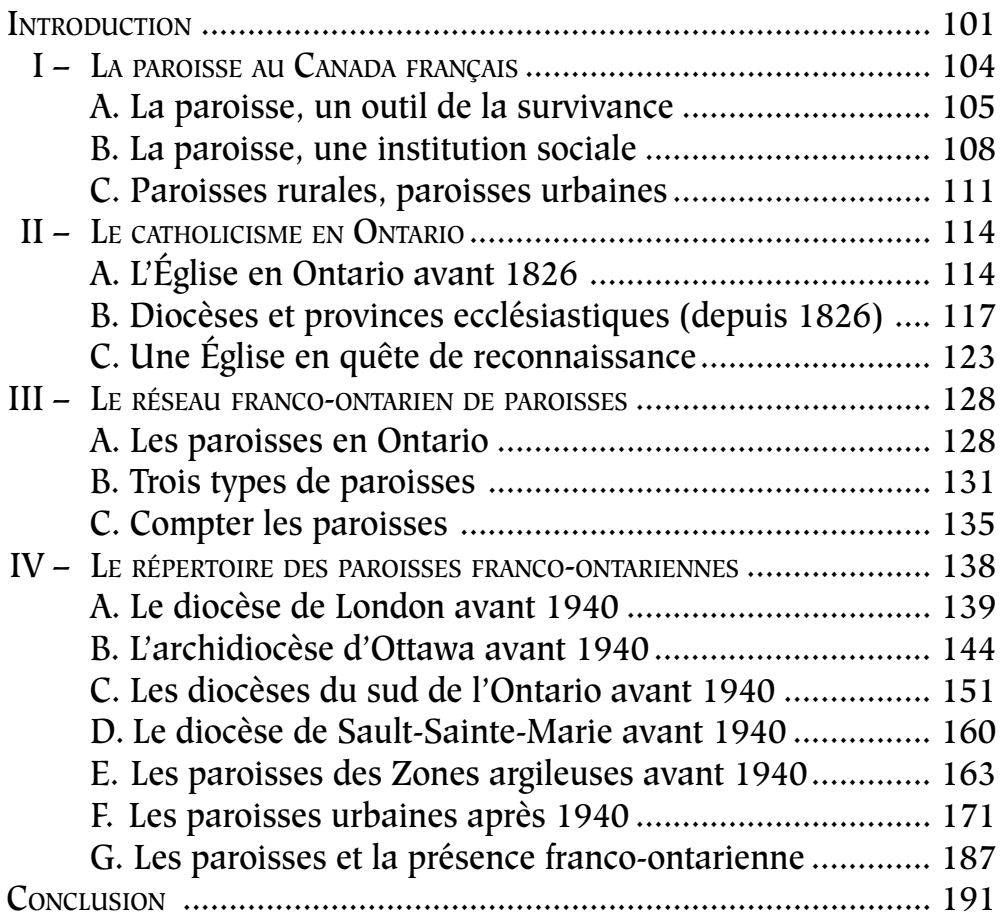




\section{Les Paroisses}

\section{DE L'ONTARIO FRANÇAIS}

\section{$1767-2000$}

\section{INTRODUCTION}

En Ontario français, c'est une vérité reçue que la survie de la communauté dépend de son réseau d'institutions. Il est également convenu que les deux institutions culturelles les plus importantes, avant les années 1960, furent la paroisse et l'école. La première évoluait dans le giron de l'Église, tandis que la seconde relevait de l'État.

Les élites franco-ontariennes ont fait preuve d'un parti pris tenace en faveur des institutions linguistiquement homogènes. La plus récente expression de cette problématique, élaborée à l'école de la sociologie, jauge la vitalité d'une communauté culturelle à l'étendue et à l'autonomie de son réseau d'institutions. En effet, peu de concepts, en Ontario français, ont connu plus de succès, depuis quatre décennies, que la notion de «complétude institutionnelle ${ }^{1} »$.

\footnotetext{
${ }^{1}$ Le sociologue Raymond Breton a fait connaître ce concept dans deux articles, «Institutional Completeness of Ethnic Communities and the Personal Relation of Immigrants", dans American Journal of Sociology 70 (2), septembre 1964, p. 193-205, et «Les Institutions et les réseaux d'organisation des communautés ethnoculturelles", dans C. Archibald (dir.), État de la recherche sur les communautés francophones hors Québec, Québec, Fédération des francophones
} 
Les luttes pour la survie culturelle et pour la création de paroisses franco-ontariennes constituaient des projets complémentaires. Infatigables dans leurs revendications, les élites canadiennes-françaises, en Ontario et ailleurs, ont consciemment élaboré une stratégie visant l'établissement d'un réseau de paroisses françaises.

La «paroisse» n'était pas une institution nouvelle quand elle arriva en Nouvelle-France ${ }^{2}$. Pour trouver l'origine lointaine de la paroisse franco-ontarienne, il faut remonter aux premiers siècles de l'ère chrétienne, dans les campagnes de la Méditerranée orientale et de l'Afrique du Nord. Après une évolution plus que millénaire, la paroisse devint au $\mathrm{XVI}^{\mathrm{e}}$ siècle, à l'heure de la Réforme protestante, l'institution centrale dans la stratégie pastorale de l'Église catholique. C'est alors que le concile de Trente (1545-1563) en définit nettement le caractère et les fonctions ${ }^{3}$. Le nouveau régime paroissial annonçait un meilleur encadrement des fidèles par un clergé mieux préparé. Voulue par les autorités romaines et adoptée par le concile, cette réforme tridentine rehaussa le rôle de la paroisse dans l'Église durant les siècles suivants. Ainsi, du point de vue ecclésial, la paroisse canadienne-française maintint sans grande originalité un type d'organisation commun à l'Occident chrétien.

hors Québec, 1984, p. 4-19. Récemment, cette thèse institutionnelle a été défendue dans une plaquette posthume de Roger Bernard, À la défense de Montfort, [Ottawa], Le Nordir, [c2000], 59 p. Cependant, les élites francoontariennes et les défenseurs de Montfort furent pris à partie par Gilles Paquet, «Montfort et les nouveaux Éléates », dans Francophonies d'Amérique, 13, 2002, p. 139-155.

${ }^{2}$ Sur l'histoire des paroisses, voir l'article de R. Naz, «Paroisse», dans R. Naz (dir.), Dictionnaire de droit canonique contenant tous les termes du droit canon [...], Paris, Librairie Letouzey et Ané, 1957, p. 1234-1247; J. Passicos, «Paroisse », dans G. Mathon et al., Hier - Aujourd'hui - Demain. Encyclopédie publiée sous le patronage de l'Institut catholique de Lille, Paris, Letouzey et Ané, volume 10, col. 671-691. Voir aussi Patrick B. McCluskey, «La Paroisse dans l'Église», dans les Semaines sociales du Canada (Section française), La Paroisse. Cellule sociale. Compte rendu des cours et conférences, Montréal, Institut social populaire, «XXX ${ }^{\mathrm{e}}$ Session B Edmundston 1953 », [1953], p. 33-48.

3 Voir: «Parish», dans New Catholic Encyclopedia, volume X, p. 1017-1019. 
La paroisse catholique, en Ontario, relève exclusivement de l'évêque, tant au point de vue juridique que canonique. Cette institution assuma évidemment des fonctions religieuses, mais elle abrita aussi, avant les années 1960, une gamme considérable d'activités séculières, dans les domaines culturel, social, éducatif et économique. L'option des élites canadiennes-françaises en faveur de la paroisse "polyvalente", encouragée par le clergé et par les laïcs locaux, explique leur investissement de cette institution pour lui donner un caractère national, c'est-à-dire catholique et français. Toutefois, cette préférence marquée des porte-parole franco-ontariens pour les paroisses linguistiquement homogènes inquiéta certains évêques, soucieux de conserver leurs prérogatives en cette matière. L'aspect ethnique de ces rivalités ayant déjà été décrit ailleurs, il n'est évoqué qu'aux fins d'aider à la compréhension de l'évolution des paroisses ${ }^{4}$.

Le présent travail tente de répondre à certaines questions : existe-t-il un réseau de paroisses franco-ontariennes? comment est-il né? quelle en est l'étendue dans le temps et dans l'espace? ce réseau correspond-il aux zones de peuplement franco-ontarien? quelles paroisses en font partie? où se trouvent ces paroisses? Pour comprendre la nature de la paroisse franco-ontarienne, il faut examiner cette institution sous le double éclairage de l'histoire (son évolution dans l'Église catholique, en Europe, au Canada français et en Ontario) et de la géographie (répartition des paroisses sur le territoire provincial). La création des paroisses catholiques, en Ontario français, a-t-elle respecté la même chronologie que les mouvements de la colonisation? Une question

\footnotetext{
${ }^{4}$ Sur toutes ces rivalités ethniques, voir les trois ouvrages de Robert Choquette: Langue et religion. Histoire des conflits anglo-français en Ontario, Ottawa, Éditions de l'Université d'Ottawa, 1977, 268 p.; L'Église catholique dans l'Ontario français du dix-neuvième siècle, [Ottawa], Éditions de l'Université d'Ottawa, «Cahiers d'histoire» 13, [c1984], 365 p.; La Foi gardienne de la langue, 1900-1950, Montréal, Bellarmin, 1987, 282 p.
} 
complémentaire se pose: la répartition géographique de la communauté franco-ontarienne et la distribution des églises sur le territoire de l'Ontario se recoupent-elles?

L'année 1940 sépare deux périodes. Avant cette date, 178 paroisses (françaises, bilingues ou desservies par un clergé de langue française) furent fondées en Ontario français, la plupart en milieu rural. Mais le nombre de paroisses urbaines, qu'elles fussent métropolitaines ou de banlieue, ne cessa de croître, surtout au $\mathrm{XX}^{\mathrm{e}}$ siècle. Dans la période après 1940 , un contingent de 80 nouvelles paroisses franco-ontariennes, généralement homogènes, naquirent surtout en milieu urbain.

\section{I - La paroisse au Canada français}

Implantée au Canada en 1664, date d'érection de la paroisse Notre-Dame de Québec, l'institution paroissiale devint, avec la seigneurie, l'unité de base de la vie religieuse, civile et militaire de la colonie ${ }^{5}$. Au milieu du XIX ${ }^{e}$ siècle, dans le Canada français, deux courants, à première vue contradictoires, se conjuguèrent: le nationalisme et l'ultramontanisme. Cette fusion permit d'élaborer une idéologie conservatrice, une sorte de nationalisme catholique qui favorisa l'émergence du projet socioculturel qu'était le Canada français. Dans la construction d'une société catholique et française, des institutions comme la paroisse et l'école furent appelées à tenir un rôle de premier plan.

Portée par le clergé et les élites nationalistes, cette idéologie régna longtemps sans partage, jusqu'aux années 1960. Ainsi, les élites canadiennes-françaises de l'Ontario eurent, à l'époque du Canada français, des opinions très arrêtées au sujet du rôle des paroisses et des écoles dans le maintien de la langue et de la foi. Le plus grand grief des

\footnotetext{
${ }^{5}$ Voir, pour une histoire de cette institution: Serge Courville et Normand Séguin (dir.), Atlas historique du Québec. La Paroisse, Sainte-Foy, Presses de l'Université Laval, 2001, xiii-296 p.
} 
nationalistes était la constante violation de ce qu'ils appelaient "nos droits religieux et nationaux». Partout, les mêmes idées, fortement influencées par le nationalisme clérical, circulaient dans la société canadienne-française.

\section{A. La paroisse, un OUTIL DE LA SURVIVANCE}

Sur la valeur sociale et nationale de la paroisse, l'accord était quasi unanime chez les élites nationalistes. L'ensemble des porte-parole du Canada français, depuis le milieu du $\mathrm{XIX}^{\mathrm{e}}$ siècle, a contribué à faire de la paroisse non seulement une institution religieuse, selon sa vocation première, mais un organisme appelé à protéger, peut-être même à promouvoir, la langue et la culture françaises. Pour un groupe minoritaire comme l'Ontario français, peu influent et doublement minorisé par la langue française et par la religion catholique, la paroisse devint un soutien et un refuge.

En 1918, le dominicain M.-A. Lamarche écrivait que «La paroisse canadienne a été jusqu'à présent le plus ferme appui de notre race et pendant près de deux siècles notre unique force nationale, seul organisme de vie publique [...], seul centre de ralliement en dehors de la famille et du rang $[\ldots]^{6} »$. Dans la même veine, le chef nationaliste Henri Bourassa a décrit la paroisse comme «le foyer de la vie sociale, le berceau des libertés politiques, l'école d'apprentissage du gouvernement représentatif et populaire ${ }^{7}$ ». Renchérissant, $\mathrm{M}^{\mathrm{gr}}$ Maurice Roy, archevêque de Québec, faisait en 1950 une conférence à l'Université de Toronto («Paroisse et démocratie») et affirmait que la paroisse préparait les citoyens à devenir de futurs chefs de file. En 1966, le professeur d'études anciennes, Maurice Lebel,

\footnotetext{
${ }^{6}$ P.-A. Lamarche, cité dans Joseph-P. Archambault, «Déclaration d'ouverture », dans les Semaines sociales du Canada (Section française), op. cit., p. 17.

${ }^{7}$ Joseph-P. Archambault, "Déclaration d'ouverture», dans les Semaines sociales du Canada (Section française), op. cit., p. 14.
} 
dressant un bilan des cadres religieux du Canada français, s'aventurait encore plus loin: «Parmi les créations les plus originales du clergé canadien-français, au plan de la civilisation, je mettrais volontiers, en premier lieu, la paroisse et son complément naturel, les missions ${ }^{8}$." On pourrait aligner des douzaines de citations semblables en faveur de la paroisse canadienne-française. Ces louanges hyperboliques traduisaient la haute opinion dans laquelle les élites nationalistes tenaient la paroisse, dont le rôle semblait d'autant plus nécessaire que les minorités françaises étaient démunies au point de vue des autres institutions culturelles, sociales ou économiques.

Dès la première ligne de son histoire de la paroisse Sainte-Anne d'Ottawa, Jules Tremblay affirmait en 1925 que «Le Canadien écrit l'Histoire avec la croix de ses clochers ${ }^{9}$." L'année suivante, dans une introduction à l'album-souvenir de la paroisse de l'Immaculée-Conception de Paincourt, comté de Kent, le curé Alfred-David Émery écrivait que «Le clocher domine tout dans la paroisse, comme la foi domine tout dans les âmes. L'Église comme une mère, rassemble autour d'elle tous ses enfants et constitue la communauté paroissiale. Au temps de la conquête, le curé resta seul au milieu de ses ouailles. [...] En matière de colonisation le rôle de la paroisse est souverain ${ }^{10}$.»

Une idée semblable est proposée par Alphonse Désilets. Cet «ingénieur agricole » publia Pour la terre et le foyer, un ouvrage qui contient une section sur «les forces paroissiales», où il déclare en partant: «Celui qui a qualifié de

\footnotetext{
${ }^{8}$ Maurice Lebel, «Les Cadres religieux», dans Guy Sylvestre (dir.), Structures sociales du Canada français. Études des membres de la Société royale du Canada, [Québec/Toronto, Presses de l'Université Laval/University of Toronto Press], 1966, p. 20.

9 Jules Tremblay, Sainte-Anne d'Ottawa. Un résumé d'histoire 1873-1923, [Ottawa], Cie d'Imprimerie d'Ottawa, 1925, p. 1.

${ }^{10}$ [A.-D. Émery], Album Souvenir de la paroisse de l'Immaculée[-]Conception de Pain Court, Ont[ario], 1851-1925, s.l., s.é., s.d., p. 141.
} 
"miracle canadien" la merveilleuse survivance d'une race abandonnée à un vainqueur puissant, n'a trouvé d'autre explication à ce miracle que la force de notre organisation paroissiale autour de l'église et du pasteur, sous l'autorité gardienne des intérêts matériels et moraux dans l'ordre civique $^{11}$." Désilets brossait un portrait idyllique de la paroisse canadienne-française d'autrefois, où toutes les familles se connaissaient, se visitaient, chacune constituant un chaînon solide, évitant la ville, leur seul but étant d'enrichir le patrimoine familial. Mais tout cela semblait menacé, selon l'agronome qui n'y voyait qu'un remède: l'organisation de la jeunesse, en contact avec le clergé paroissial, afin d'effectuer un retour à la terre.

La création d'une paroisse constituait d'abord un acte religieux, certes, mais la naissance d'une paroisse française (et même bilingue) pouvait devenir un geste politique, comme l'ont bien compris tant les promoteurs que les adversaires des paroisses homogènes de langue française. L'importance même de cette institution dans la vie culturelle en faisait un objet de sollicitude. Les 21 et 22 novembre 1964, la Société Saint-Jean-Baptiste de l'Ontario tenait son onzième congrès, à Ottawa. Elle adopta une proposition d'appui à ses membres désireux d'établir des paroisses nationales, partout en Ontario où c'est «humainement possible», en distinguant entre une paroisse nationale et une paroisse territoriale ${ }^{12}$.

L'idée d'un lien essentiel entre la paroisse et la survivance fut donc fortement ancrée chez les élites canadiennesfrançaises.

${ }^{11}$ Alphonse Désilets, Pour la terre et le foyer. Économie rurale et domestique. Éducation et sociologie, préface d'Édouard Montpetit, Québec, chez l'Auteur, 1926, p. 159.

12 «Les Franco-Ontariens se choisissent un drapeau», dans Le Droit, 23 novembre 1964. 
B. LA PAROISSE, UNE INSTITUTION SOCIALE

En deuxième lieu, la paroisse a rempli en Ontario français une fonction sociale, devenant, dans plusieurs communautés, le carrefour des activités locales, un lieu de sociabilité et de rencontre. Dans les grandes paroisses urbaines, comme dans les nombreuses paroisses rurales, une gamme d'activités et d'associations permirent quelque temps de regrouper et de renforcer les communautés ${ }^{13}$.

Dans les paroisses, diverses associations intervenaient. Plusieurs eurent une vocation religieuse ou pieuse (surtout la trilogie que forment les Dames de Sainte-Anne, les Enfants de Marie et les Ligues du Sacré-Cœur), ce qui est bien naturel dans une institution comme la paroisse. De la Société Saint-Vincent-de-Paul aux diverses confréries, en passant par les clubs du rosaire et les sociétés de placiers, les organismes de dévotion ou de charité se comptèrent nombreux.

On trouvait aussi dans les paroisses des mouvements "nationaux», le plus important étant sans doute la Société Saint-Jean-Baptiste. On pouvait également compter sur la présence d'organismes économiques (les coopératives, les mutuelles et les caisses populaires), de clubs sociaux (tels les clubs Richelieu fondés en 1944), de mouvements civiques (les scouts et guides, les zouaves, les sections de la Fédération des femmes canadiennes-françaises ou les Chevaliers de Colomb), sans oublier les activités sociales (fêtes, soirées, rencontres) et culturelles (théâtre, chant, musique). Chaque paroisse possédait, selon sa situation, selon ses moyens, selon le zèle de son clergé, selon ses effectifs, un éventail plus ou moins complet de groupes de piété, d'animation communautaire, d'action économique. La disponibilité d'un laïc, d'un vicaire ou d'un curé pouvait

\footnotetext{
${ }^{13}$ Voir: Fernand Harvey, «Le Diocèse catholique au Québec: un cadre territorial pour l'histoire sociale», dans Cahiers des Dix, 56, 2002, p. 51-124. 
rapidement étendre une activité, mais leur départ pouvait aussi causer la fin de certains organismes.

Sur la paroisse régnait le curé auquel la tradition attribue un rôle éminent, encore que mal connu. Dans l'imaginaire populaire, il dirigeait sa paroisse comme un bon père guide sa famille. Sa stature légendaire tient en partie à la longévité de son travail dans une même paroisse. On compte bien 88 curés qui ont occupé la même cure pendant plus de vingt ans. En Ontario français, le cas le plus remarquable de longévité provient sans doute de $\mathrm{M}^{\mathrm{gr}}$ Hercule Touchette, qui fut 56 ans curé de Sainte-Euphémie de Casselman (18971953); dans ce palmarès de persévérance, il est suivi par Pierre Morin, 52 ans curé à l'Immaculée-Conception de Val-Gagné (1921-1972) et par Jean-Urgel Forget, 50 ans curé de Saint-Jacques d'Embrun (1896-1946). Quatorze autres curés ont servi la même paroisse pendant plus de 40 ans, 17 ont dirigé la même paroisse de 30 à 39 ans, le reste (51 curés) a occupé la même cure entre 20 et 29 ans. Certains acquirent une grande renommée, comme les curés F.-X. Barrette (49 ans à Saint-Charles-Borromée d'Ottawa [Vanier], 1912-1961), Oscar Racette (48 ans à Saint-JeanBaptiste de Verner, 1914-1962), J.-Alfred Myrand (44 ans curé à Sainte-Anne d'Ottawa, 1903-1947), Thomas Marchildon (33 ans à Sainte-Croix de Lafontaine, 19371970), Charles-A. Parent (39 ans à Saint-Françoix-Xavier de Tilbury, 1905-1944) et Philippe Marchand (37 ans curé à Sacré-Cour de Toronto, 1887-1924).

Jouissant d'un grand prestige social, les curés élargirent parfois leur champ d'action bien au-delà du domaine religieux. Certains, à l'occasion, intervinrent dans des secteurs profanes. On trouve ainsi le curé entrepreneur, le curé éducateur, le curé politicien, le curé spéculateur, le curé agriculteur, le curé bâtisseur. Il existe en particulier une riche imagerie du curé colonisateur. Personne, au Canada français, sans doute, n'a mieux incarné ce rôle que le célèbre curé Antoine Labelle, figure légendaire parmi les 
nombreux promoteurs de la colonisation, une activité que l'Église a fortement encouragée.

Au Canada français, l'Église catholique a une longue histoire de promotion de la colonisation et du peuplement. Longtemps, le clergé ultramontain a chanté les gloires de la vie rurale, trouvant peu à redire sur ce mode de vie. L'emplacement de la paroisse idéale semblait se trouver à la campagne. Le curé A.-D. Émery écrivait en 1926 que la grande transformation de la paroisse « est due aux prêtres qui toujours ont pénétré dans le pays en y emmenant les catholiques avec eux, car il est constaté de par l'histoire que nos paroisses Canadiennes-françaises [sic] ont toujours eu pour chef d'exploration le prêtre qui s'avance dans la forêt pour trouver un bon terrain afin d'ériger une paroisse $^{14} »$.

Les deux premiers évêques d'Ottawa, $\mathrm{M}^{\text {gr }}$ Bruno Guigues (1847-1874) et $\mathrm{M}^{\mathrm{gr}} \mathrm{J}$. -Thomas Duhamel (1874-1909), ont appuyé ces mouvements dans leurs lettres pastorales. Le premier lança en 1849 une société de colonisation œuvrant dans l'Est ontarien, alors que le second parraina la Société de colonisation du diocèse d'Ottawa en 1884, une organisation mise sur pied pour promouvoir la colonisation du Témiscamingue. Plusieurs prêtres colonisateurs sillonnèrent l'Amérique pour recruter des colons, dans les vieilles paroisses ou aux États-Unis, et pour établir ces recrues dans les régions de colonisation, comme le fit le père Charles-Alfred Paradis près de Verner. Certains évêques affectèrent des prêtres à cette œuvre de colonisation, alors que le gouvernement canadien finançait un programme de missionnaires colonisateurs.

Tant les gouvernements fédéral que provincial firent de la propagande en faveur de la colonisation ${ }^{15}$. En Ontario,

${ }^{14}$ [A-.D. Émery], op. cit., p. 6.

${ }^{15}$ Voir, par exemple, le Guide du colon du Nouvel-Ontario. District de SaultS[ain]te-Marie, préface de S. Corbeil, Montréal, Imprimerie des Sourds-Muets, 
le gouvernement provincial a élaboré des politiques de colonisation qu'il continua de soutenir jusque dans les années 1930; mais il ne fit appel ni au clergé ni aux paroisses pour soutenir la colonisation. L'appui à cette cause provint de tous les milieux sans acception de langue, de religion ou de classe sociale.

Le clergé canadien-français, omniprésent dans les zones de colonisation et imbu d'idées agriculturistes, continua en Ontario de voir dans la paroisse l'encadrement nécessaire à la colonisation catholique, tant française qu'irlandaise.

Les politiques de $\mathrm{M}^{\mathrm{gr}}$ Guigues et de $\mathrm{M}^{\mathrm{gr}}$ Duhamel illustrent l'importance que le clergé accordait à la colonisation; mais l'appui vint aussi des agronomes, des intellectuels, des politiciens et des acteurs sociaux. Canada français, survivance, paroisse, colonisation, voilà autant de termes complémentaires.

\section{Paroisses ruRales, paroisses urbaines}

Deux facteurs bouleversèrent le monde des paroisses franco-ontariennes après la Deuxième Guerre mondiale: d'abord le défi des paroisses urbaines, puis le concile de Vatican II (1962-1965).

En Ontario, comme ailleurs en Amérique, les colons vinrent en grand nombre ouvrir des terres au XIX ${ }^{e}$ siècle. Mais la population se pressait de plus en plus dans les villes, de sorte qu'au début du $\mathrm{XX}^{\mathrm{e}}$ siècle, la population ontarienne devint majoritairement urbaine. Soutenue par l'industrialisation croissante de l'économie ontarienne,

1925, 59 p. La brochure contient: «La Paroisse canadienne » par H. Magnan, p. 5-14, et de brèves sections sur «Le Nouvel-Ontario », p. 15-23; avec de brefs historiques de paroisses et autres informations utiles. Pour la propagande des gouvernements, voir Benoît-Beaudry Gourd, «La Colonisation des Clay Belts du Nord-Ouest québécois et du Nord-Est ontarien: étude de la propagande des gouvernements du Québec et de l'Ontario à travers leurs publications officielles (1900-1930)", dans Revue d'histoire de l'Amérique française 27(2), septembre 1973 , p. 235-256. 
l'urbanisation continua, inexorablement, puis prit une grande ampleur après la Deuxième Guerre mondiale. La transition entre un monde rural et la société urbaine a duré un siècle. L'Ontario français s'urbanisait comme le reste de l'Ontario, mais moins rapidement que la population générale. Les élites franco-ontariennes gardèrent longtemps un souvenir nostalgique de la vie rurale. Pour elles, la paroisse rurale avait l'avantage de limites clairement établies, de terres occupées par des habitants propriétaires, de familles souvent unies par des liens de parenté. Cette vision idyllique de la vie rurale, où les chefs de famille et le curé travaillaient ensemble, dans un climat harmonieux et dépourvu de conflits, est une image déformante qui occulte les grandes difficultés attendant le colon et sa famille.

Plusieurs facteurs annoncent après 1945 le déclin du rôle social de la paroisse en Ontario français. Le concile de Vatican II (1962-1965) modernisa les institutions de l'Église, y compris les paroisses qui furent ramenées à leur vocation pastorale. Certains facteurs ont profondément modifié le rôle de la paroisse, à savoir la baisse des effectifs du clergé au Canada français, la diminution de la pratique religieuse et la réduction des activités séculières dans les paroisses. De même, le nationalisme canadien-français traditionnel recula fortement à cette époque, privant les minorités de l'aide apportée depuis longtemps par le clergé canadien-français, en partie recruté au Québec. Le relais fut pris par les écoles, par les centres culturels et par une foule d'organismes culturels et éducatifs.

Au milieu du $\mathrm{XX}^{\mathrm{e}}$ siècle, d'autres phénomènes démographiques importants se conjuguèrent. L'immigration fit croître la population catholique, alors que l'agrandissement de la banlieue, avec ses villes-dortoirs, accrut la demande de nouvelles paroisses. En effet, le réseau paroissial franco-ontarien a traversé une période de croissance 
rapide entre 1945 et 1960: 80 paroisses, à peu près toutes urbaines, furent érigées durant ces quinze années (14 dans le Sud, 31 dans l'Est et 35 dans le Nord). Autour de toutes les villes - Toronto, Ottawa, Windsor, Cornwall, Sudbury et Timmins -, on peut vérifier ce phénomène. Même en milieu urbain, la paroisse resta un temps une institution centrale.

Puis, tout s'arrêta net dans les années 1970. On n'ouvrit plus de nouvelles paroisses. En fait, on commença à fermer les églises. Il s'agit là d'un phénomène qui se produisit à travers le monde occidental. Théologiens et pasteurs s'inquiétèrent d'ailleurs de l'avenir de la paroisse urbaine. Le virage urbain compromettait beaucoup de pratiques qui étaient habituelles à la campagne. Comment conserver au curé son rôle traditionnel et sa présence auprès des fidèles? La structure de la paroisse urbaine est plus variée, comptant souvent de 15000 à 20000 personnes, largement non pratiquantes.

Les autorités religieuses se souciaient beaucoup de la difficulté pour les pasteurs de connaître leurs paroissiens ( «rue par rue, maison par maison» dit un texte de Pie XII en 1951), un défi accru par les déménagements fréquents des Ontariens. Les paroissiens ne se connaissaient plus entre eux, d'où la difficulté de constituer une communauté. On peut à ce sujet évoquer les difficultés de rejoindre les familles canadiennes-françaises vivant dans les grandes villes industrielles comme Toronto (la paroisse du SacréCour), Hamilton (Notre-Dame-du-Perpétuel-Secours) ou Oshawa (Assomption-de-Notre-Dame).

En milieu urbain, l'institution paroissiale n'arrivait plus, comme en milieu rural, à maintenir son emprise morale. De plus, Vatican II a défini la paroisse comme une communauté, non plus comme une entité administrative et territoriale. Par conséquent, les activités non religieuses, dans beaucoup de paroisses, cessèrent, étant parfois remplacées 
par des organismes aux mandats plus larges, comme l'Action catholique, fonctionnant à l'échelle diocésaine ${ }^{16}$. Mais celle-ci fut abolie en 1966. Les activités profanes furent abandonnées d'autant plus facilement que la pratique religieuse déclinait fortement et que les effectifs cléricaux tombaient en chute libre.

\section{II - Le Catholicisme en Ontario}

C'est dans le creuset religieux de la Nouvelle-France que les premières paroisses canadiennes virent le jour. Après la Conquête de 1760 , le catholicisme fut longtemps considéré comme la religion des Français. Le Haut-Canada étant une terre protestante appartenant à la Grande-Bretagne, les autorités ont souvent craint qu'une expansion de l'Église catholique ne devienne une menace. Pour l'Église catholique en Ontario, par conséquent, deux défis semblaient se poser. Il fallait d'abord s'affranchir de la tutelle gouvernementale et obtenir la pleine liberté d'action, un objectif atteint en 1826 (lors de la création du diocèse de Kingston) et en 1844 (avec l'établissement de la première province ecclésiastique au Canada). Ensuite, l'Église devait s'intégrer à la société ontarienne, ce qu'elle tenta de réaliser en remplaçant le français par l'anglais dans ses institutions.

\section{A. L'ÉGLISE EN ONTARIO AVANT 1826}

Avant 1826, date d'érection du diocèse de Kingston, les catholiques de l'Ontario relevaient de l'évêché de Québec. En 1658, Rome érigeait le vicariat apostolique de la NouvelleFrance et nommait François de Montmorency Laval, évêque de Pétrée in partibus, comme vicaire apostolique. Lors de la création du diocèse de Québec, en 1674, $\mathrm{M}^{\text {gr }}$ de Laval en devint le titulaire. Son autorité s'étendait sur toutes les possessions nord-américaines de la France.

\footnotetext{
${ }^{16}$ Gilles Routhier, «La Paroisse québécoise : évolutions récentes et révisions actuelles», dans S. Courville et N. Séguin, op. cit., p. 46-59.
} 
Les limites actuelles du territoire de l'Ontario englobent des parties de deux zones coloniales. Au sud, la province occupe ce qui était, à l'époque de la Nouvelle-France, la partie septentrionale des Pays-d'en-haut, c'est-à-dire du bassin des Grands-Lacs; au nord, au-delà de la ligne de partage des eaux, s'étend l'ancienne Terre de Rupert, jusqu'en 1869 propriété de la Compagnie de la baie d'Hudson. Le territoire ontarien a d'abord attiré les missionnaires jésuites. On les retrouva partout, mais surtout, au XVII ${ }^{e}$ siècle, en Huronie et au lac Supérieur, puis, au XVIII ${ }^{e}$ siècle, à la Mer de l'Ouest, à Michillimakinac et au Détroit du lac Érié. Après la Conquête de 1760 , seul subsista le jésuite Pierre Potier, arrivé en 1744 pour travailler dans la mission huronne de l'Assomption et décédé en 1781.

Ne produisant pas de prêtres, la région de l'Ontario resta longtemps une terre de missions. Les missionnaires y ont donc occupé une place importante. Plusieurs vinrent de France, puis du Québec, depuis l'époque de la NouvelleFrance. Ils appartenaient à diverses communautés religieuses (les récollets, les jésuites, les sulpiciens, les oblats, les basiliens et plusieurs autres). La formation d'un clergé local ne commença qu'à la fin du XIX ${ }^{e}$ siècle. Mais l'Église continua encore longtemps de recevoir des renforts de France et du Québec, non seulement dans les missions amérindiennes et européennes, mais aussi dans les paroisses qui eurent parfois des missionnaires de langue française en attendant la formation d'un clergé de langue anglaise. Le premier grand séminaire au Canada anglais n'ouvrit ses portes qu'en 1913 à Toronto (Saint Augustine's Seminary). On compte aussi, en Ontario, des grands séminaires à London (St. Peter's Seminary), à Toronto (Saint Philip's Seminary) et à Ottawa (Séminaire universitaire SaintPaul).

La longue marche de l'Église catholique vers la pleine reconnaissance progressa durant les divers régimes politiques, en commençant par la période d'incertitudes du 
régime militaire (1760-1763). Le régime de la Proclamation royale (1763-1774) ne réussit pas à convertir les Canadiens au protestantisme, comme l'avaient brièvement espéré les autorités britanniques. Au fait, une législation de Londres, l'Acte de Québec (1774), restaura le droit civil français et autorisa le libre exercice de la religion catholique (1774-1791). Cependant, le parlement impérial conservait depuis le $\mathrm{XVI}^{\mathrm{e}}$ siècle des lois anticatholiques qui interdisaient l'établissement d'une hiérarchie catholique. Sous le régime de l'Acte constitutionnel (1791-1841), les tentatives de conférer à l'Église d'Angleterre un statut officiel échouèrent. Le droit de l'Église catholique à s'organiser librement fut reconnu en 1844, sous le régime du Canada-Uni (1841-1867).

En Ontario, l'histoire du catholicisme commença par les missions, comme celle de l'Assomption du Détroit. Les colons français s'y établirent après 1749. Un deuxième groupe de catholiques européens arriva dans la colonie à la fin du siècle. Il se composait de highlanders, des Écossais catholiques qui avaient combattu avec les Britanniques contre la France révolutionnaire. Ils avaient reçu des terres situées au nord du fleuve Saint-Laurent, entre Kingston et le lac Saint-François. Puis arrivèrent, par centaines de milliers, les Irlandais catholiques, à partir des années 1820.

Très tôt, l'évêque de Québec voulut qu'un diocèse fût érigé dans le Haut-Canada. Déjà en $1789, \mathrm{M}^{\mathrm{gr}}$ Jean-François Hubert (1788-1797), dans une lettre au cardinal Leonardo Antonelli, préfet de la Propagande, demandait quatre coadjuteurs: pour la Nouvelle-Écosse, pour Montréal, pour le Haut-Canada, pour le Nord-Ouest. Ses successeurs $\mathrm{M}^{\mathrm{gr}}$ Pierre Denaut (1797-1806) et $\mathrm{M}^{\mathrm{gr}}$ Joseph-Octave Plessis (1806-1825) poursuivirent leurs démarches, mais Londres n'approuvait pas la création de diocèses catholiques dans ses colonies. En attendant, les évêques de Québec firent deux visites pastorales dans le Haut-Canada. À l'été de 
1801, M ${ }^{\text {gr }}$ Denaut visita Kingston et se rendit jusqu'à Détroit en visite pastorale; en juillet 1816, M ${ }^{\text {gr }}$ Plessis se rendit à l'Assomption.

En 1807, Mrr Plessis tenta à nouveau de faire nommer un évêque pour le Haut-Canada, mais n'obtint qu'un vicaire général. Reconnaissant envers les Écossais catholiques pour leur appui lors des guerres européennes et envers les Canadiens pour leur participation à la Guerre de 1812 contre les États-Unis, le gouvernement impérial atténua son opposition à la création de diocèses catholiques. Il accepta d'abord la suggestion de Rome de nommer, auprès de l'évêque de Québec, un évêque auxiliaire pour le HautCanada. En 1818, le gouverneur ne permit pas de créer quatre nouveaux diocèses (Maritimes, Montréal, HautCanada et Ouest), comme le souhaitait $M^{\text {gr }}$ Plessis, mais il autorisait l'évêque de Québec à s'adjoindre quatre évêques auxiliaires, chacun responsable d'une région. Ainsi, le « district du Haut-Canada» fut confié à $\mathrm{M}^{\mathrm{gr}}$ Alexander Macdonell (McDonell), tandis que $\mathrm{M}^{\mathrm{gr}}$ Plessis, par une bulle de janvier 1819, était promu au rang d'archevêque de Québec. $\mathrm{M}^{\mathrm{gr}}$ Alexander Macdonell fut sacré évêque de Rhesaina in partibus en 1820 et nommé évêque auxiliaire de Québec pour le Haut-Canada.

En 1826, le "district du Haut-Canada» devenait le diocèse de Kingston, le premier de l'Ontario. C'est le début de l'organisation ecclésiastique catholique en Ontario.

\section{B. Diocèses et PRovinces eCClÉSIASTIQUES (DEPUIS 1826)}

Dans l'Église catholique, l'unité administrative de base est le diocèse, chacun confié à un évêque, chacun occupant un territoire particulier. Les auxiliaires d'un évêque détiennent en propre des diocèses dans des régions non chrétiennes, et sont dits in partibus infidelium. Au début de l'ère chrétienne, chaque communauté de croyants élisait son évêque, mais cette "élection" est depuis longtemps 
décidée, dans l'Église catholique, par l'évêque de Rome, c'est-à-dire le pape. À des fins administratives, Rome créa aussi des "provinces ecclésiastiques" qui réunissaient quelques diocèses. Chaque province ecclésiastique comprend un «siège métropolitain » qui reçoit la dignité d'archidiocèse et un nombre variable de diocèses dits «suffragants». Les diocèses sont divisés en paroisses ${ }^{17}$.

L'immense diocèse de Québec fut démembré à plusieurs reprises pour créer de nouveaux diocèses. Le dépeçage commença en territoire américain. Les États-Unis ayant conquis leur indépendance, le clergé et les fidèles catholiques avaient, dès 1783 , réclamé un évêque. Rome avait institué l'année suivante le vicariat apostolique des ÉtatsUnis, érigé en 1789 en diocèse de Baltimore.

Durant le Régime de l'Union (1841-1867), quatre nouveaux diocèses ontariens s'ajoutèrent à celui de Kingston (1826). Ce dernier, en 1841, fut divisé en deux pour créer le diocèse de Toronto, ville appelée à devenir la capitale économique et politique de la province.

\footnotetext{
${ }^{17}$ Sur l'organisation des diocèses et pour des biographies d'évêques, voir: Jean LeBlanc, Dictionnaire biographique des évêques catholiques du Canada. Les diocèses catholiques canadiens des Églises latines et orientales et leurs évêques; repères chronologiques et biographiques 1658-2002, Ottawa [Montréal], Wilson \& Lafleur, 2002, $881 \mathrm{p}$.
} 


\section{Carte I}

Les diocèses et les provinces ecclésiastiques catholiques de I'Ontario aujourd'hui

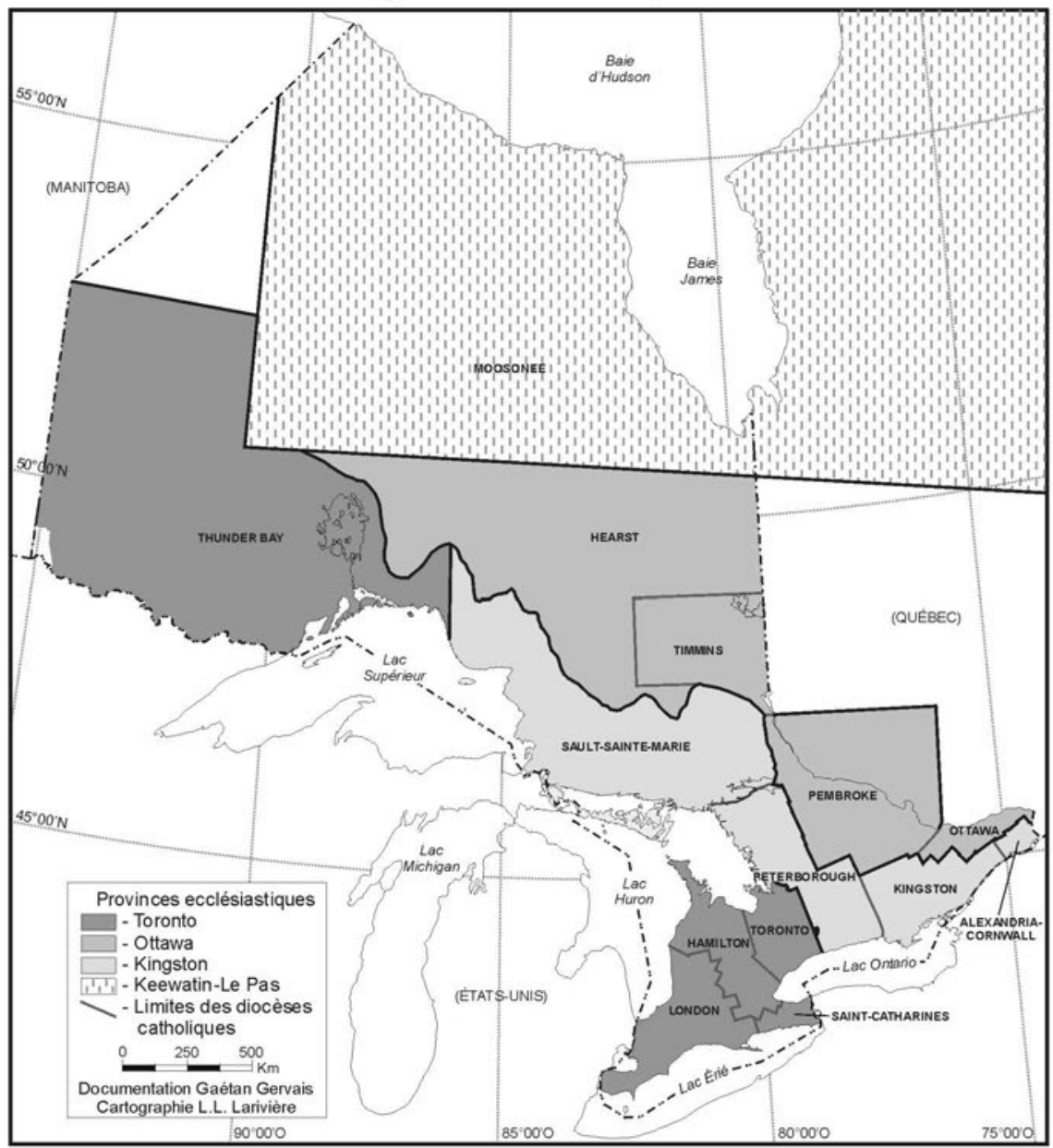




\section{TABLEAU I}

Diocèses et provinces ecclésiastiques catholiques

de l'Ontario en 2000

I - Province ecclésiastique de Toronto (1870)

1. Archidiocèse de Toronto

TOR

- diocèse de Toronto (1841-1870)

- archidiocèse de Toronto (1870- )

2. Diocèse de Hamilton (1856)

HAM

3. Diocèse de London (1856)

LON

4. Diocèse de Thunder-Bay (1952)

THU

5. Diocèse de Saint-Catharines (1958)

SCA

II - Province ecclésiastique d'Ottawa (1887)

6. Archidiocèse d'Ottawa

OTT

- diocèse de Bytown (1847-1860)

- diocèse d'Ottawa (1860-1886)

- archidiocèse d'Ottawa (1886- )

- siège métropolitain (1887)

7. Diocèse de Pembroke

PEM

- vicariat apostolique de Pontiac (1882-1898)

- diocèse de Pembroke (1898- )

8. Diocèse de Timmins

TIM

- vicariat apostolique du Témiscamingue (1908-1915)

- diocèse de Haileybury (1915-1938)

- diocèse de Timmins (1938- )

9. Diocèse de Hearst

HEA

- préfecture apostolique d'Ontario-Nord (1919-1920)

- vicariat apostolique d'Ontario-Nord (1920-1938)

- diocèse de Hearst (1938- )

III - Province ecclésiastique de Kingston (1889)

10. Archidiocèse de Kingston

- diocèse de Kingston (1826-1889)

- archidiocèse de Kingston (1889- )

11. Diocèse de Peterborough

- vicariat apostolique du Nord du Canada (1874-1882)

- diocèse de Peterborough (1882- )

12. Diocèse d'Alexandria-Cornwall

- diocèse d'Alexandria in America (1890-1910)

- diocèse d'Alexandria in Ontario (1910-1976)

- diocèse d'Alexandria-Cornwall (1976-)

13. Diocèse de Sault-Sainte-Marie (1904- )

IV. - Province ecclésiastique de Keewatin-Le Pas (1967)

14. Diocèse de Moosonee (1967- ) 
La population augmentait aussi dans la vallée de l'Outaouais. L'évêque de Montréal, $M^{\mathrm{gr}}$ Ignace Bourget, avec l'accord de l'évêque de Kingston, Mrr Rémi Gaulin, et de son coadjuteur $\mathrm{M}^{\text {gr }}$ Patrick Phelan, demanda à Rome le démembrement de leur diocèse respectif pour créer dans l'Outaouais un autre diocèse qui chevaucherait les parties ontarienne et québécoise de la vallée. On érigea en 1847 le diocèse de Bytown (renommé Ottawa en 1860) ${ }^{18}$. Ces trois diocèses (Kingston, Toronto et Ottawa), tous suffragants de Québec avant 1870, devinrent des sièges métropolitains: Toronto en 1870, Ottawa en 1887 et Kingston en 1889.

Le démembrement du diocèse de Toronto permit dès 1856 de créer les deux diocèses de Hamilton et de London ${ }^{19}$, puis en 1874 le vicariat apostolique du Canada Nord.

La Confédération canadienne de 1867 ramena l'Ontario et le Québec à des existences autonomes avec le statut de provinces. Dans cette logique provinciale, Rome créa en 1870 la province ecclésiastique de Toronto, dont les suffragants étaient les diocèses de Kingston, de Hamilton et

\footnotetext{
${ }^{18}$ Sur le diocèse d'Ottawa: Alexis de Barbezieux, Histoire de la province ecclésiastique d'Ottawa et de la colonisation dans la vallée de l'Ottawa, 2 volumes, Ottawa, La C ${ }^{\text {ie }}$ d'Imprimerie d'Ottawa, 1897, 609 p. + 507 p.; Hector Legros et Sœur Paul-Émile, Le Diocèse d'Ottawa 1847-1948, Ottawa, s.é., 1949, 905 p.; Edgar Thivierge, "À la naissance du diocèse d'Ottawa", dans Rapport. Société canadienne d'histoire de l'Église catholique, 2, 1934-1935, p. 27-38; Pierre Hurtubise, Mark McGowan et Pierre Savard (dir.), Planté près du cours des eaux. Le diocèse d'Ottawa 1847-1997, Ottawa, Novalis, 1997, 232 p.

${ }^{19}$ Sur le diocèse de London: John F. Coffey (comp.), The City and Diocese of London, Ontario, Canada. An Historical Sketch, London, 1885, 78 p.; John K.A. Farrell, The History of the Roman Catholic Church in London, Ontario, 1826-1931, Thèse de maîtrise, University de Western Ontario, 1949, v-203 p.; Pasquale Fiorino, "The Nomination of Michael Fallon as Bishop of London", dans Historical Studies, 62, 1996, p. 33-46; Gustave Lacasse, "Soixante-etquinze ans de vie catholique et française en Ontario. Vicissitudes et transformations d'un diocèse d'origine et de traditions françaises", dans Rapport. Société canadienne d'histoire de l'Église catholique, 8, 1940-1941, p. 19-28, dans Maurice Lacasse, Le Lion de la Péninsule (1890-1953). Biographie et poèmes du Sénateur Gustave Lacasse (s.l., s.é., [c1975], 177 p.), p. 111-125 et aussi publié en brochure (10 p.).
} 
de London, mais pas le diocèse d'Ottawa, qui restait suffragant de Québec. La création du vicariat apostolique du Canada Nord (créé en 1874 et devenu en 1882 le diocèse de Peterborough) entraîna une réplique de la part d'Ottawa.

En 1882, M ${ }^{\text {gr }}$ Duhamel obtint la création du vicariat apostolique de Pontiac (qui devint en 1898 le diocèse de Pembroke), suffragant d'Ottawa. Mais, surtout, Ottawa devint en 1886 un archidiocèse et, en 1887, un siège métropolitain avec le vicariat apostolique de Pontiac pour suffragant. Des rumeurs se répandirent qu'on formerait un nouveau diocèse au nord de Montréal, avec des territoires pris aux deux diocèses de Montréal et d'Ottawa, comme le réclamait le curé Labelle, et aussi un autre diocèse dans l'Est ontarien, par un démembrement de Kingston. Les évêques anglo-celtiques, réunis à Toronto pour préparer la succession de $\mathrm{M}^{\mathrm{gr}}$ John Lynch, mort en mai 1888, résolurent d'arrêter l'expansion d'Ottawa en proposant à Rome de diviser la province ecclésiastique de Toronto pour créer une nouvelle province de Kingston qui comprendrait le diocèse de Peterborough et un nouveau diocèse englobant tout l'Est ontarien (Stormont et Glengarry, mais aussi la partie ontarienne du diocèse d'Ottawa). Rome approuva la demande en quelques mois (l'archevêché fut créé le 28 décembre 1889), nomma James Vincent Cleary archevêque de la métropole de Kingston et créa le nouveau diocèse d'Alexandria en janvier $1890^{20}$.

\footnotetext{
${ }^{20}$ Sur l'histoire du diocèse d'Alexandria-Cornwall: Robert Choquette, De la controverse à la concorde. L'Église d'Alexandria-Cornwall, [Ottawa], Éditions L'Interligne, 1990, 126 p.; Rudolph Villeneuve, Cent Mille Bienvenues. Ceud Mile Failte. Histoire du diocèse d'Alexandria-Cornwall 1890-1990, traduction de Charles-Émile Claude, [Cornwall, Publication du diocèse d'AlexandriaCornwall], 1990, x-204 p. (L'original anglais: Rudolph Villeneuve. One Hundred Thousand Welcomes. Ceud Mile Failte. The Story of the Diocese of AlexandriaCornwall 1890-1990, [Cornwall, Diocèse d'Alexandria-Cornwall], 1990, xi-289 p.)
} 
Le diocèse de Sault-Sainte-Marie (1904), créé pour la population croissante du nord de l'Ontario, devint suffragant de Kingston, alors que les deux diocèses de Timmins (appelé Haileybury de 1915 à 1938) et de Hearst (1938) furent constitués suffragants d'Ottawa. Dans la région industrielle du Centre, le diocèse de Saint-Catharines fut créé en 1958, suffragant de Toronto, comme le devint le diocèse de Thunder-Bay (1952) dans le Nord-Ouest. Enfin, le diocèse de Moosonee (1967) occupa le Grand Nord, avec le statut de suffragant de Keewatin-Le Pas, au Manitoba.

Aujourd'hui, l'Ontario compte quatorze diocèses catholiques, répartis dans quatre provinces ecclésiastiques (Tableau I et Carte I). Dans celle de Toronto se trouvent l'archidiocèse de Toronto et ses quatre sièges suffragants de Hamilton, de London, de Thunder-Bay et de SaintCatharines; la province d'Ottawa comprend l'archidiocèse d'Ottawa et ses trois diocèses suffragants de Pembroke, de Timmins et de Hearst: enfin, sont regroupés, dans la province de Kingston, l'archidiocèse de Kingston et les trois diocèses suffragants de Peterborough, d'Alexandria-Cornwall et de Sault-Sainte-Marie. Enfin, dans le Grand Nord, le diocèse de Moosonee est suffragant de l'archidiocèse de Keewatin-Le Pas au Manitoba. Depuis 1943, les évêques du Canada sont aussi regroupés au sein de la Conférence des évêques catholiques du Canada (CECC), reconnue par la Vatican en 1948 et faisant partie d'un réseau mondial de conférences épiscopales établies en 1965. La CECC comprend en outre quatre conférences régionales, dont la Conférence des évêques catholiques de l'Ontario (CECO)

\section{UNE ÉGLISE EN QUÊTE DE RECONNAISSANCE}

Avec l'affranchissement juridique de l'Église, en 1844, les derniers obstacles à l'organisation complète de la hiérarchie catholique furent levés. De la sorte, l'Église surmonta un premier défi. Le second serait d'intégrer le catholicisme à la société majoritaire. 
L'Église catholique présenta longtemps un visage français. La hiérarchie catholique de l'Ontario, au XIX siècle, comprenait au début plusieurs prélats français ou canadiensfrançais. C'est le cas de quelques Français, tels $\mathrm{M}^{\mathrm{gr}}$ LouisArmand Charbonnel (deuxième évêque de Toronto 1850-1860), $\mathrm{M}^{\mathrm{gr}}$ Bruno Guigues (premier évêque d'Ottawa 1847-1874) et $\mathrm{M}^{\mathrm{gr}} \mathrm{J}$ Jean-François Jamot (vicaire apostolique du Nord du Canada, puis évêque de Peterborough 1874-1886), mais aussi des Canadiens-Français, en commençant par $M^{\text {gr }}$ Rémi Gaulin (deuxième évêque de Kingston 1840-1849), $\mathrm{M}^{\mathrm{gr}}$ Pierre-Adolphe Pinsonneault (premier évêque de London 1856-1866), $\mathrm{M}^{\mathrm{gr}} \mathrm{J}$.- Thomas Duhamel (deuxième évêque d'Ottawa 1874-1909) et $\mathrm{M}^{\mathrm{gr}}$ NarcisseZéphirin Lorrain (vicaire apostolique de Pontiac puis évêque de Pembroke 1882-1915). À partir des années 1860, l'origine ethnique des prélats ontariens devint de plus en plus écossaise et, surtout, irlandaise. Au XX $\mathrm{X}^{\mathrm{e}}$ siècle, Rome a préconisé plusieurs évêques canadiens-français, mais seulement dans les diocèses d'Ottawa, de Timmins et de Hearst, plus tard dans Alexandria et plus tard encore dans Sault-Sainte-Marie.

\section{Le projet messianique irlandais}

De plus en plus nombreux, le clergé irlandais eut pour politique de faire de l'anglais la langue du catholicisme en Amérique du Nord. Le célèbre discours du cardinal Francis Bourne, au Congrès eucharistique de Montréal en 1910, et la cinglante riposte d'Henri Bourassa exposèrent le point de vue des nationalistes et de leurs adversaires. Cette divergence créa des tensions entre le clergé français et le clergé irlandais, comme entre certains évêques irlandais et leurs ouailles de langue française.

Aux États-Unis comme au Canada, la stratégie du clergé irlandais fut de donner un visage anglais au catholicisme pour le rendre plus acceptable à la majorité anglaise et 
protestante du continent. Le messianisme canadien-français trouvait ainsi son double dans le projet de convertir l'Amérique au catholicisme. Longtemps, dans le vocabulaire courant, les termes "irlandais" et "catholique de langue anglaise " furent quasi synonymes. Devenu dominant en Amérique du Nord dans la seconde moitié du XIX ${ }^{e}$ siècle, le clergé irlandais, allié au clergé écossais et appuyé par Rome, voulut limiter au Québec le catholicisme au visage français.

Avant 1870, des Français, des Canadiens-Français et des Irlandais francisés formèrent une grande partie du clergé catholique au Canada. Beaucoup d'Irlandais catholiques réclamaient donc un clergé de langue anglaise. À leurs yeux, les vrais persécuteurs se trouvaient du côté du clergé de langue française. À la fin du siècle, des évêques utilisaient des termes comme "agression" et "invasion" pour décrire l'expansion des colons et du clergé canadienfrançais en Ontario. Toutefois, dans les provinces anglaises, cette politique d'«irlandisation» heurta les populations canadiennes-françaises qui réclamaient, partout où la majorité des catholiques était française, des paroisses et des évêques de langue française.

L'« irlandisation » de l'Église ontarienne s'accentua après 1860 , date où $\mathrm{M}^{\mathrm{gr}}$ John Joseph Lynch devint évêque de Toronto. Après des études en Europe et après avoir longtemps travaillé aux États-Unis, il partageait, avec une partie de l'épiscopat irlando-américain, l'idée d'un messianisme irlandais, selon lequel la Providence avait anglicisé les Irlandais dans le dessein d'en faire un instrument pour convertir le monde anglais au catholicisme. $\mathrm{M}^{\mathrm{gr}}$ Lynch (évêque puis archevêque de Toronto 1860-1888) et son successeur $\mathrm{M}^{\mathrm{gr}}$ John Walsh (archevêque 1889-1898) tentèrent de faire coïncider le territoire de l'Ontario et celui de la province ecclésiastique de Toronto. Selon leurs intentions, Ottawa devait devenir un diocèse qui serait, soit ontarien et anglais, soit québécois et français. 
La question des «paroisses ethniques » se posa partout en Amérique du Nord. Les immigrants souhaitaient fortement retrouver qui une paroisse allemande, qui une paroisse polonaise, qui une paroisse italienne, qui une paroisse canadienne-française. L'épiscopat, surtout s'il était irlandais et donc de langue anglaise, préférait l' «américanisation" des immigrants et leur incorporation dans le réseau des paroisses territoriales plutôt que dans des paroisses dites nationales. Chez les immigrants, la paroisse servait à conserver la tradition tout en permettant de commencer leur intégration ${ }^{21}$. Partout ailleurs, le clergé irlandais voulait le plus tôt possible «américaniser» les immigrants.

L'archevêque John Lynch rêva en vain de faire partie de l'élite sociale de Toronto, cultivant de bonnes relations avec le premier ministre provincial Oliver Mowat et avec le ministre de l'Éducation, George W. Ross. À vrai dire, M ${ }^{\text {gr }}$ Lynch fut moins un membre de l'élite torontoise, comme il l'aurait voulu, que le chef des Irlandais dans la VilleReine. Il considérait le clergé canadien-français comme arriéré, ignorant, borné, imprudent ${ }^{22}$. En 1870, il devint archevêque de Toronto. Il fit nommer des hommes de confiance, recrutés tant en Irlande que parmi le clergé local, aux sièges épiscopaux. Mrr James Vincent Cleary à Kingston et $\mathrm{M}^{\mathrm{gr}}$ Joseph Carberry à Hamilton furent recrutés directement en Irlande.

\footnotetext{
${ }^{21}$ Stephen J. Shaw, «The Cities and the Plains, a Home for God's People. A History of the Catholic Parish in the Midwest", dans Jay P. Dolan (dir.), The American Parish. A History from 1850 to the present, Volume II : Pacific States, Intermountain West, Midwest, New York, Paulist Press, [c1987], p. 306. Pour de longues analyses au sujet des paroisses ethniques et de leur évolution, voir cet article et la thèse de cet historien.

${ }^{22}$ Voir: Robert Perin, Rome et le Canada. La bureaucratie vaticane et la question nationale 1870-1903, traduction de Christiane Teasdale, [Montréal], Boréal, [c1993], p. 26-29.
} 


\section{La résistance franco-ontarienne}

Or, la création des paroisses françaises ou bilingues dépendait des évêques, détenteurs de tous les pouvoirs. $\mathrm{Ni}$ concordat ni érection civile des paroisses n'entravaient en Ontario la toute-puissance de l'évêque sur les paroisses de son diocèse. Seul le code du droit canonique pouvait contraindre un évêque à agir dans un certain sens. En Ontario, rien ne limitait son autorité en matière religieuse, hormis les rappels ponctuels de Rome à la modération.

La nomination d'évêques fut parfois l'occasion de conflits $^{23}$. En fait, il convient de situer ces affrontements dans le cadre d'une grande lutte cléricale, à l'échelle de l'Amérique du Nord, opposant l'épiscopat français ou canadienfrançais, mis en place au XIX ${ }^{e}$ siècle, et l'épiscopat anglo-celte, qui, peu à peu, l'évinça presque partout, avec l'appui du Vatican ${ }^{24}$.

Bref, la création de paroisses françaises contrariait l'intention d'imposer l'anglais comme langue commune des catholiques en Amérique du Nord. Quelques conflits surgirent entre les autorités et les fidèles de langue française ${ }^{25}$. En Ontario, les Canadiens-Français se considéraient comme membres d'un peuple fondateur de la Confédération et donc en droit de recevoir le statut de partenaire égal.

${ }^{23}$ Sur ces querelles, voir Donald Cartwright, «Ecclesiastical Territorial Organization and Institutional Conflict in Eastern and Northern Ontario, 1840 to 1910 ", dans Historical Papers/Communications historiques, 1978, p. 176-199; Robert Choquette, Langue et religion, op. cit.; Voir aussi : Philippe Prévost, La France et les nominations épiscopales au Canada de 1921 à 1940. Un combat pour la francophonie, Saint-Boniface, Éditions du Blé, 1995, [iv]177 p.; Luc Bouvier, Les Sacrifiés de la bonne entente. Histoire des francophones du Pontiac, [Monréal, Éditions de L'Action nationale, c2002], 240 p.

${ }^{24}$ Sur le parti pro-anglais de la bureaucratie vaticane et son refus d'appuyer le nationalisme canadien-français, dans les conflits scolaires par exemple, voir Roberto Perin, op. cit., et voir les textes de Bourne (p. 150-153) et de Bourassa (p. 161-167) dans XXXI ${ }^{e}$ Congrès eucharistique. Montréal, Montréal, Librairie Beauchemin, 1911, $1102 \mathrm{p}$.

${ }^{25}$ Roberto Perin, op. cit., p. 20. 


\section{III - LE RÉSEAU FRANCO-ONTARIEN DE PAROISSES}

Il faut bien dire que l'idée d'un « réseau paroissial francoontarien", c'est d'abord une vue de l'esprit. Ce réseau, dépourvu de toute existence officielle, est une manière commode de regrouper les paroisses qu'unissent des liens culturels et linguistiques. En 1910, les organisateurs du congrès de fondation de l'Association canadienne-française d'éducation d'Ontario (ACFEO) se servirent tout naturellement du réseau des paroisses pour recueillir des fonds. D'ailleurs, on donna aux curés le droit de siéger d'office au bureau de l'Association. Plus tard, diverses associations, y compris les caisses populaires, furent organisées en fonction des paroisses. Ce réseau franco-ontarien possédait donc une existence réelle, mais non officielle.

\section{A. Les paroisses EN ONTARio}

En Ontario, plusieurs facteurs ont, à tour de rôle, contribué à la création de nouvelles paroisses, tant du côté protestant que catholique. Parfois, une mission, amérindienne ou européenne, se transformait en paroisse (par exemple, Sainte-Anne de Mattawa, 1864, et Saint-JeanBaptiste d'Amherstburg, 1844); ailleurs, c'est l'immigration qui rendait nécessaire la construction de nouvelles églises (Sacré-Cour de Welland, 1920); en d'autres endroits, c'est la colonisation qui engendra des paroisses (Sainte-Félicité de Clarence-Creek, 1855, ou Sainte-Gertrude de Smooth-Rock-Falls, 1917); enfin, la croissance urbaine entraîna la formation de plusieurs paroisses nouvelles (Sainte-Thérèse-de-Lisieux de Cornwall, 1955, ou NotreDame-de-la-Paix de Kapuskasing, 1954). On a parlé pour l'Ontario d'une profusion of spires ${ }^{26}$.

${ }^{26}$ John Webster Grant, A Profusion of Spires. Religion in Nineteenth-Century Ontario, Toronto, Ontario Historical Studies Series/University of Toronto Press, [c1988], xxviii-291 p. 
La population franco-ontarienne, concentrée dans certaines régions et donc répartie autrement que la population générale, est peu présente dans la grande zone industrielle de Toronto, mais se trouve beaucoup plus représentée dans l'Est (Ottawa et les quatre comtés de Prescott, de Russell, de Stormont et de Glengarry), dans le Nord-Est (les districts de Nipissing, de Sudbury, d'Algoma, de Cochrane et de Timiskaming), dans le Sud-Ouest (les comtés d'Essex et de Kent) et forme quelques isolats linguistiques (en Huronie ou à Welland). Ainsi, la carte des paroisses françaises et bilingues reflète la distribution de la population franco-ontarienne.

Sur le territoire qui deviendrait un jour l'Ontario, la première paroisse fut érigée en 1767 , en face du fort Pontchartrain du Détroit. Par ce geste, la mission huronne fondée en 1728 devenait la paroisse de l'Assomption, où des familles françaises occupaient officiellement des terres depuis 1749. La création de cette paroisse ne suscita apparemment aucune objection de la part des autorités britanniques.

En 1851, le recensement du Canada montra que la population de l'Ontario dépassait celle du Québec. Grâce à l'immigration, la population ontarienne augmentait, y compris la population catholique. La province comptait 952004 personnes en 1851, dont 167695 (17,6\%) catholiques. Les Canadiens-Français étaient au nombre de 26417 (soit 15,8\% de la population catholique) (Tableau II). Cette proportion est juste dans la mesure où l'on admet que les CanadiensFrançais appartiennent tous à l'Église catholique. 
TABLEAU II

Population catholique de l'Ontario 1842-1971

\begin{tabular}{ccccc}
\hline & $\begin{array}{c}\text { Population } \\
\text { totale }\end{array}$ & $\begin{array}{c}\text { Population } \\
\text { catholique }\end{array}$ & $\begin{array}{c}\text { Population } \\
\text { canadienne- } \\
\text { française }\end{array}$ & $\begin{array}{c}\% \text { de } \\
\text { Canadiens- } \\
\text { Français parmi } \\
\text { les catholiques } \\
(4)=(3) \div(2)\end{array}$ \\
1842 & 487053 & 65203 & 13969 & $21,4 \%$ \\
1851 & 952004 & 167695 & 26417 & $15,8 \%$ \\
1861 & 1396091 & 258251 & 33287 & $12,9 \%$ \\
1871 & 1620851 & 276516 & 75383 & $27,3 \%$ \\
1881 & 1926922 & 322105 & 102743 & $31,9 \%$ \\
1891 & 2114321 & 362478 & 101123 & $27,9 \%$ \\
1901 & 2182947 & 391943 & 161151 & $41,1 \%$ \\
1911 & 2523208 & 487373 & 202442 & $41,5 \%$ \\
1921 & 2933662 & 577118 & 248000 & $43,0 \%$ \\
1931 & 3341383 & 716939 & 299532 & $41,8 \%$ \\
1941 & 3787655 & 854127 & 373990 & $43,8 \%$ \\
1951 & 4597542 & 1142140 & 477677 & $41,8 \%$ \\
1961 & 6236092 & 1873110 & 647941 & $34,9 \%$ \\
1971 & 7703105 & 2568695 & 737360 & $28,7 \%$ \\
\hline
\end{tabular}

SOURCE: Recensement du Canada 1961 (Série 7.1), Bulletin 7,1-11 (colonnes 1 et 2); Recensements 1842-1981, passim (colonne 3).

D'une part, les Canadiens-Français ont subi, depuis le $\mathrm{XIX}^{\mathrm{e}}$ siècle, une «minorisation» démographique. Leur poids relatif dans le pays, en pourcentage, diminue depuis plus de deux siècles. D'autre part, le Tableau II montre qu'en Ontario, les Franco-Ontariens ont représenté une forte proportion de la population catholique. Les Canadiens-Français de l'Ontario (selon leur origine), en 1861, constituaient 12,9\% de la population catholique de la province, mais ce pourcentage grimpa à $41,1 \%$ en 1901 , atteignant même $43,8 \%$ en 1941. Le pourcentage déclina par la suite et n'était plus que de $28,7 \%$ en 1971 . Quand certains évêques parlaient d' "invasion", d' "agression" ou de "conquête», ce sont sans doute ces chiffres qui les inquiétaient. 
Au rythme de l'immigration catholique, d'autres paroisses catholiques s'organisèrent en Ontario à partir de 1802. Les premières furent écossaises (St. Raphael et St. Andrew, dans le comté de Glengarry). La date de fondation des paroisses se trouve dans le Canada ecclésiastique (1887-1974) et dans l'Annuaire de l'Église catholique au Canada (annuel depuis 1983), mais leur âge est parfois exagéré. Néanmoins, ces années de fondation permettent de voir l'évolution globale. Ainsi, on peut dénombrer, dans la première moitié du XIX $^{e}$ siècle, près de 90 paroisses catholiques dans le HautCanada (l'Ontario). La plupart se trouvent dans les diocèses actuels de Kingston (19 paroisses), de London (16 paroisses), d'Ottawa (13 paroisses) et de Hamilton (11 paroisses). Environ 225 autres paroisses sont fondées dans le demisiècle 1850-1900, dont 39 dans le diocèse de London, 28, 22 et 19 dans ceux de Toronto, de Hamilton et de Kingston, respectivement.

$\mathrm{Au}$ sein de cet ensemble, les paroisses françaises et bilingues ne représentent qu'une partie plutôt modeste. On en trouve sept avant 1850 (sur un total de 90, soit $7,8 \%$ ), et 46 de plus dans la période 1850-1900 (sur un total de 255 , soit $18 \%$ ). La population française augmentait plus rapidement que la population anglo-catholique de l'Ontario. Ces paroisses françaises et bilingues se retrouvaient soit dans le Sud-Ouest (les comtés de Kent et d'Essex), soit dans l'Est (les comtés de Prescott, de Russell et de Carleton), soit en Huronie (le comté de Simcoe).

\section{B. TROIS TYPES DE PAROISSES}

Les paroisses franco-ontariennes appartiennent à trois types. Le plus important regroupe les paroisses françaises. Elles forment une sorte de «noyau dur » du réseau. Dans le cas des paroisses bilingues, une grande variété de situations se présente, selon la part du français. Dans ce 
deuxième type, le statut linguistique n'est pas toujours explicite. Il existe aussi, en troisième lieu, des paroisses dont le clergé est français, mais non les fidèles. Les histoires de paroisse sont généralement peu loquaces sur ces questions linguistiques, peut-être parce qu'il s'agit d'un sujet sensible.

Dans le cas d'une paroisse française, les paroissiens et le clergé utilisent le français. Linguistiquement homogènes, elles représentent la norme dans plusieurs diocèses (Ottawa, Sault-Sainte-Marie, Timmins et Hearst) et même dans la région du Centre (dans la grande région de Toronto). Grâce à une population nombreuse et concentrée, l'Est possède aujourd'hui le plus grand nombre de paroisses françaises (les diocèses d'Ottawa et d'AlexandriaCornwall). Enfin, le Nord-Est comprend plusieurs paroisses françaises (diocèses de Sault-Sainte-Marie, de Timmins et de Hearst).

Ces paroisses fonctionnaient en français et furent souvent d'importants foyers d'activités communautaires. Dans ce cas, les fidèles prient en français, le curé parle cette langue en chaire et dans l'administration des sacrements, les activités paroissiales se déroulent en français. Les exemples sont nombreux, tels Saint-Jacques à Embrun, Saint-Jean-Baptiste à Verner, la Nativité-de-Marie à Moonbeam, Sacré-Cour à Toronto, Saint-Jérôme à Windsor, Saint-Pascal-Baylon de Saint-Pascal (1908), l'Annonciation de Sudbury (1953) ou les Saints-Martyrs-Canadiens de Cambridge (1976). Toutes ces paroisses, et plusieurs dizaines d'autres, entrent sans hésitation dans l'inventaire des paroisses françaises.

Les paroisses bilingues sont tantôt à dominance française, où la majorité des paroissiens sont de langue française, comme le clergé, tantôt à dominance anglaise, où la majorité des paroissiens sont de langue anglaise. Ces paroisses furent parfois le lieu de conflits, ce qui aurait pu 
faire penser qu'on devait les éviter. Pourtant, elles furent longtemps la norme dans le diocèse de London. Divers facteurs ont joué dans la détermination du statut linguistique de chaque paroisse (le financement, la disponibilité du personnel, les distances), certes, mais le bilinguisme représentait une sorte d'échec, puisque ni les partisans de la paroisse anglaise, ni les demandeurs de la paroisse française n'avaient obtenu satisfaction.

On peut citer des exemples de paroisses bilingues comme Saint-Simon-et-Saint-Jude de Belle-Rivière, Saint-Patrick de Perkinsfield, Saint-François-Xavier de Cartier et NotreDame-du-Très-Saint-Rosaire de Crysler. Le statut bilingue se trouve dans la pratique plutôt que dans les principes. Les Canadiens-Français s'accommodaient de ce statut linguistique, mais ne le réclamaient jamais.

La difficulté de repérer les paroisses bilingues se pose surtout dans certains diocèses. Dans Alexandria, dont les évêques sont de langue française à partir de 1921, toutes les paroisses (à une exception près, la paroisse bilingue de la Nativité-de-la-Bienheureuse-Vierge-Marie de Cornwall, 1887) furent anglaises, mais plusieurs sont aujourd'hui devenues bilingues ou françaises. Le diocèse de Pembroke eut pour premier évêque Narcisse-Zéphirin Lorrain (18821915) et comptait plusieurs paroisses au Québec. Au début, le diocèse profita aussi des services d'un clergé missionnaire de langue française. Ainsi, la paroisse SaintJean-Chrysostome d'Arnprior, fondée en 1867 et dirigée par le curé Joseph Bouvier de 1867 à 1916, a connu une "période bilingue» (1867-1916). Le diocèse de Pembroke s'étendait au Québec et au Nipissingue. Pourtant, le bilinguisme déclina après 1915 .

Dans le diocèse de London, avant la création de SaintJérôme en 1958, une paroisse destinée à rassembler tous les fidèles de langue française, beaucoup de paroisses de Windsor furent plus ou moins bilingues. 
Dans certains cas, le statut linguistique des paroisses est clair. C'est l'état de chose qui prévaut à Saint-Hilarion de Cobalt, d'abord bilingue, qui devint une paroisse française en 1913 quand fut créée la paroisse anglaise St. Patrick. Une situation semblable prévalut à Saint-Joseph d'Ottawa, paroisse bilingue fondée en 1856 et qui devint anglaise en 1889 , lors de la fondation de la paroisse française du Sacré-Cour. À Pembroke, la paroisse bilingue de Saint-Jean-Baptiste, fondée en 1921, devint une paroisse française en 1941, quand la partie anglaise devint Most Holy Name of Jesus. À côté de ces situations claires, on trouve les paroisses «bilingues » dont le statut linguistique n'est pas bien connu.

Dans les nouvelles régions de peuplement, le bilinguisme devient une solution temporaire pour desservir les deux groupes linguistiques quand le personnel religieux est peu nombreux. On voit bien ce phénomène dans le diocèse de Sault-Sainte-Marie, créé en 1904. Sur son territoire œuvrent six prêtres séculiers (dont quatre sont de langue française) et 30 jésuites. Sur les 31064 catholiques du diocèse, 20064 (64,6\%) sont des CanadiensFrançais et 5000 des Amérindiens ${ }^{27}$. Durant quelques décennies, toutes les paroisses sont bilingues. C'est même le cas de Sainte-Anne-des-Pins, la paroisse mère du diocèse, fondée à Sudbury en 1883 et bilingue jusqu'en 1917 .

La troisième catégorie comprend les paroisses qui, souvent avec de fortes majorités de langue anglaise, ont des pasteurs de langue française. Cette situation se présentait parfois à l'époque des missionnaires, quand le clergé séculier manquait et que le clergé régulier, souvent de langue française, s'occupait de paroisses, surtout de langue anglaise. On en trouve des cas dans London, mais aussi dans d'autres diocèses comme Pembroke (Saint-Jean-

${ }^{27}$ Lorenzo Cadieux, Fondateurs du diocèse du Sault-Sainte-Marie, Sudbury, Société historique du Nouvel-Ontario, «Documents historiques» 6, p. 5 et 31. 
Chrysostome d'Arnprior) et Sault-Sainte-Marie (Sacré-Coeurde-Jésus de Sault-Sainte-Marie ou Immaculée-Conception de Massey). Cette situation s'est surtout produite dans le Nord-Ouest. Dans cette région, les jésuites de langue française s'occupèrent de certaines paroisses $\mathrm{du}$ lac Supérieur (Immaculée-Conception de Fort-William et Saint-André de Port-Arthur). Mais au-delà de la hauteur des terres, avant la création en 1952 du diocèse de ThunderBay, les missions et les paroisses relevaient de l'archidiocèse de Saint-Boniface, qui les confia parfois aux oblats, parfois au clergé séculier.

Il y a donc beaucoup de nuances et d'explications à fournir pour rendre compte du rôle des paroisses bilingues. Les conflits linguistiques furent fréquents dans certaines régions, mais ces disputes ne représentent pas la norme. La plupart des paroisses ne connurent pas de conflits linguistiques.

\section{COMPTER LES PAROISSES}

L'objectif étant de montrer la concomitance entre une carte des églises appartenant au réseau franco-ontarien de paroisses catholiques et les régions de peuplement francoontarien, il s'avère indispensable de compiler la liste des paroisses qui font partie (plus ou moins fortement, plus ou moins longtemps) du réseau.

Le nombre d'églises catholiques augmente depuis longtemps en Ontario comme l'illustre le Tableau III. 
TABLEAU III

Nombre de paroisses et de dessertes (ou missions) catholiques en Ontario en 1901, 1931, 1961 et 2001

\begin{tabular}{|c|c|c|c|c|c|c|c|c|}
\hline \multirow[b]{2}{*}{ Diocèse } & \multicolumn{2}{|c|}{1901} & \multicolumn{2}{|c|}{1931} & \multicolumn{2}{|c|}{1961} & \multicolumn{2}{|c|}{2001} \\
\hline & Par. & Miss. & Par. & Dess. & Par. & Dess. & Par. & Miss. \\
\hline Ottawa & 39 & 10 & 56 & 4 & 80 & 12 & 113 & 1 \\
\hline Pembroke & 22 & 48 & 41 & 51 & 16 & 38 & 19 & \\
\hline Timmins & & & 52 & 42 & 70 & 16 & 30 & 2 \\
\hline Hearst & & & 17 & 34 & 34 & 65 & 29 & 6 \\
\hline Toronto & 47 & & 80 & 22 & 127 & 26 & 222 & 18 \\
\hline Hamilton & 36 & & 57 & & 91 & 38 & 120 & \\
\hline London & 41 & & 66 & & 135 & & 149 & \\
\hline Thunder-Bay & & & & & 32 & 43 & 42 & 8 \\
\hline $\begin{array}{l}\text { Saint- } \\
\text { Catharines }\end{array}$ & & & & & 40 & 5 & 45 & 2 \\
\hline Kingston & 29 & & 41 & & 49 & & 52 & \\
\hline $\begin{array}{l}\text { Peterborough } \\
\text { Alexandria- }\end{array}$ & 27 & & 24 & & 33 & & 43 & 23 \\
\hline $\begin{array}{l}\text { Cornwall } \\
\text { Sault-Sainte- }\end{array}$ & 12 & & 17 & & 28 & & 34 & \\
\hline $\begin{array}{l}\text { Marie } \\
\text { Moosonee }\end{array}$ & & & 52 & & 80 & & $\begin{array}{l}94 \\
16\end{array}$ & 21 \\
\hline
\end{tabular}

Par. $=$ Paroisses, Miss. $=$ Missions, Dess. $=$ Dessertes et $\mathrm{Q} / \mathrm{O}=$ Comprend le Québec et l'Ontario.

SOURCES: Le Canada ecclésiastique de 1902, 1932 et 1962, et l'Annuaire catholique du Canada de 2002. Ces annuaires reflètent la situation de l'année précédente.

En examinant les dates de fondation des paroisses, on peut reconnaître les temps forts où beaucoup de paroisses se forment. On peut aussi voir dans quelles régions se produisent ces fondations. Le Tableau IV présente, selon les trois grandes régions (l'Est, le Nord et le Sud) et par périodes de vingt ans, le nombre de fondations. Ces données permettent de dresser un bilan assez exact.

Dans le sud de l'Ontario, 44 paroisses ont vu le jour. Parmi les 14 paroisses fondées entre 1940 et 1975, presque toutes sont françaises plutôt que bilingues, alors que la période précédente, avant 1940, n'avait produit que des paroisses bilingues dans le Sud-Ouest et dans le Centre, 
l'exception étant la paroisse du Sacré-Couur de Toronto (1887). Les 92 paroisses de l'Est forment un bloc culturel et religieux homogène, notamment dans Prescott et Russell. Les 122 paroisses du Nord en comprennent dix du NordOuest, dont le clergé est français (de l'archidiocèse de Saint-Boniface) jusqu'à leur annexion au diocèse de Thunder-Bay créé en 1952.

\section{TABLEAU IV}

Nombre de fondations de paroisses catholiques, françaises et bilingues, par régions et par périodes de vingt ans, en Ontario de 1840 à 2000

\begin{tabular}{lcccc}
\hline $\begin{array}{c}\text { Période } \\
\text { Avant } 1840\end{array}$ & $\begin{array}{c}\text { Sud } \\
\text { ontarien }\end{array}$ & $\begin{array}{c}\text { Est } \\
\text { ontarien }\end{array}$ & $\begin{array}{c}\text { Nord } \\
\text { ontarien }\end{array}$ & $\begin{array}{c}\text { Nombre } \\
\text { total }\end{array}$ \\
$1840-1860$ & 3 & 3 & 0 & 6 \\
$1860-1880$ & 6 & 7 & 0 & 13 \\
$1880-1900$ & 5 & 13 & 3 & 21 \\
$1900-1920$ & 5 & 14 & 11 & 30 \\
$1920-1940$ & 3 & 17 & 36 & 56 \\
$1940-1960$ & 8 & 7 & 37 & 52 \\
$1960-1980$ & 8 & 21 & 28 & 57 \\
$1980-2000$ & 6 & 8 & 5 & 19 \\
Total & 0 & 2 & 2 & 4 \\
\hline
\end{tabular}

Le Graphique I montre le nombre de paroisses fondées durant chaque période quinquennale. Ainsi, on peut distinguer trois grandes périodes de fondations de paroisses: la première (1875-1890) correspond à la colonisation de l'Est ontarien et comprend 29 fondations en 15 ans, la deuxième (1900-1930) répond au peuplement du NordEst avec 91 nouvelles paroisses en 30 ans et la troisième (1945-1965) s'explique par l'urbanisation qui suivit la Deuxième Guerre mondiale et compte 55 érections de paroisses en 20 ans. Parmi les 258 paroisses de l'Ontario français, 178 (soit $70 \%$ ) furent fondées avant 1940, année qui marque donc un tournant. 


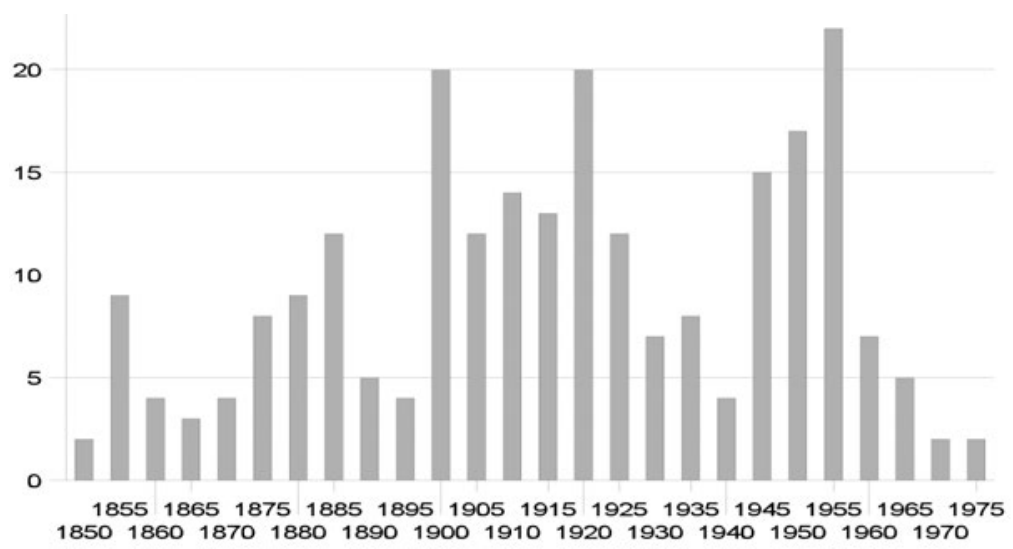

\section{IV - LE RÉPERTOIRE DES PAROISSES FRANCO-ONTARIENNES}

Il est possible de proposer une première vue d'ensemble du réseau des paroisses franco-ontariennes, de les situer dans leur diocèse respectif et de voir leur répartition dans la province. Représentées sur des cartes, ces informations pourront confirmer ou infirmer l'hypothèse d'une concomitance, géographique et chronologique, entre la répartition des paroisses catholiques françaises en territoire ontarien et la distribution de la population franco-ontarienne selon les régions ${ }^{28}$.

Ces cartes, numérotées de II à XVIII, illustrent les différentes parties du réseau. À chacune correspond, sous forme de tableau, une légende contenant des informations complémentaires. Dans ces tableaux à six colonnes, la pre-

${ }^{28}$ La réalisation de cette série de cartes, exécutées par le géographe Léo Larivière, a été rendue possible grâce à une subvention de l'Université Laurentienne, accordée par les deux vice-recteurs à l'enseignement, MM. Harley d'Entremont et Doug Parker. Qu'ils trouvent ici l'expression de notre grande reconnaissance. 
mière attribue à chaque paroisse un numéro de série dans le «réseau franco-ontarien " (au total, 258 paroisses), alors que la deuxième compte le nombre de paroisses figurant sur la carte correspondant à la légende. Les noms de lieu des paroisses sont alignés dans la colonne suivante, tous les toponymes énumérés se retrouvant sur la carte d'en face, à côté du symbole cartographique d'une église (un petit carré surmonté d'une croix). Sur les cartes, les numéros accolés aux toponymes correspondent à différentes paroisses dans les cas où une ville en comprendait plus d'une. La quatrième colonne identifie le diocèse auquel appartient chaque paroisse aujourd'hui. Enfin, les deux dernières colonnes donnent la date de fondation et le nom de chaque paroisse. C'est par les noms de lieu que se fait le lien entre les cartes, d'une part, et, d'autre part, les légendes.

\section{A. LE DIOCÈSE DE LONDON AVANT 1940}

Aux yeux des élites canadiennes-françaises, les paroisses bilingues étaient préférables aux paroisses anglaises, certes, mais nettement moins désirables que des paroisses françaises. Adeptes des institutions linguistiquement homogènes, les porte-parole nationalistes se méfièrent d'institutions qui tenaient lieu d'antichambre de l'assimilation. Les querelles autour de ces institutions bilingues témoignent de problèmes réels. Alors que des douzaines de paroisses françaises n'ont, pour ainsi dire, pas d'histoire, les paroisses bilingues ont parfois causé des frictions linguistiques. Que leur reproche-t-on? Justement de contribuer à l'assimilation dans les communautés canadiennes-françaises fragilisées qui auraient le plus besoin de paroisses homogènes. En Ontario, c'est dans le diocèse de London que s'est posée le plus clairement la question des paroisses bilingues. Aucune région n'a aligné une telle proportion de paroisses bilingues, aucune n'a connu plus de conflits linguistiques. 
La Carte II montre que le diocèse de London, avant 1940 , a compté 23 paroisses qui furent, pendant un temps au moins, soit françaises, soit bilingues. Toutefois, ce nombre cache une réalité moins reluisante. Quelques-unes, comme l'Immaculée-Conception de Paincourt (1853), furent longtemps considérées comme des paroisses françaises, mais peu de paroisses homogènes ont conservé leur statut linguistique. La plupart, à la vérité, sont aujourd'hui de langue anglaise.

\section{TABLEAU V}

PARTIE DU DIOCÈSE DE LONDON (voir Carte II)

Paroisses françaises et bilingues fondées avant 1940

(Comtés d'Essex et de Kent)

\begin{tabular}{cccccc}
\hline \multirow{2}{*}{$N^{\circ}$} & $N^{\circ}$ & & & & \\
Série & Carte & Lieu & Diocèse & Fondée & Paroisse \\
1 & 1 & Amherstburg & LON & 1844 & Saint-Jean-Baptiste \\
2 & 2 & Belle-Rivière & LON & 1842 & Saint-Simon-et-Saint-Jude \\
3 & 3 & Grande-Pointe & LON & 1882 & Saint-Philippe \\
4 & 4 & Jeannette & LON & 1802 & Saint-Pierre-de-la-Tranche \\
5 & 5 & French-Settlement & LON & 1854 & Saint-Pierre \\
6 & 6 & Lasalle & LON & 1921 & Sacré-Cóur \\
7 & 7 & McGregor & LON & 1879 & Saint-Clément \\
8 & 8 & Paincourt & LON & 1853 & Immaculée-Conception \\
9 & 9 & Pointe-aux-Roches & LON & 1867 & Annonciation \\
10 & 10 & Rivière-aux-Canards & LON & 1864 & Saint-Joseph \\
11 & 11 & Saint-Joachim & LON & 1882 & Saint-Joachim \\
12 & 12 & Staples & LON & 1909 & Très-Saint-Rédempteur \\
13 & 13 & Técumseh & LON & 1859 & Sainte-Anne \\
14 & 14 & Tilbury & LON & 1856 & Saint-François-Xavier \\
15 & 15 & Windsor (1) & LON & 1767 & Assomption \\
16 & 16 & Windsor (2) & LON & 1865 & Saint-Alphonse \\
17 & 17 & Windsor (3) & LON & 1884 & Notre-Dame-du-Rosaire \\
18 & 18 & Windsor (4) & LON & 1885 & Saint-Édouard \\
19 & 19 & Windsor (5) & LON & 1904 & Immaculée-Conception \\
20 & 20 & Windsor (6) & LON & 1924 & Sacré-Coeur-de-Jésus \\
21 & 21 & Windsor (7) & LON & 1928 & Sainte-Rose-de-Lima \\
22 & 22 & Windsor (8) & LON & 1928 & Christ-Roi \\
23 & 23 & Windsor (9) & LON & 1928 & Sainte-Thérèse-de-l'Enfant-Jésus \\
\hline
\end{tabular}

Nombre de paroisses sur la Carte II: 23. 
Carte II

Partie du diocèse de London

Paroisses françaises et bilingues fondées avant 1940

(Comtés d'Essex et de Kent)

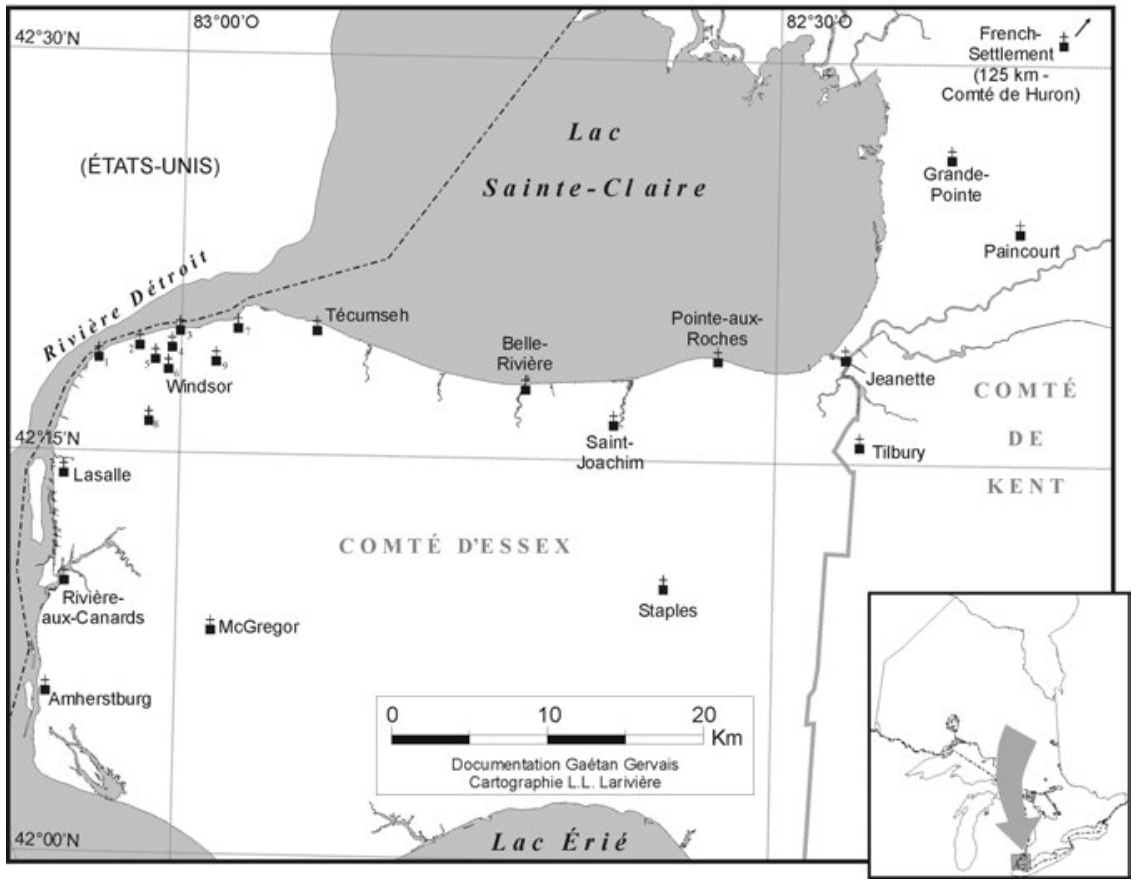

On peut répartir ces 23 paroisses en trois groupes régionaux: d'abord les neuf paroisses aujourd'hui englobées dans le Grand-Windsor, ensuite les quatre situées au sud de Windsor, enfin les dix de la région du lac Sainte-Claire.

La première zone contient la doyenne des paroisses en Ontario, l'Assomption de la Pointe-de-Montréal, érigée en 1767 par l'évêque de Québec. Elle se trouve aujourd'hui à l'intérieur des limites de Windsor, ville fondée en 1854 et qui a peu à peu annexé ses voisines. Dans les environs de cette ville, l'Assomption (1767) fut la seule paroisse catholique jusqu'à l'érection de Saint-Alphonse de Windsor (1865). À la fin du siècle, les terrains industriels s'étendirent vers l'est dans les quartiers de Walkerville, plus tard de Ford-City et de Windsor-Est. Deux paroisses y furent fondées pour desservir les nombreux ouvriers venus gagner 
leur vie dans cette ville industrielle: Notre-Dame-du-Lac de Walkerville (1884) et Saint-Édouard de Walkerville (1885). Une cinquième paroisse s'ajouta lors de la fondation de l'Immaculée-Conception de Windsor (1904).

L'évêque fondateur du diocèse de London (1856), $\mathrm{M}^{\mathrm{gr}}$ Pierre-A. Pinsonneault, transféra le siège épiscopal de London à Sandwich (aujourd'hui Windsor), élevant ainsi l'église de l'Assomption au rang de cathédrale, entre 1859 et 1869. L'année suivante, cette paroisse de langue française fut confiée aux pères basiliens. Suite à l'arrivée de nombreux immigrants irlandais, la paroisse devint bilingue, puis l'usage du français ne cessa de décroître jusqu'en 1958 quand il disparut complètement.

Dans toutes les paroisses bilingues de Windsor, la place du français diminuait, un déclin favorisé entre 1909 et 1931 par l'évêque qui nommait souvent des curés parlant peu ou pas le français. L'hostilité de $\mathrm{M}^{\mathrm{gr}}$ Fallon à l'usage du français et son rôle dans l'affaire du Règlement XVII (19121927) en firent, chez les Canadiens-Français, le modèle achevé de l'évêque irlandais francophobe. Durant les années 1912-1917, plusieurs fidèles signèrent des témoignages assermentés destinés à Rome (plus précisément la Sainte Rote et la Congrégation consistoriale), dans le cadre de procès canoniques où s'opposaient, d'une part, des fidèles et certains curés canadiens-français et, d'autre part, leur évêque belliqueux ${ }^{29}$. Les griefs contre l'évêque étaient nombreux. Par exemple, on se plaignait d'une pénurie de prêtres de langue française, alors que l'évêque refusait d'admettre dans son diocèse des prêtres formés ailleurs, surtout au Québec (le diocèse comptait alors 70 séculiers, dont 18 de langue française, et 18 réguliers, dont 4 canadiensfrançais). $\mathrm{M}^{\mathrm{gr}}$ Fallon pensait que c'était le clergé français qui persécutait les Irlandais.

${ }^{29}$ Voir: La Situation religieuse des Catholiques-Français. Mémoire 1, 1912, et Rapport et documents relatifs aux difficultés religieuses actuelles au Canada 1917, s.l., s.é., 1917, 39 p. 
Le pire incident se produisit en 1917 à Ford-City. À la mort de leur curé nationaliste (l'abbé L.-A. Beaudoin), les paroissiens prirent possession de leur église et du presbytère, pour éviter qu'un disciple de $\mathrm{M}^{\mathrm{gr}}$ Fallon n'entre en fonction. Le grand vicaire et le nouveau curé, venus avec douze officiers de police prendre possession des lieux, se heurtèrent à une foule de quelques milliers de paroissiens. Une émeute s'ensuivit et l'on appela à la rescousse une centaine de militaires. La foule occupait les édifices, la porte principale de l'église étant gardée par une dizaine de femmes. On enfonça à coups de pied une porte de côté du presbytère pour y introduire le nouveau curé de NotreDame-du-Lac, F.-X. Laurendeau, aidé du grand vicaire Dennis O'Connor, le futur évêque de Peterborough, pour ne «pas passer sur le corps d'une dizaine de mères de famille qui défendaient la porte principale» (curé A.-D. Émery).

À Windsor, quatre autres paroisses furent érigées: SacréCour-de-Jésus de Windsor en 1924, puis, en 1928, les trois paroisses de Sainte-Rose-de-Lima de Riverside, Sacré-Courde-Jésus de Roseland et Sainte-Thérèse-de-l'Enfant-Jésus de Windsor. Depuis 1958, aucune de ces neuf paroisses ne fait de pastorale en français.

En 1802, la paroisse de l'Assomption avait établi deux missions, Saint-Pierre-de-la-Tranche, à l'est, et Saint-JeanBaptiste, au sud, à Amherstburg. Cette dernière n'obtint un curé permanent qu'en 1844, ce qui constitue le début de la paroisse d'Amherstburg. Au sud de Windsor, on trouve aussi la paroisse Saint-Joseph de Rivière-aux-Canards (1864), à mi-chemin entre Sandwich au nord et Amherstburg au sud. Par la suite vinrent la paroisse Saint-Clément de McGregor (1879) et Sacré-Couur de Lasalle (1921).

La plus française des trois régions encercle le lac SainteClaire par le sud et l'est, entre Técumseh à l'ouest et, plus à l'est, Saint-Pierre-de-la-Tranche, et même au-delà, jusqu'à 
Saint-Pierre de French-Settlement dans le comté de Huron. La paroisse de Saint-Simon-et-Saint-Jude de Belle-Rivière fut fondée en 1842, à mi-chemin entre l'Assomption et SaintPierre-de-la-Tranche. Cette zone agricole attira des colons canadiens-français, notamment dans la deuxième moitié du $\mathrm{XIX}^{\mathrm{e}}$ siècle. Ces deux secteurs, c'est-à-dire les environs de Windsor et la rive sud du lac Sainte-Claire, devinrent à cette époque d'importantes zones de peuplement canadienfrançais. Dans le comté de Kent, la paroisse de l'ImmaculéeConception de Paincourt, en 1853, devint une grande paroisse française, souvent citée en exemple.

Aux paroisses formées avant 1856, date de création du diocèse de London, il faut ajouter Sainte-Anne de Técumseh (1859), l'Annonciation de Pointe-aux-Roches (1867), SaintJoachim de Saint-Joachim (1882) et Saint-Philippe-Apôtre de Grande-Pointe (1882). Puis le mouvement de création de paroisses s'arrêta en 1882, la seule autre paroisse fondée par la suite étant le Très-Saint-Rédempteur de Staples (1909).

$\mathrm{Au} \mathrm{XX}^{\mathrm{e}}$ siècle, on ne créa plus de paroisses françaises. Les nouvelles paroisses dans les comtés d'Essex et de Kent furent de langue anglaise.

\section{B. L'ARCHIDIOCÈSE D'OTTAWA AVANT 1940}

À l'autre extrémité de la province, à l'est, se trouve le diocèse d'Ottawa. Cette région devint pendant plusieurs décennies le principal foyer de peuplement francoontarien, dépassant ainsi la région du Sud-Ouest. Une élite canadienne-française se constitua à Ottawa et plusieurs institutions culturelles de langue française s'y établirent, faisant de cette ville le chef-lieu de l'Ontario français et le siège de la plupart de ses grandes institutions.

Avant 1940, on dénombre 16 paroisses françaises ou bilingues dans Ottawa et sa banlieue (le comté de Carleton) et 29 autres dans les comtés de Prescott et de Russell 
(Cartes III et IV), soit un total de 45 paroisses, en ne comptant que celles qui sont situées dans la partie ontarienne du diocèse d'Ottawa. Une vingtaine de nouvelles paroisses s'ajoutèrent après 1945 .

Le petit village de Bytown se constitua à la sortie du canal Rideau, construit entre 1826 et 1832. Mais un grand destin l'attendait puisqu'il devint la capitale du Canada et un important centre religieux. Dans la paroisse SaintJacques (plus tard rebaptisée Notre-Dame-d'Ottawa), fondée en 1827, la question linguistique se posa rapidement. Anglaise, la paroisse devint bilingue en raison de l'immigration canadienne-française stimulée par l'industrie du bois. Les Irlandais grognèrent de mécontentement, en 1844, quand un oblat unilingue de langue française, le père Adrien Telmon, fut nommé curé de la paroisse. Celle-ci devint française après l'érection en 1855 de la paroisse irlandaise de St. Patrick.

Grâce à l'industrie du bois, la population canadiennefrançaise s'accrut dans la vallée de l'Outaouais. Cette activité économique donna naissance à plusieurs villes: Hawkesbury, Rockland, Ottawa, Pembroke, Mattawa et autres. La colonisation progressa dans les régions où des terres agricoles restaient disponibles aux familles de colons. Les comtés de Prescott et de Russell, notamment, se transformèrent en campagne française. Cette colonisation bénéficia, au point de vue institutionnel, de la présence de la ville d'Ottawa, un centre qui grandissait grâce à l'arrivée des fonctionnaires du gouvernement fédéral, des traducteurs et des journalistes. La population tira avantage de la présence d'un évêché, d'une université, de journaux.

Aux deux paroisses de la ville d'Ottawa (Notre-Dame et St. Patrick), s'ajouta en 1856 la paroisse bilingue de SaintJoseph, confiée aux oblats et située sur la Côte-de-Sable, à l'ombre du collège de Bytown. Dans le demi-siècle qui suivit, une couronne de paroisses françaises encercla la 
ville, une sorte de «cordon sanitaire » dénoncé par certains Irlandais. Ces paroisses renforcèrent considérablement la communauté canadienne-française. Pour desservir les catholiques de l'ouest de la ville, $M^{\text {gr }}$ Guigues décida de fonder dans ce quartier une paroisse française, dans le secteur de Lebreton-Flats: Saint-Jean-Baptiste (1872). L'année suivante, une autre paroisse française (Sainte-Anne, 1873 ) était érigée dans la partie orientale de la Basse-Ville. Puis, en 1889, la paroisse bilingue de Saint-Joseph, fondée en 1856, devint anglaise, alors qu'on érigea pour la population de langue française de la Côte-de-Sable la paroisse du Sacré-Cour (fondée en 1889). L'année suivante, les franciscains prirent la direction, dans Hintonburg, de SaintFrançois-d'Assise. Puis s'ajouta dans Ottawa-Est, la paroisse de Sainte-Famille (1901).

TABLEAU VI

OTTAWA ET SA BANLIEUE (voir carte III)

(PARTIE DE L'ARCHIDIOCÈSE D'OTTAWA)

Paroisses françaises et bilingues fondées avant 1940 (Comté de Carleton)

\begin{tabular}{cccccc}
\hline $\mathrm{N}^{\mathrm{o}}$ & $\mathrm{N}^{\mathrm{o}}$ & & & & \\
Série & Carte & Lieu (quartiers) & Diocèse & Fondée & Paroisse \\
24 & 1 & Basse-Ville (1) & OTT & 1827 & Notre-Dame-d'Ottawa \\
25 & 2 & Basse-Ville (2) & OTT & 1873 & Sainte-Anne \\
26 & 3 & Billing's-Bridge & OTT & 1887 & Saint-Thomas-d'Aquin \\
27 & 4 & Carlington (Ottawa-Ouest) & OTT & 1923 & Saint-Bonaventure \\
28 & 5 & Carlsbad-Springs (Gloucester) & OTT & 1910 & Saint-Laurent \\
29 & 6 & Cyrville & OTT & 1873 & Notre-Dame-de-Lourdes \\
30 & 7 & Côte-de-Sable (1) & OTT & 1856 & Saint-Joseph \\
31 & 8 & Côte-de-Sable (2) & OTT & 1889 & Sacré-Cour \\
32 & 9 & Eastview (Vanier) (1) & OTT & 1887 & Notre-Dame-de-Lourdes \\
33 & 10 & Eastview (Vanier) (2) & OTT & 1908 & Saint-Charles \\
34 & 11 & Ottawa-Centre (1) & OTT & 1916 & Saint-Gérard-Majella \\
35 & 12 & Ottawa-Centre (2) & OTT & 1930 & Christ-Roi \\
36 & 13 & Hintonburg & OTT & 1890 & Saint-François-d'Assise \\
37 & 14 & Lebreton-Flats & OTT & 1872 & Saint-Jean-Baptiste \\
38 & 15 & Ottawa-Est & OTT & 1901 & Sainte-Famille \\
39 & 16 & Westborough-Ouest & OTT & 1923 & Sainte-Jeanne-d'Arc \\
\hline
\end{tabular}

Nombre de paroisses sur la Carte III: 16. 


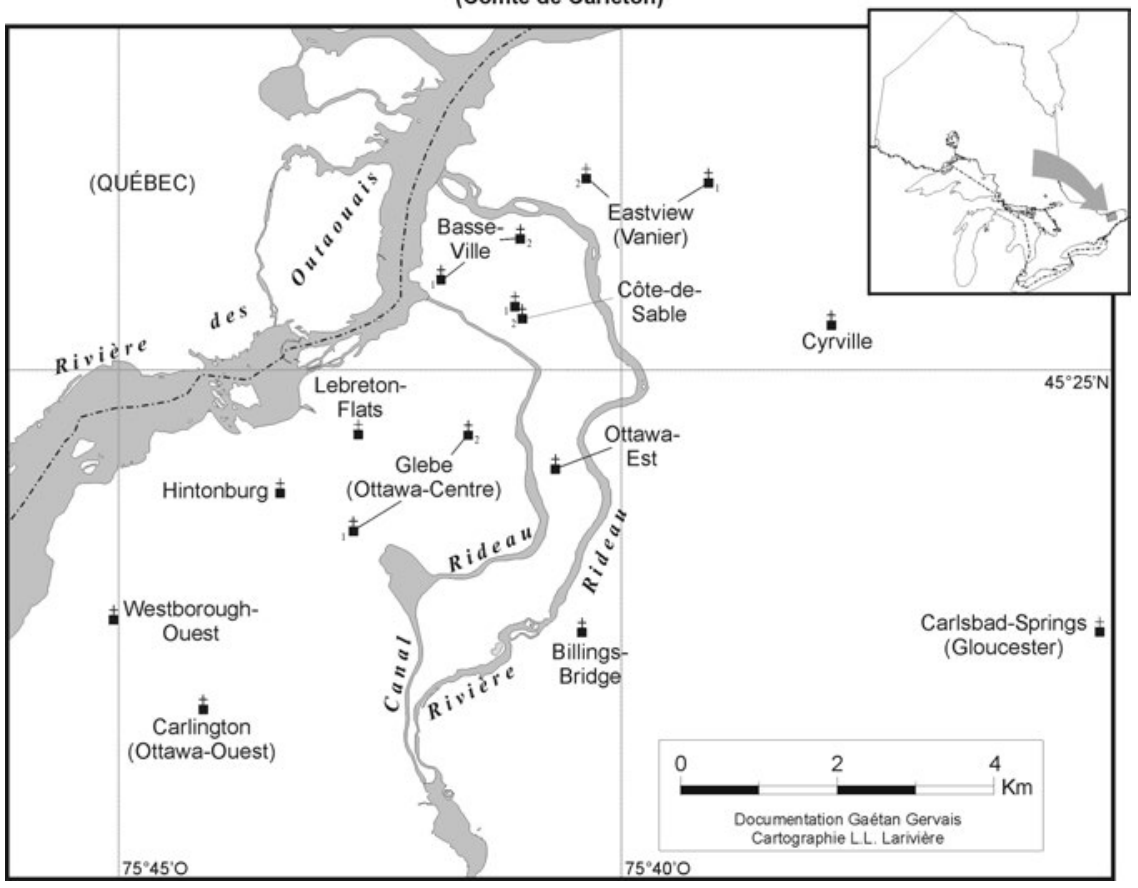

En comptant la paroisse de la cathédrale, Ottawa possédait donc, au début du $\mathrm{XX}^{\mathrm{e}}$ siècle, six paroisses dans le réseau franco-ontarien. Elles furent jusque dans les années 1960 d'importants remparts de la vie française. La ville s'agrandissant, quatre nouvelles paroisses virent le jour après la Première Guerre mondiale: Saint-GérardMajella (1916), Sainte-Jeanne-d'Arc de Westborough-Ouest (1923), Saint-Bonaventure de Carlington (1923) et ChristRoi (1930), ce qui donne onze paroisses au total. Dans le village voisin d'Eastview (aujourd'hui Vanier, un quartier d'Ottawa), une première paroisse fut fondée en 1887 (NotreDame-de-Lourdes) et une deuxième en 1908 (Saint-CharlesBorromée). Des paroisses naquirent aussi dans les centres périphériques, en commençant, à l'est, par Cyrville (Notre- 
Dame-de-Lourdes, 1873). Au sud, la paroisse Saint-Laurent de Billing's-Bridge ouvrit en 1887. À la campagne, une paroisse fut fondée à Carlsbad-Springs (Saint-Laurent de Gloucester, 1917). Les paroisses urbaines étaient nombreuses et enviées par les paroisses rurales.

\section{TABLEAU VII}

COMTÉS DE PRESCOTT ET DE RUSSELL (voir Carte IV)

(PARTIE DE L'ARCHIDIOCÈSE D'OTTAWA)

Paroisses françaises et bilingues fondées avant 1940

\begin{tabular}{cccccc}
\hline $\mathrm{N}^{\mathrm{e}}$ & $\mathrm{N}^{\mathrm{o}}$ & & & & \\
Série & Carte & Lieu & Diocèse Fondée & Paroisse \\
40 & 1 & Alfred & OTT & 1871 & Saint-Victor \\
41 & 2 & Bourget & OTT & 1885 & Sacré-Cour \\
42 & 3 & Casselman & OTT & 1886 & Sainte-Euphémie \\
43 & 4 & Chute-à-Blondeau & OTT & 1884 & Saint-Joachim \\
44 & 5 & Clarence-Creek & OTT & 1855 & Sainte-Félicité \\
45 & 6 & Curran & OTT & 1839 & Saint-Luc \\
46 & 7 & Embrun & OTT & 1858 & Saint-Jacques \\
47 & 8 & Fournier & OTT & 1867 & Saint-Bernard \\
48 & 9 & Hammond & OTT & 1902 & Saint-Mathieu \\
49 & 10 & Hawkesbury & OTT & 1901 & Saint-Alphonse-de-Liguori \\
50 & 11 & Lefaivre & OTT & 1879 & Saint-Thomas \\
51 & 12 & Lemieux & OTT & 1901 & Saint-Joseph \\
52 & 13 & Limoges & OTT & 1901 & Saint-Viateur \\
53 & 14 & L'Orignal & OTT & 1836 & Saint-Jean-Baptiste \\
54 & 15 & Marionville & OTT & 1904 & Sainte-Thérèse-d'Avila \\
55 & 16 & Orléans & OTT & 1860 & Saint-Joseph \\
56 & 17 & Plantagenet & OTT & 1877 & Saint-Paul \\
57 & 18 & Rockland & OTT & 1889 & Sainte-Trinité \\
58 & 19 & Saint-Albert & OTT & 1878 & Saint-Albert \\
59 & 20 & Ste-Anne-de-Prescott & OTT & 1885 & Sainte-Anne \\
60 & 21 & Saint-Bernardin & OTT & 1912 & Saint-Bernardin \\
61 & 22 & St-Eugène-de-Prescott & OTT & 1855 & Saint-Eugène \\
62 & 23 & St-Isidore-de-Prescott & OTT & 1879 & Saint-Isidore \\
63 & 24 & Saint-Pascal-Baylon & OTT & 1908 & Saint-Pascal-Baylon \\
64 & 25 & Sarsfield & OTT & 1886 & Saint-Hugues \\
65 & 26 & Treadwell & OTT & 1923 & Saint-Léon-le-Grand \\
66 & 27 & Vankleek-Hill & OTT & 1878 & Saint-Grégoire-de-Naziance \\
67 & 28 & Vars & OTT & 1917 & Saint-Guillaume \\
68 & 29 & Wendover & OTT & 1901 & Saint-Benôt-Labre \\
\hline
\end{tabular}

Nombre de paroisses sur la Carte IV: 29. 
Carte IV

Comtés de Prescott et de Russell (partie de l'archidiocèse d'Ottawa)

Paroisses françaises et bilingues fondées avant 1940

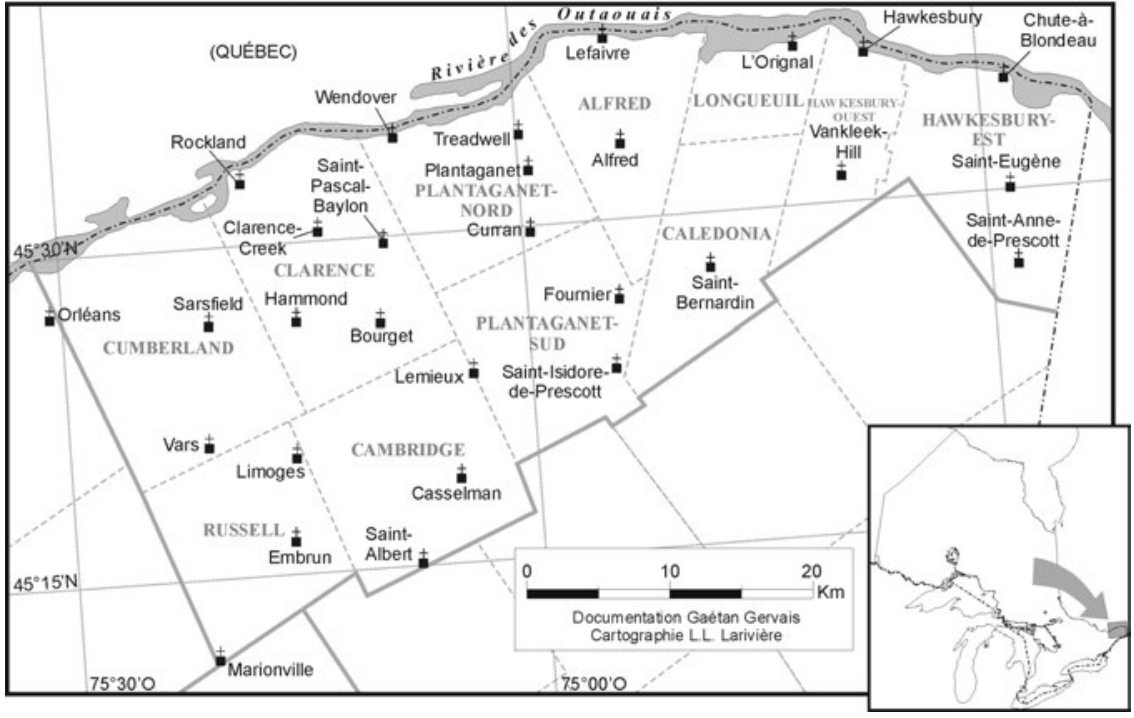

La grande concentration de paroisses rurales se trouvait plus à l'est, dans les comtés de Prescott et de Russell. Nulle part en Ontario le réseau paroissial franco-ontarien n'a été plus serré, plus dense, plus complet, plus conforme au programme du nationalisme canadien-français. C'est aussi le milieu le plus homogène et le plus résistant à l'assimilation de tout l'Ontario français.

Adossé au Québec, le comté de Prescott compte 16 paroisses françaises. Les deux plus anciennes furent érigées en 1836 (Saint-Jean-Baptiste de L'Orignal) et en 1839 (SaintLuc de Curran, dans le township de Plantagenet-Nord). Les familles canadiennes-françaises arrivèrent ici surtout après 1850 , mais leur nombre augmenta si vite que la population française formait la majorité au recensement de 1861. Dans la décennie suivante, naquirent les paroisses de Saint-Eugène (dans Hawkesbury-Est en 1855) et de Saint-Bernard (fondée en 1867 à Fournier). Cinq autres s'ajoutèrent dans les années 1870: Saint-Victor d'Alfred 
en 1871, Saint-Paul de Plantagenet en 1877, Saint-Grégoirede-Naziance de Vankleek-Hill en 1878, Saint-Thomas de Lefaivre en 1879 et Saint-Isidore de Saint-Isidore-dePrescott en 1879. Puis s'ajoutèrent des paroisses dans l'ancien centre de Chute-à-Blondeau (Saint-Joachim, 1884) et dans Sainte-Anne-de-Prescott (Sainte-Anne, 1885). Ces fondations illustrent le succès de la colonisation canadiennefrançaise. Dans Hawkesbury, la principale ville du comté, la paroisse de Saint-Alphonse-de-Liguori n'est fondée qu'en 1901. Les trois dernières paroisses de la période sont érigées à Wendover (Saint-Benoît-Labre, 1901), à Saint-Bernardin (Saint-Bernardin, 1912) et à Treadwell (Saint-Léon-le-Grand, 1923).

Situé entre les comtés de Prescott et de Carleton, le comté de Russell devint aussi une région fortement française. Avant 1940, Russell contenait 13 paroisses, les trois plus anciennes étant Sainte-Félicité de Clarence-Creek (1855), Saint-Jacques d'Embrun (1858) et Saint-Joseph d'Orléans (1860). Un autre groupe de paroisses naquit entre 1878 et 1889 . Il s'agit de Saint-Albert de Saint-Albert (1878), de Sacré-Cour de Bourget (1885), de SaintHugues de Sarsfield (1886), de Sainte-Euphémie de Casselman (1886) et de Sainte-Trinité de Rockland (1889). Après un répit qui dura jusqu'en 1901, cinq autres suivirent: Saint-Viateur de Limoges (1901), Saint-Mathieu de Hammond (1902), Sainte-Thérèse-d'Avila de Marionville (1904), Saint-Pascal-Baylon de Saint-Pascal-Baylon (1904) et, finalement, Saint-Guillaume de Vars (1917).

Dans le diocèse d'Ottawa, les évêques ont encouragé l'immigration catholique, tant irlandaise que canadiennefrançaise, mais ils eurent aussi pour politique de regrouper les immigrants et les colons selon leur langue. Cette politique assurait mieux l'existence de paroisses homogènes. Les querelles linguistiques autour des paroisses furent rares. En plus, l'est de l'Ontario a pu profiter de cette concentra- 
tion de paroisses pour encourager diverses activités (comme l'Union des cultivateurs franco-ontariens - UCFO, ou la Fédération des femmes canadiennes-françaises).

\section{LES DIOCĖsES DU SUD DE L'ONTARIO AVANT 1940}

Le sud de l'Ontario comprend tous les territoires de la partie méridionale de la province, allant de Windsor à l'ouest jusqu'à Alexandria à l'est, puis au nord jusqu'au lac Nipissing et à la rivière des Français.

Aux 23 paroisses du diocèse de London et aux 45 autres de l'archidiocèse d'Ottawa, il faut ajouter, pour que le compte soit complet dans le Sud ontarien, les paroisses, françaises et bilingues, érigées dans les six autres diocèses: six à Toronto (dont deux passèrent au diocèse de SaintCatharines en 1958), aucune dans les diocèses de Hamilton et de Peterborough, mais dix dans chacun des diocèses d'Alexandria et de Pembroke. Les Cartes V, VI et VII montrent l'emplacement de ces paroisses. Soit 27 paroisses dans ces six diocèses.

\section{Diocèse d'Alexandria (Glengarry et Stormont)}

Ironiquement, le diocèse d'Alexandria illustre une évolution contraire à celle du diocèse de London. Celui d'Alexandria, érigé en 1890 par le démembrement du diocèse de Kingston, devait, dans l'intention des évêques angloceltes de l'Ontario, servir de rempart contre la colonisation canadienne-française. Ce nouveau diocèse devait surtout arrêter l'expansion en Ontario de la hiérarchie canadiennefrançaise émanant du Québec. Ce grand projet échoua et le plus petit diocèse au Canada, plus tard, devint majoritairement français. Ainsi, plusieurs des paroisses bilingues ou même françaises ont commencé leur existence comme paroisses anglaises. 
TABLEAU VIII

DIOCÈSE D'ALEXANDRIA (voir Carte V)

Paroisses françaises et bilingues fondées avant 1940

(Comtés de Glengarry et de Stormont)

\begin{tabular}{|c|c|c|c|c|c|}
\hline $\mathrm{N}^{o}$ & $\mathrm{~N}^{0}$ & & & & \\
\hline Série & Carte & Lieu & Diocèse & Fondée & Paroisse \\
\hline 69 & 1 & Alexandria & ALE & 1909 & Sacré-Cœur \\
\hline 70 & 2 & Cornwall (1) & ALE & 1887 & $\begin{array}{c}\text { Nativité-de-la-Bienheureuse- } \\
\text { Vierge-Marie }\end{array}$ \\
\hline 71 & 3 & Cornwall (2) & ALE & 1935 & Saint-François-de-Sales \\
\hline 72 & 4 & Cornwall (3) & ALE & 1937 & Saint-Félix-de-Valois \\
\hline 73 & 5 & Crysler & ALE & 1870 & Notre-Dame-du-Rosaire \\
\hline 74 & 6 & Glen-Robertson & ALE & 1895 & Saint-Martin-de-Tours \\
\hline 75 & 7 & Glen-Walter & ALE & 1907 & Précieux-Sang \\
\hline 76 & 8 & Greenfield & ALE & 1894 & Sainte-Catherine-de-Sienne \\
\hline 77 & 9 & Lancaster & ALE & 1904 & Saint-Joseph \\
\hline 78 & 10 & Moose-Creek & AKE & 1882 & Notre-Dame-des-Anges \\
\hline
\end{tabular}

Nombre de paroisses sur la Carte V: 10.

Le diocèse d'Alexandria ne recouvre que les deux comtés de Glengarry et de Stormont. La ville de Cornwall, fondée en 1784, attira au siècle suivant de plus en plus de travailleurs, souvent canadiens-français, venus des comtés voisins de Prescott et de Russell, mais aussi du Québec. La composition de sa population se modifia au $\mathrm{XX}^{\mathrm{e}}$ siècle pour devenir presque majoritairement de langue française. Reflétant cette nouvelle situation démographique, plusieurs paroisses de langue anglaise se transformèrent pour devenir bilingues, parfois même de langue française. Le diocèse d'Alexandria-Cornwall fournit le rare exemple de francisation d'un diocèse catholique ontarien.

Au début, quelques activités se déroulèrent en français à St. Columban de Cornwall (1829) et à St. Finnan d'Alexandria (1833), deux paroisses dont la population française augmenta au cours du siècle. En 1890, lors de sa création par démembrement de Kingston, le diocèse d'Alexandria ne comptait que dix paroisses, dont deux figuraient parmi les premières de la province (St. Andrew et 
St. Raphaël, fondées dès 1802). À la fin du XIX ${ }^{\mathrm{e}}$ siècle, la population canadienne-française de Cornwall réclamait une paroisse française, mais l'évêque de Kingston ne créa qu'une paroisse bilingue, la Nativité-de-la-Bienheureuse-ViergeMarie (1887). Elle fait partie du diocèse d'Alexandria à partir de 1890 et devint en 1893 une paroisse française, la seule du nouveau diocèse. La deuxième paroisse française (Sacré-Cœur, 1909) est située à Alexandria, dans la ville épiscopale.

Carte V

Diocèse d'Alexandria

Paroisses françaises et bilingues fondées avant 1940

(Comtés de Glengarry et de Stormont)

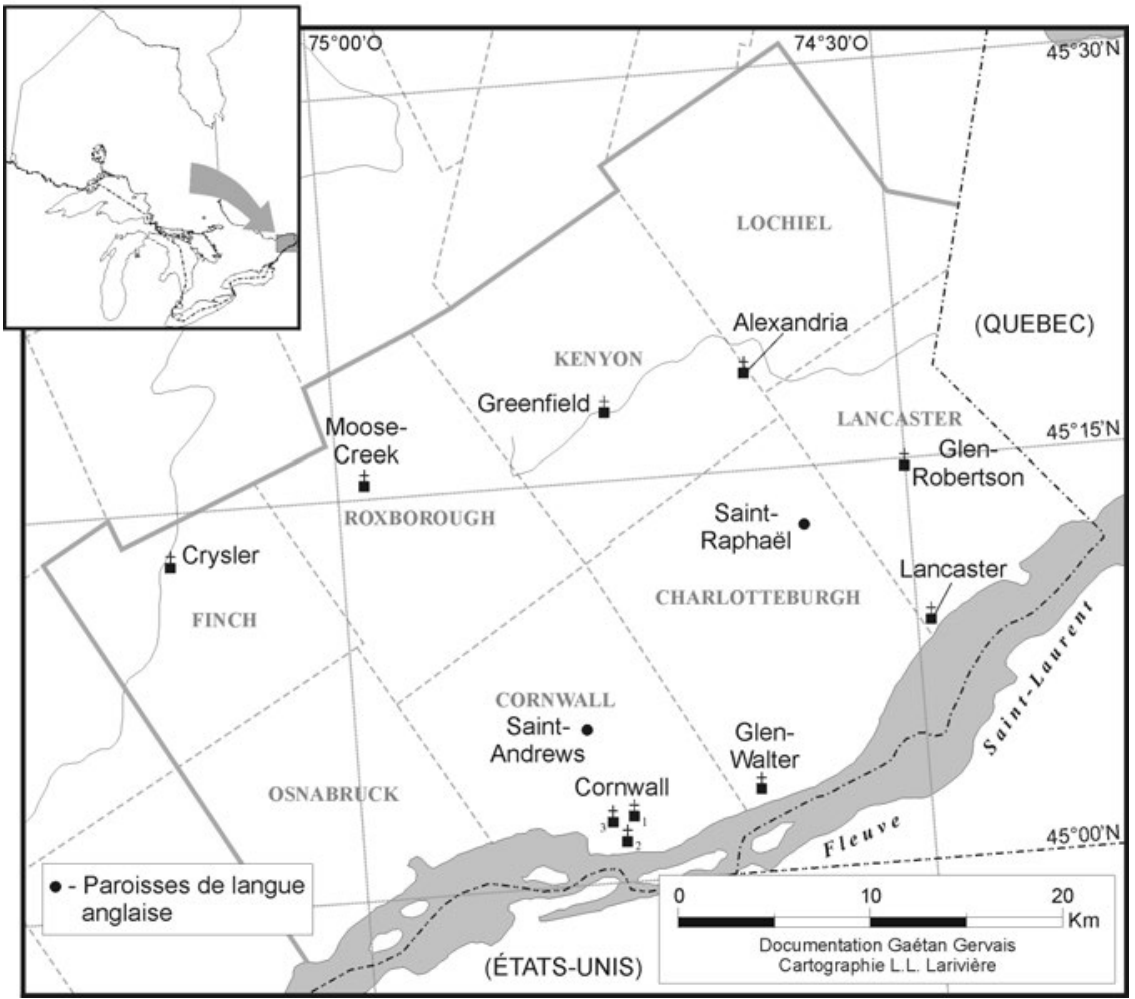

Ainsi, au XIX ${ }^{\mathrm{e}}$ siècle, toutes les paroisses du diocèse d'Alexandria, sauf une, furent de langue anglaise. C'est le 
cas à Crysler (1870) et à Moose-Creek (1887), où la population française augmentait, sans que le bilinguisme ne s'améliorât. À Crysler, l'évêque de Kingston érigea la paroisse de l'Immaculée-Conception (rebaptisée Notre-Damedu-Rosaire dans les années 1920). Les premiers curés s'appellent Spratt, Duffus, Fox, Twoney, McKinnon, Macdonald, Fitzpatrick, Leahy puis, après 1931, ils se nomment Bougie, Goulet, Guindon, Gagnon, Desrosiers. Le même phénomène se produisit à Moose-Creek (NotreDame-des-Anges, 1882): aux curés Leahy, Fox, McRae, Secours et Cameron, succèdent, après 1930, les curés Rouleau, Danis, Leduc, Pilon, Hallé, Lussier.

Il existe d'autres cas de francisation. La paroisse SainteCatherine-de-Sienne de Greenfield fut fondée en 1894 et eut des pasteurs anglais jusqu'en 1955. En 1895, la paroisse de Saint-Martin-de-Tours de Glen-Robertson était fondée. Ses curés furent d'abord de langue anglaise, puis de langue française à partir de 1950. La paroisse SaintJoseph de Lancaster, fondée en 1904, eut des curés canadiens-français à compter de 1933. La paroisse du Précieux-Sang de Glen-Walter, fondée en 1907, eut un pasteur français après 1937.

À Cornwall, une deuxième paroisse française fut fondée en 1935 (Saint-François-de-Sales) et une troisième deux ans plus tard (Saint-Félix-de-Valois, 1937). Avant 1940, on dénombre peu de paroisses bilingues ou françaises. Mais plusieurs existaient alors comme paroisses anglaises qui devinrent plus tard françaises.

Archidiocèse de Toronto avant 1940

Peu de Canadiens-Français vivaient dans la région du Centre de l'Ontario, où se trouve la plus grande partie de la population ontarienne. Être catholique et français, dans un milieu comme Toronto, à la fin du XIX ${ }^{\mathrm{e}}$ siècle, représentait un double défi. Parmi les sept paroisses françaises ou 
bilingues de l'archidiocèse de Toronto, créées avant 1940, il faut mentionner d'abord les trois de la Huronie (Pénétanguishene, Lafontaine et Perkinsfield), les deux créées dans les années 1920, à Welland (Sacré-Cơur, 1920) et à Saint-Catharines (Immaculée-Conception, 1924). Malgré son statut de métropole du Canada, Toronto ne compta longtemps qu'une seule paroisse française (Sacré-Cour, 1887), puis en posséda brièvement une deuxième dont le curé offrit des services en français pendant une dizaine d'années (Sainte-Jeanne-d'Arc, érigée en 1919). La troisième paroisse française de Toronto attendit trois quarts de siècle avant de voir le jour (Saint-Louis-de-France, 1967).

Au nord du diocèse de Toronto, en Huronie, au sud de la baie Georgienne, se maintient un îlot de peuplement français, implanté en 1828 par un groupe de voyageurs de la fourrure, bientôt rejoints par d'autres colons dans les décennies suivantes. Ici se trouvent les trois paroisses de la Huronie, à Pénétanguishene (Sainte-Anne, 1836), à Lafontaine (Exaltation-de-la-Sainte-Croix, 1861) et à Perkinsfield (Saint-Patrick, 1908).

Dans le diocèse de Toronto, les disputes linguistiques n'eurent pas lieu dans les paroisses homogènes, comme Sacré-Cour de Toronto (1887), Sacré-Cơur de Welland (1920) ou Immaculée-Conception de Saint-Catharines (1924), mais dans les paroisses bilingues, comme celles de la Huronie, notamment à Pénétanguishene. Alors que le diocèse de London a donné l'exemple d'un évêque assimilateur, la ville de Pénétanguishene a fourni des exemples de curés assimilateurs. Surtout, il est question du curé Jean-Marie ( John») Castex (1938-1967), qui préconisait l'assimilation des Franco-Ontariens ${ }^{30}$. Ainsi, Sainte-Anne de Pénétanguishene (1836) fut une paroisse d'abord française, ensuite bilingue, puis finalement anglaise.

${ }^{30}$ Daniel Marchildon, La Huronie. Trois siècles et demi d'histoire francoontarienne dans la région de Penetanguishene, Ottawa, Centre franco-ontarien de ressources pédagogiques, «Pro-F-Ont», 1984, p. 178-186. 
TABLEAU IX

ARCHIDIOCÈSE DE TORONTO

ET DIOCÈSE DE HAMILTON (voir Carte VI)

Paroisses françaises et bilingues fondées avant 1940

(Comtés de Simcoe, York, Peel, Halton, Wentworth, Lincoln et Welland)

\begin{tabular}{cccccc}
\hline$N^{\circ}$ & $N^{\circ}$ & & & & \\
Série & Carte & Lieu & Diocèse & Fondée & Paroisse \\
79 & 1 & Lafontaine & TOR & 1861 & Exaltation-de-la-Sainte-Croix \\
80 & 2 & Pénétanguishene & TOR & 1836 & Sainte-Anne \\
81 & 3 & Perkinsfield & TOR & 1908 & Saint-Patrick \\
82 & 4 & Saint-Catharines & SCA & 1924 & Immaculée-Conception \\
83 & 5 & Toronto & TOR & 1887 & Sacré-Cour \\
84 & 6 & Welland & SCA & 1920 & Sacré-Cour \\
\hline
\end{tabular}

Nombre de paroisses sur la Carte VI: 6.

Castex, un Français d'origine basque, traversa l'Atlantique en 1888 , fut ordonné à Ottawa en 1896 en tant que montfortain, une communauté dont il fut expulsé en 1910. Séjournant en France en 1914, il fut conscrit mais s'évada par l'Espagne (sa condamnation à mort ne fut levée qu'en 1945). Admis dans le diocèse de Toronto, il fut nommé, en 1921, curé de St. Margaret de Midland (où la moitié des familles sont françaises, mais où Castex ne dit jamais un mot de français). Il s'opposa aux écoles bilingues et fit même ouvrir une école catholique anglaise pour bloquer le projet d'une école bilingue. Promu prélat d'honneur en 1946, M ${ }^{\text {gr }}$ Castex ne cessa de promouvoir l'assimilation des Franco-Ontariens. Il devint citoyen canadien en 1955. Daniel Marchildon, l'historien local qui a raconté la vie de ce personnage, a noté qu'entre 1882 et 1915 la paroisse Sainte-Anne a obtenu sept vicaires (dont cinq de langue anglaise); de 1915 à 1938, le curé Brunelle eut douze vicaires (dont dix de langue anglaise). Cet accroissement de la présence anglaise se produisit dans une paroisse composée à $92 \%$ de familles françaises. C'est à Philippe Brunelle que Castex succéda en tant que curé en 1938. 
Carte VI

Archidiocèse de Toronto et diocèse de Hamilton

Paroisses françaises et bilingues fondées avant 1940

(Comtés de Simcoe, York, Peel, Halton, Wentworth, Lincoln et Welland)




L'archidiocèse de Toronto ne compte avant 1940 que six paroisses bilingues ou françaises: trois en Huronie, toutes bilingues, et trois dans les villes de Toronto, de SaintCatharines et de Welland, de langue française.

\section{Diocèse de Pembroke avant 1940}

Le vicariat apostolique de Pontiac fut érigé en 1882 par démembrement du diocèse d'Ottawa, dont il devint suffragant en 1887. En 1898, le vicariat devenait le diocèse de Pembroke. Son évêque fondateur, $\mathrm{M}^{\mathrm{gr}}$ Narcisse-Zéphirin Lorrain (1882-1915), fut le premier et le seul évêque canadien-français de ce diocèse qui, comme Ottawa, chevauche la frontière provinciale. Alors que les diocèses d'Ottawa, de Timmins et de Hearst sont aujourd'hui entièrement situés en terre ontarienne, Pembroke et Moosonee chevauchent encore les deux provinces de l'Ontario et du Québec.

Dans le diocèse de Pembroke, on trouve onze paroisses qu'on pourrait répartir ainsi: premièrement, les trois paroisses bilingues qui devinrent anglaises, c'est-à-dire SaintJean-Chrysostome d'Arnprior (1867), Saint-François-Xavier de Renfrew (1852) et Notre-Dame-du-Saint-Rosaire de Griffith (1900); deuxièmement, les paroisses bilingues de Pembroke (Saint-Columbkille, 1856) et de Lapasse (NotreDame-du-Mont-Carmel, 1858); et, troisièmement, les cinq paroisses françaises de la région du Nipissingue, SainteAnne de Mattawa (1864), Sainte-Philomène de Bonfield (1882), Saint-Thomas-d'Aquin d'Astorville (1900), SacréCour-de-Jésus de Corbeil (1920) et Saint-Louis-de-France de Chiswick (1920). Le diocèse de Pembroke comprend aussi d'autres paroisses françaises, mais elles se trouvent en territoire québécois. 


\section{TABLEAU X}

DIOCÈSE DE PEMBROKE (voir Carte VII)

Paroisses françaises et bilingues fondées avant 1940

(Comté de Renfrew et une partie du district de Nipissing)

\begin{tabular}{cccccc}
\hline \multirow{2}{*}{$\mathrm{N}^{\circ}$} & \multirow{2}{*}{$\mathrm{N}^{\mathrm{o}}$} & & & & \\
Série & Carte & Lieu & Diocèse & Fondée & Paroisse \\
85 & 1 & Arnprior & PEM & 1867 & Saint-Jean-Chrysostome \\
86 & 2 & Astorville & PEM & 1902 & Saint-Thomas-d'Aquin \\
87 & 3 & Bonfield & PEM & 1882 & Sainte-Bernadette (Philomène) \\
88 & 4 & Chiswick & PEM & 1920 & Saint-Louis-de-France \\
89 & 5 & Corbeil & PEM & 1920 & Sacré-Coeur-de-Jésus \\
90 & 6 & Griffith & PEM & 1900 & Notre-Dame-du-Saint-Rosaire \\
91 & 7 & Lapasse & PEM & 1858 & Notre-Dame-du-Mont-Carmel \\
92 & 8 & Mattawa & PEM & 1864 & Sainte-Anne \\
93 & 9 & Pembroke (1) & PEM & 1856 & Saint-Columbkille \\
94 & 10 & Pembroke (2) & PEM & 1921 & Saint-Jean-Baptiste \\
95 & 11 & Renfrew & PEM & 1852 & Saint-François-Xavier \\
\hline
\end{tabular}

Nombre de paroisses sur la Carte VII : 11.

Carte VII

Diocèse de Pembroke

Paroisses françaises et bilingues fondées avant 1940

(Comté de Renfrew et une partie du district de Nipissing)




L'industrie du bois explique la croissance de Pembroke où fut fondée en 1856 la paroisse de Saint-Colomban (en anglais: Saint-Columbkille), dont le clergé fut français de 1868 à 1906. À compter de 1906, les curés sont anglais, mais les vicaires parlent le français. En 1921, la paroisse bilingue de Saint-Jean-Baptiste fut fondée. À Arnprior, Griffith et Renfrew, le clergé fut d'abord français, mais les paroisses devinrent bientôt anglaises.

\section{LE diocèse de SAULT-SAINTE-MARIE AVANT 1940}

Le nord-est de l'Ontario regroupe une grande partie de la population franco-ontarienne, environ $30 \%$. Les trois diocèses catholiques de cette région ont créé 63 paroisses françaises avant 1940, soit 26 dans le diocèse de SaultSainte-Marie, 19 dans celui de Timmins et 28 dans celui de Hearst.

À partir de leur mission dans l'île Manitouline, les jésuites parcoururent la région canadienne des Grands-Lacs, allant évangéliser à l'ouest jusqu'à Fort-William. Ils furent ainsi à l'origine de paroisses telles que Saint-Pierre de Port-Arthur (1875) ou Saint-Patrice de Fort-William (1893) (Carte XVI). D'autres missions devinrent les paroisses du Saint-Coeur-de-Jésus de Sault-Sainte-Marie (1875), ou de l'Annonciation-de-la-Bienheureuse-Vierge-Marie de PetitCourant (Little-Current) (1905).

La région du Moyen-Nord se peupla après 1880 , grâce au chemin de fer, aux mines et à l'industrie forestière. Ces mêmes activités économiques expliquent la colonisation dans les trois diocèses du Nord-Est. Le diocèse de SaultSainte-Marie fut fondé en 1904.

En 1883, les jésuites s'établirent à Sainte-Anne-des-Pins de Sudbury (1883) d'où ils exercèrent leur ministère dans les régions situées entre la hauteur des terres et les lacs Supérieur et Huron. Les missionnaires se déplaçaient souvent en train, puisque les paroisses longeaient presque 
toutes le chemin de fer. Dans le Moyen-Nord, les plus anciennes sont les paroisses du Sacré-Cour de Sturgeon-Falls (1891), de Saint-Jean-Baptiste de Verner (1895) et de SaintJoseph de Chelmsford (1896) ${ }^{31}$, toutes situées le long de la ligne ferroviaire. Certains villages bordent la voie principale, comme les paroisses de Saint-Thomas-Apôtre de Warren (1901), de Notre-Dame-de-la-Merci de Coniston (1913), de Saint-François-Xavier de Cartier (1925) et de Saint-Marc de Markstay (1928), alors que d'autres sont établies le long de l'embranchement entre Sudbury et Sault-Sainte-Marie: Immaculée-Conception de Massey en 1889, Saint-Ignace de Sault-Sainte-Marie en 1902, Sacré-Coeur-de-Marie de Cutler en 1910 et Saint-Sébastien de Spanish en 1928.

La présence de l'industrie du bois explique aussi la naissance de Sainte-Thérèse-d'Avila de Cache-Bay en 1906 et de Notre-Dame-des-Victoires de Field en 1902. Mais la progression de la colonisation agricole se poursuivit surtout à l'ouest du lac Nipissingue (Saint-Charles-Borromée de Saint-Charles en 1904, Saint-David de Noëlville en 1905. Notre-Dame-de-la-Visitation de Lavigne en 1914, Notre-Dame-de-Lourdes d'Alban en 1934 et Sainte-Rosede-Lima de River-Valley en 1936).

Quelques paroisses furent fondées dans les environs de Sudbury, soit dans la zone agricole de «la Vallée» (NotreDame-du-Rosaire de Blezard-Valley en 1901, Saint-Jacques de Hanmer en 1905), soit dans les quartiers de la ville (Saint-Jean-de-Brébeuf au Moulin-à-Fleur en 1930 et La Toussaint à Minnow-Lake en 1938).

À North-Bay, l'évêque Scollard n'accepta qu'à contrecœur la création d'une paroisse française (Saint-Vincent-de-Paul, 1914), paroisse qu'il croyait vouée à une inévitable pauvreté. Une légende, amusante mais invérifiable, veut que

${ }^{31}$ La paroisse Saint-Joseph a récemment fait l'objet d'une analyse: Donald Dennie, À l'ombre de l'INCO. Étude de la transition d'une communauté canadiennefrançaise de la région de Sudbury (1890-1972), Ottawa, Presses de l'Université d'Ottawa, «Amérique française», 8, [c2001], p. 234-249. 
l'évêque ait pour cette raison placé la nouvelle paroisse sous la protection du patron des pauvres, saint Vincent de Paul. À Sudbury, la paroisse bilingue de Sainte-Anne-desPins fut scindée en 1917 pour créer la paroisse anglaise Saint-Joseph de Sudbury, au milieu de conflits autour du partage des biens et des recettes.

\section{TABLEAU XI}

DIOCÈSE DE SAULT-SAINTE-MARIE (voir Carte VIII)

Paroisses françaises et bilingues fondées avant 1940

(Parties des districts d'Algoma, de Sudbury et de Nipissing)

\begin{tabular}{cccccc}
\hline $\mathrm{N}^{\circ}$ & \multirow{2}{*}{$\mathrm{N}^{\mathrm{r}}$} & & & & \\
Série & Carte & Lieu & Diocèse & Fondée & Paroisse \\
96 & 1 & Alban & SSM & 1934 & Notre-Dame-de-Lourdes \\
97 & 2 & Blezard-Valley & SSM & 1901 & Notre-Dame-du-Rosaire \\
98 & 3 & Cache-Bay & SSM & 1906 & Sainte-Thérèse-d'Avila \\
99 & 4 & Cartier & SSM & 1925 & Saint-François-Xavier \\
100 & 5 & Coniston & SSM & 1913 & Notre-Dame-de-la-Merci \\
101 & 6 & Chelmsford & SSM & 1896 & Saint-Joseph \\
102 & 7 & Cutler & SSM & 1910 & Sacré-Coeur-de-Marie \\
103 & 8 & Field & SSM & 1902 & Notre-Dame-des-Victoires \\
104 & 9 & Hanmer & SSM & 1905 & Saint-Jacques \\
105 & 10 & Lavigne & SSM & 1914 & Notre-Dame-de-la-Visitation \\
106 & 11 & Markstay & SSM & 1928 & Saint-Marc \\
107 & 12 & Massey & SSM & 1889 & Immaculée-Conception \\
108 & 13 & Noëlville & SSM & 1905 & Saint-David \\
109 & 14 & North-Bay & SSM & 1914 & Saint-Vincent-de-Paul \\
110 & 15 & Petit-Courant & SSM & 1905 & Annonciation-de-la- \\
& & (Little Current) & & & Bienheureuse-Vierge-Marie \\
111 & 16 & River-Valley & SSM & 1936 & Sainte-Rose-de-Lima \\
112 & 17 & Sault-Sainte-Marie (1) & SSM & 1875 & Sacré-Coeur-de Jésus \\
113 & 18 & Sault-Sainte-Marie (2) & SSM & 1902 & Saint-Ignace \\
114 & 19 & Saint-Charles & SSM & 1904 & Saint-Charles-Borromée \\
115 & 20 & Spanish & SSM & 1928 & Saint-Sébastien \\
116 & 21 & Sturgeon-Falls & SSM & 1891 & Sacré-Coeur \\
117 & 22 & Sudbury (1) & SSM & 1883 & Sainte-Anne-des-Pins \\
118 & 23 & Sudbury (2) & SSM & 1930 & Saint-Jean-de-Brébeuf \\
119 & 24 & Sudbury (3) & SSM & 1938 & La Toussaint \\
120 & 25 & Verner & SSM & 1895 & Saint-Jean-Baptiste \\
121 & 26 & Warren & SSM & 1901 & Saint-Thomas-Apôtre \\
\hline & & & &
\end{tabular}

Nombre de paroisses sur la Carte VIII: 26. 


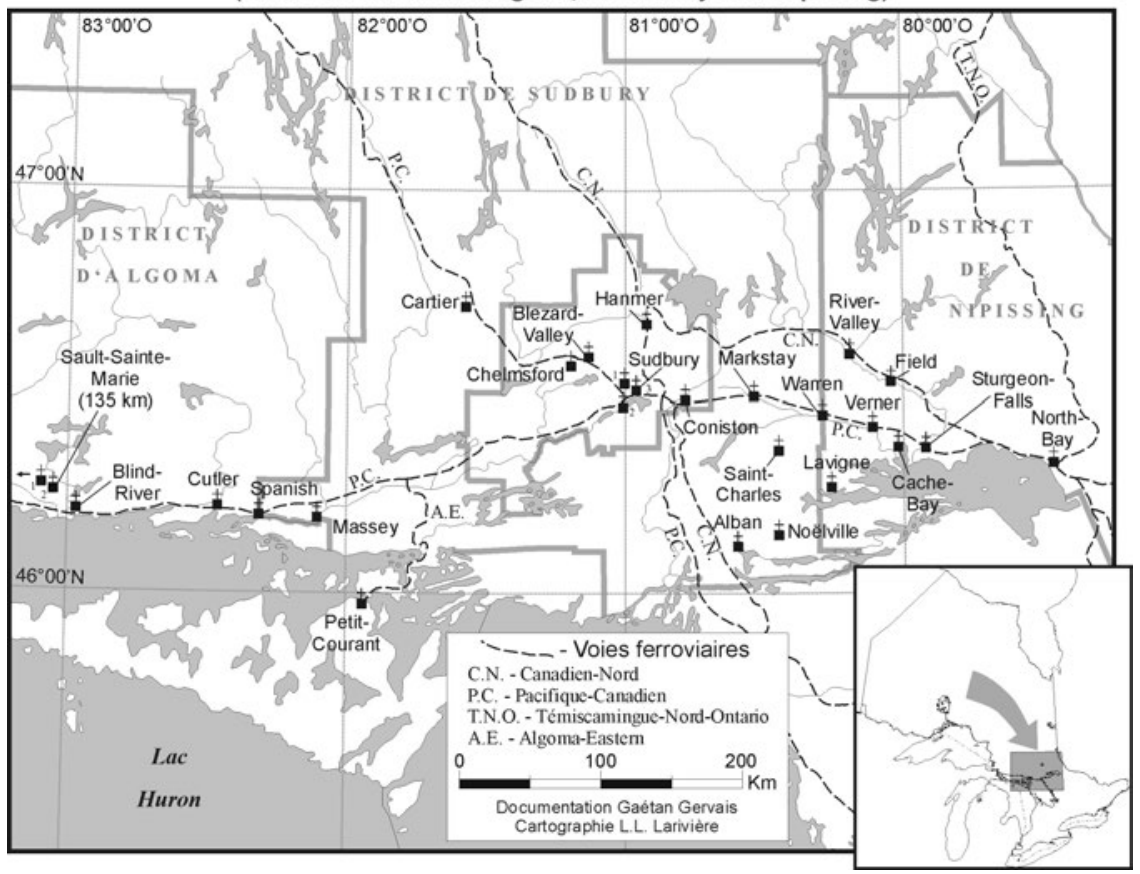

\section{E. LES PAROISSES DES ZONES ARGILEUSES AVANT 1940}

Dans la vaste région située au nord de la ligne de partage des eaux, s'étend la Grande Zone argileuse et, plus près du lac Témiscamingue, la Petite Zone argileuse. Ces deux zones, grosso modo, correspondent aux diocèses de Haileybury (devenu diocèse de Timmins en 1938) et de Hearst. En 1900, le gouvernement provincial envoya dix équipes en exploration pour inventorier les richesses naturelles situées au nord de la voie ferrée du PacifiqueCanadien. Un rapport, rendu public en 1901, laissait entrevoir des terres agricoles et des forêts en grandes quantités. Cet enthousiasme incita le gouvernement provincial à construire une voie ferrée. La construction débuta en 
1903 et permit la découverte, la même année, des riches gisements argentifères de Cobalt. Ces découvertes semblaient donner raison aux plus optimistes, qui entrevoyaient, pour cette région, un brillant avenir.

\section{La Petite Zone argileuse (Témiscamingue)}

À partir de 1845 , les missions de la vallée de l'Outaouais et de la baie d'Hudson furent prises en main par les oblats. Ceux-ci effectuaient des voyages annuels au lac Abitibi et à la baie James, puis, en 1863, ils fondèrent la mission de Sainte-Anne à Mattawa. La paroisse Sainte-Anne (1864) donna aux missionnaires une résidence permanente plus rapprochée du Grand-Nord, alors qu'Ottawa se trouvait encore plus loin à l'est. Les oblats fondèrent en 1886 une mission permanente à Ville-Marie (au Québec). Du côté ontarien, certains avaient rêvé d'un rempart anglais contre la colonisation canadienne-française, mais l'attrait des terres l'emporta et des colons canadiens-français s'établirent aussi dans ces régions ontariennes.

Dans la décennie suivant la découverte de gisements d'argent à Cobalt en 1903, les prospecteurs trouvèrent des veines d'or à Elk-Lake, Gowganda, Kirkland-Lake, LarderLake et Porcupine (Timmins). L'exploitation forestière, commencée quelques décennies plus tôt, l'exploitation des mines et la colonisation rurale se conjuguèrent pour peupler la Petite Zone argileuse. Haileybury formait la plus importante agglomération de cette région. La colonisation se développa durant les trois premières décennies du $\mathrm{XX}^{\mathrm{e}}$ siècle, stimulée avant 1920 par une véritable ruée vers l'or. Comme dans le Moyen-Nord, les chemins de fer amenèrent des colons pour occuper les régions neuves.

Avant 1940, 19 paroisses, françaises ou bilingues, furent érigées dans le diocèse de Haileybury. Un premier groupe de onze paroisses se trouve autour du lac 
Témiscamingue, mais il faut leur ajouter une deuxième zone d'occupation aux environs d'Iroquois-Falls (quatre paroisses) et une troisième dans la région de Timmins (quatre paroisses).

Le premier groupe de paroisses occupe l'ouest et le nord du lac Témiscamingue. La plus vieille paroisse (SainteCroix de Haileybury, 1904) fut désignée en 1908 comme siège du vicariat apostolique du Témiscamingue (19081915), puis comme siège épiscopal du nouveau diocèse de Haileybury en 1915. Des paroisses agricoles existent dans les villages de Matachewan (Ascension, 1909), de BelleVallée (Notre-Dame-de-Bon-Secours, 1913), de NewLiskeard (Sacré-Coeur, 1915), d'Earlton (Saint-Jean-Baptiste, 1918) et de Charlton (Saint-Étienne, 1920).

Cette région du Témiscamingue comprend aussi des paroisses nées dans des villes minières. Deux exemples se trouvent plus au sud (Sainte-Thérèse-de-l'Enfant-Jésus de Cobalt, fondée en 1913, et Notre-Dame-du-Sacré-Coeur de North-Cobalt, créée en 1921). Les autres paroisses en zone minière correspondent aux diverses découvertes faites en 1907 à Elk-Lake (Nativité-de-Notre-Seigneur, 1909), à Kirkland-Lake (Assomption-de-la-Très-Sainte-Vierge, 1921) et à Larder-Lake (Notre-Dame-du-Lac, 1937).

Une deuxième région de la Petite Zone argileuse, où dominent le bois et l'agriculture, comprend les quatre paroisses de Val-Gagné (Immaculée-Conception, 1911), d'Iroquois-Falls (Sainte-Anne, 1914), de Ramore (SaintLaurent, 1917) et de Matheson (Marie-Reine-du-Monde, 1922). Dans cette partie du Nord, le régime agroforestier domine fortement.

La troisième zone comprend la région minière de Timmins. Deux paroisses furent érigées dans la ville: SaintAntoine-de-Padoue en 1912 et Notre-Dame-de-Lourdes en 1936. En 1938, le siège du diocèse fut déménagé de 
Haileybury à Timmins, ce qui confirmait que Timmins occupait désormais le rang de première ville de cette région. Ajoutons enfin les paroisses à Porcupine (Saint-Jude, 1917) et à South-Porcupine (Saint-Joachim, 1923).

\section{TABLEAU XII}

DIOCÈSE DE HAILEYBURY (voir Carte IX)

(RENOMMÉ TIMMINS EN 1938)

Paroisses françaises et bilingues fondées avant 1940

(District de Témiscamingue et partie du district de Cochrane)

\begin{tabular}{cccccc}
\hline \multirow{2}{*}{$\mathrm{N}^{\mathrm{e}}$} & $\mathrm{N}^{\mathrm{r}}$ & & & & \\
Série & Carte & Lieu & Diocèse & Fondée & Paroisse \\
122 & 1 & Belle-Vallée & TIM & 1913 & Notre-Dame-de-Bon-Secours \\
123 & 2 & Charlton & TIM & 1920 & Saint-Étienne \\
124 & 3 & Cobalt & TIM & 1906 Sainte-Thérèse-de-l'Enfant-Jésus \\
125 & 4 & Earlton & TIM & 1918 & Saint-Jean-Baptiste \\
126 & 5 & Elk-Lake & TIM & 1909 & Nativité-de-Notre-Seigneur \\
127 & 6 & Haileybury & TIM & 1904 & Sainte-Croix \\
128 & 7 & Iroquois-Falls & TIM & 1914 & Sainte-Anne \\
129 & 8 & Kirkland-Lake & TIM & 1921 & Assomption-de-la- \\
& & & & & Très-Sainte-Vierge \\
130 & 9 & Larder-Lake & TIM & 1937 & Notre-Dame-du-Lac \\
131 & 10 & Matachewan & TIM & 1909 & Ascension \\
132 & 11 & Matheson & TIM & 1922 & Marie-Reine-du-Monde \\
133 & 12 & New-Liskeard & TIM & 1915 & Sacré-Coeur \\
134 & 13 & North-Cobalt & TIM & 1921 & Notre-Dame-du-Sacré-Coeur \\
135 & 14 & Porcupine & TIM & 1917 & Saint-Jude \\
136 & 15 & Ramore & TIM & 1917 & Saint-Laurent \\
137 & 16 & South-Porcupine & TIM & 1923 & Saint-Joachim \\
138 & 17 & Timmins (1) & TIM & 1912 & Saint-Antoine-de-Padoue \\
139 & 18 & Timmins (2) & TIM & 1936 & Notre-Dame-de-Lourdes \\
140 & 19 & Val-Gagné & TIM & 1911 & Immaculée-Conception \\
\hline
\end{tabular}

Nombre de paroisses sur la Carte IX: 19. 
Carte IX

Diocèse de Haileybury (renommé Timmins en 1938)

Paroisses françaises et bilingues fondées avant 1940

(District de Témiscamingue et partie du district de Cochrane)

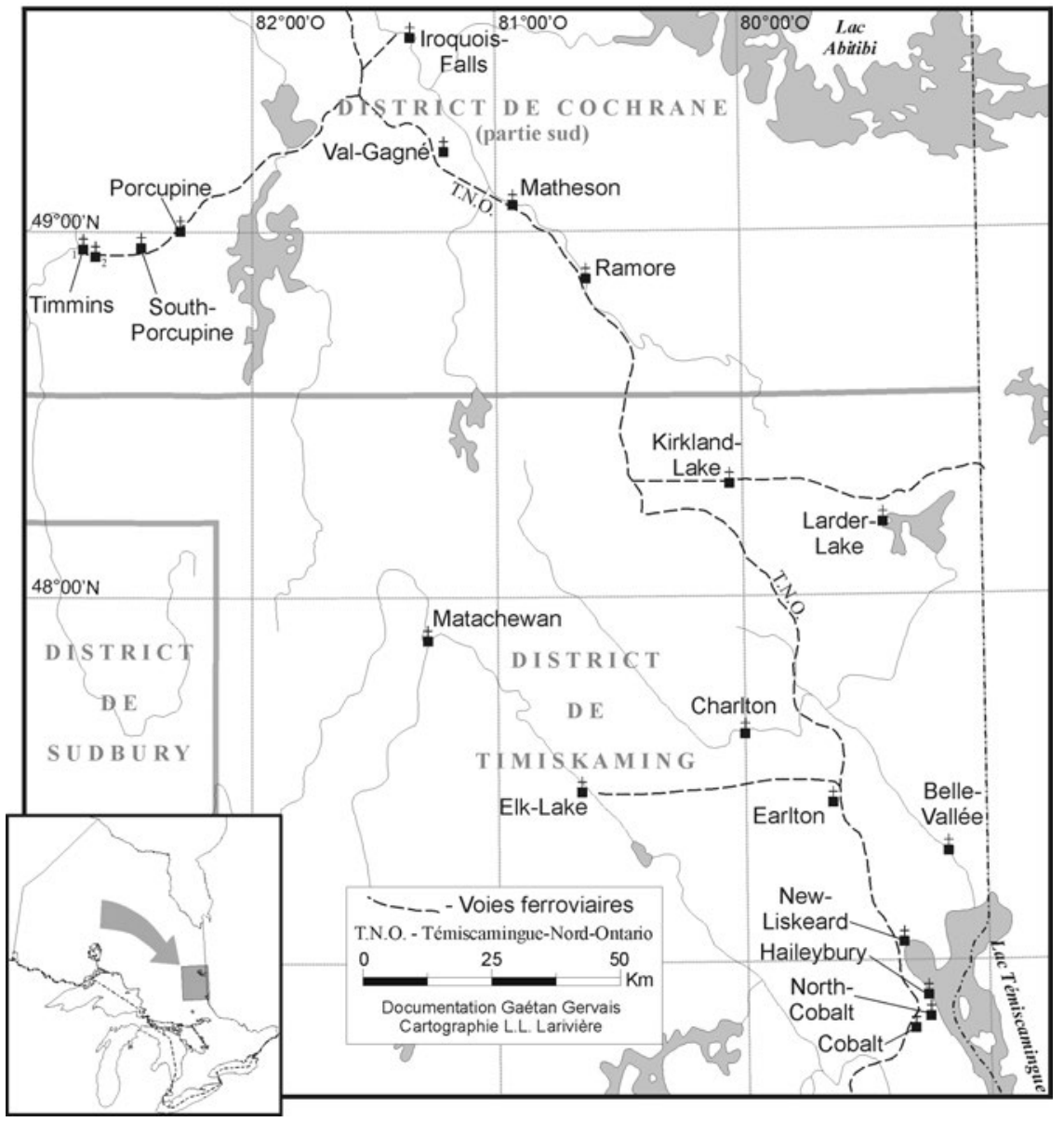

\section{La Grande Zone argileuse (Diocèse de Hearst)}

Plus au nord, s'étendant sur le Nord-Est ontarien et le Nord-Ouest québécois, la Grande Zone argileuse se forma à la fin de la dernière glaciation. C'est une région de vastes étendues d'épinettes, où les étés sont brefs. Une colonisation rurale s'est produite dans certains villages, mais c'est 
l'industrie du bois qui s'est imposée. Le peuplement se constitua le long des voies ferrées, principalement le long de la ligne du Transcontinental construite après 1907. Elle traverse la région d'est en ouest.

\section{TABLEAU XIII}

DIOCÈSE DE HEARST (voir Carte X)

Paroisses françaises et bilingues fondées avant 1940

(Parties des districts de Cochrane, d'Algoma et de Sudbury)

\begin{tabular}{|c|c|c|c|c|c|}
\hline $\mathrm{N}^{\circ}$ & $\mathrm{N}^{\circ}$ & & & & \\
\hline Série & Carte & Lieu & Diocèse & Fondée & Paroisse \\
\hline 141 & 1 & Chapleau & HEA & 1883 & Sacré-Couur-de-Jésus \\
\hline 142 & 2 & Cochrane & HEA & 1909 & La Transfiguration \\
\hline 143 & 3 & Coppell & HEA & 1922 & Sainte-Élisabeth-de-Hongrie \\
\hline 144 & 4 & Driftwood & HEA & 1925 & Saint-Jean-l'Évangéliste \\
\hline 145 & 5 & Fauquier & HEA & 1917 & Sainte-Agnès \\
\hline 146 & 6 & Foleyet & HEA & $1919 I$ & Notre-Dame-des-Sept-Douleurs \\
\hline 147 & 7 & Frederickhouse & HEA & 1922 & Sainte-Angèle-de-Mérici \\
\hline 148 & 8 & Génier & HEA & 1919 & Notre-Dame-des-Oliviers \\
\hline 149 & 9 & Geraldton & HEA & $1935 S$ & Sainte-Thésèse-de-l'Enfant-Jésus \\
\hline 150 & 10 & Gogama & HEA & 1922 & Notre-Dame-du-Rosaire \\
\hline 151 & 11 & Hallébourg & HEA & 1924 & Sainte-Anne \\
\hline 152 & 12 & Harty & HEA & 1932 & Saint-Stanislas \\
\hline 153 & 13 & Hearst & HEA & 1917 & Notre-Dame-de-l'Assomption \\
\hline 154 & 14 & Hornepayne & HEA & 1925 & Saint-Nom-de-Jésus \\
\hline 155 & 15 & Jogues & HEA & 1920 & Sainte-Anne-des-Prés \\
\hline 156 & 16 & Kapuskasing & HEA & 1922 & Immaculée-Conception \\
\hline 157 & 17 & Lac-Sainte-Thérèse & HEA & $1934 S$ & Sainte-Thérèse-de-l'Enfant-Jésus \\
\hline 158 & 18 & Lowther & HEA & 1934 & Saint-François-d'Assise \\
\hline 159 & 19 & Mattice & HEA & 1924 & Saint-François-Xavier \\
\hline 160 & 20 & Moonbeam & HEA & 1917 & Nativité-de-Marie \\
\hline 161 & 21 & Norembéga & HEA & 1926 & Saint-Raphaël \\
\hline 162 & 22 & Opasatika & HEA & 1926 & Saint-Antoine-de-Padoue \\
\hline 163 & 23 & Ryland & HEA & 1925 & Saint-Joseph \\
\hline 164 & 24 & Smooth-Rock-Falls & HEA & 1917 & Sainte-Gertrude \\
\hline 165 & 25 & Strickland & HEA & 1921 & Saint-Étienne \\
\hline 166 & 26 & Sultan & HEA & 1934 & Saint-Jean-de-Brébeuf \\
\hline 167 & 27 & Val-Côté & HEA & 1936 & Très-Saint-Sacrement \\
\hline 168 & 28 & Val-Rita & HEA & 1926 & Sainte-Rita \\
\hline
\end{tabular}

Nombre de paroisses sur la Carte X: 28. 
Carte X

Diocèse de Hearst

Paroisses françaises et bilingues fondées avant 1940

(Parties des districts de Cochrane, d'Algoma et de Sudbury)

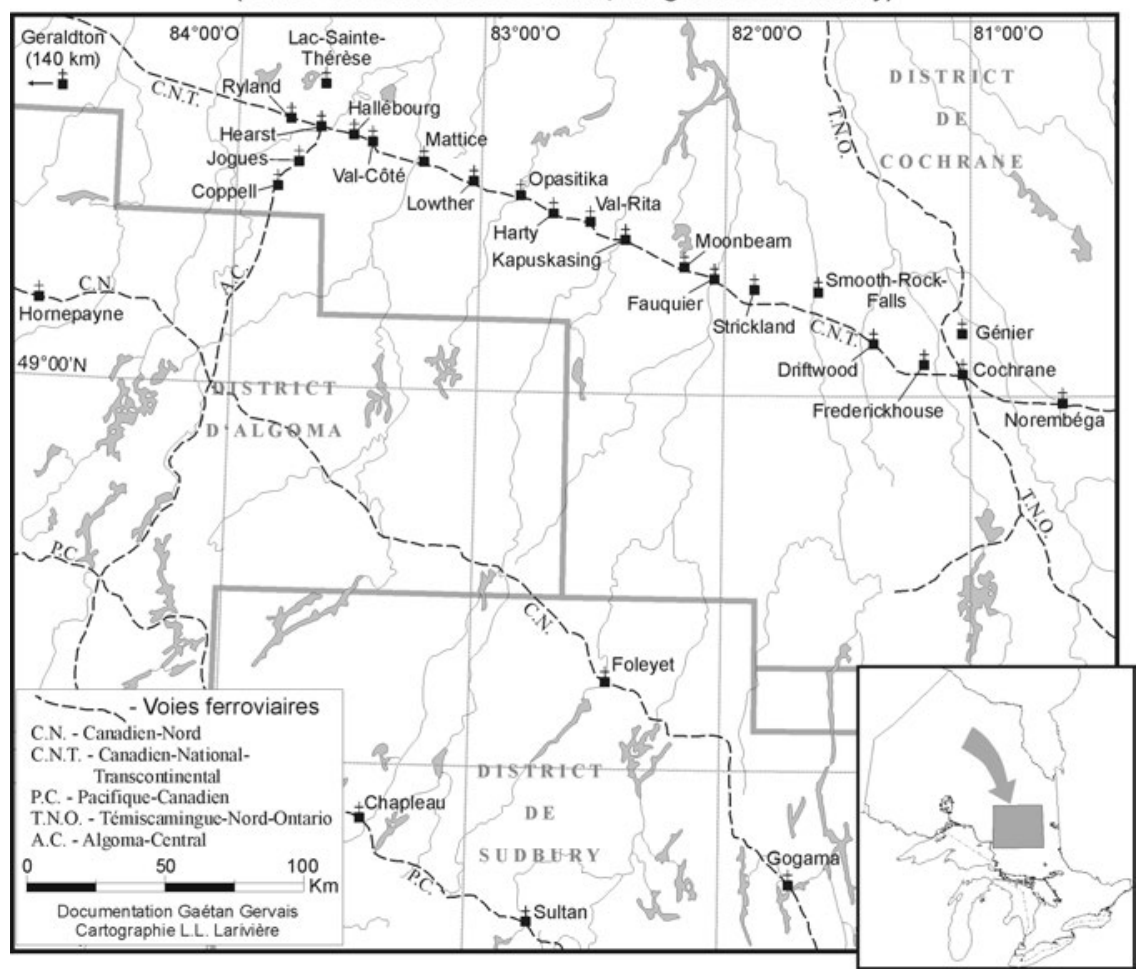

Le diocèse de Hearst (fondé en 1938) fut d'abord une préfecture apostolique (1919), avant de devenir le vicariat apostolique d'Ontario-Nord (1920-1938). La Carte X montre que 28 paroisses ont été fondées dans ce qui était appelé à devenir le diocèse de Hearst. Elles sont presque toutes situées le long de la voie ferrée du Transcontinental et presque toutes créées dans les années 1920.

Deux paroisses s'écartèrent des voies ferrées: Notre-Damedes-Oliviers de Génier (1919) et Sainte-Thérèse-de-l'EnfantJésus de Lac-Sainte-Thérèse (1934). Ailleurs, les paroisses se formèrent le long des voies ferrées: le Pacifique-Canadien où se trouvent les paroisses de Sacré-Coeur-de-Jésus de 
Chapleau (1883) et de Saint-Jean-de-Brébeuf de Sultan (1925); le Canadien-Nord-Ontario où s'alignent Notre-Damedes-Sept-Douleurs de Foleyet (1919), Notre-Dame-duRosaire de Gogama (1922) et Saint-Nom-de-Jésus de Hornepayne (1925). Le long du chemin de fer AlgomaCentral se trouvent Sainte-Anne-des-Prés de Jogues (1920) et Sainte-Élisabeth-de-Hongrie de Coppell (1922).

Dix-neuf des 28 paroisses s'alignent, comme les grains d'un chapelet, le long de la voie ferrée du Transcontinental, une ligne qui reliait Moncton et Winnipeg en traversant la Grande Zone argileuse. Les paroisses françaises entre Geraldton à l'ouest (Sainte-Thérèse-de-l'Enfant-Jésus, 1935) et Norembéga à l'est (Saint-Raphaël, 1926) comprennent des centres plus importants, comme Cochrane et son raccordement avec le Témiscamingue-Nord-Ontario (TNO) (La Transfiguration de Cochrane, 1909), comme Kapuskasing avec son industrie du bois (ImmaculéeConception de Kapuskasing, 1922), comme Hearst où se raccordent le Transcontinental et l'Algoma-Central (NotreDame-de-l'Assomption, 1917).

Restait alors une dizaine de petits villages, vivant principalement des activités de la coupe du bois et d'une agriculture marginale: Sainte-Agnès de Fauquier (1917), Nativité-de-Marie de Moonbeam (1917), Sainte-Gertrude de Smooth-Rock-Falls (1917), Saint-Étienne de Strickland (1921), Sainte-Angèle-de-Mérici de Frederickhouse (1922), Sainte-Anne de Hallébourg (1924), Saint-François-Xavier de Mattice (1924), Saint-Jean-l'Évangéliste de Driftwood (1925), Saint-Joseph de Ryland (1925), Saint-Antoine-dePadoue d'Opasatika (1926), Sainte-Rita de Val-Rita (1926), Saint-Stanislas de Harty (1932), Saint-François-d'Assise de Lowther (1934) et Très-Saint-Sacrement de Val-Côté (1936). En tout, le diocèse de Hearst a compté 28 paroisses avant 1940 . 
Au Témiscamingue, l'industrie minière poursuivit le long déclin dont elle souffre encore. Plusieurs mines ont cessé d'exister. Des fermes, spécialisées en production laitière, existent encore, mais l'agriculture aussi décline. La colonisation de la Grande Zone argileuse se produisit surtout après 1914, attirant dans cette région une importante population de langue française. La déruralisation s'accentua après la Deuxième Guerre mondiale et l'industrie du bois devint la grande activité économique de la région.

\section{F. LES PAROISSES URBAINES APRÈS 1940}

La Deuxième Guerre mondiale interrompit la construction d'églises et la fondation de nouvelles paroisses. Puis la grande prospérité de l'après-guerre et l'importante croissance démographique de cette époque, attribuables au baby boom et à une forte immigration, accrurent la demande de nouvelles paroisses. La plupart seraient urbaines.

\section{Le sud de l'Ontario après 1940}

La carte des paroisses du sud de l'Ontario après 1940 (voir Carte XI) illustre parfaitement ce phénomène. En excluant la paroisse rurale de Notre-Dame-de-Lourdes (Comber, 1952), les 13 autres nouvelles paroisses s'implantèrent justement dans tous les grands centres urbains du Centre et du Sud-Ouest: Toronto, entouré des grandes villes industrielles d'Oshawa, de Brampton, de Georgetown, de Burlington, de Cambridge, de Hamilton, de Niagara-Falls et de Port-Colborne. 


\section{TABLEAU XIV \\ ARCHIDIOCÈSE DE TORONTO \\ ET DIOCÈSES DE HAMILTON, DE LONDON \\ ET DE SAINT-CATHARINES (voir Carte XI) \\ Paroisses françaises et bilingues fondées depuis 1940 \\ (Comtés du sud de l'Ontario)}

\begin{tabular}{cccccc}
\hline \multirow{2}{*}{$\mathrm{N}^{\circ}$} & $\mathrm{N}^{\mathrm{o}}$ & & & & \\
Série & Carte & Lieu & Diocèse & Fondée & Paroisse \\
169 & 1 & Brampton & TOR & 1976 & Sainte-Famille \\
170 & 2 & Burlington & HAM & 1968 & Saint-Philippe \\
171 & 3 & Cambridge & HAM & 1976 & Saints-Martyrs-Canadiens \\
172 & 4 & Comber & LON & 1952 & Notre-Dame-de-Lourdes \\
173 & 5 & Don-Mills (Toronto) & TOR & 1967 & Saint-Louis-de-France \\
174 & 6 & Georgetown & HAM & 1966 & Sacré-Coeur \\
175 & 7 & Hamilton & HAM & 1951 Notre-Dame-du-Perpétuel-Secours \\
176 & 8 & Kingston & KIN & 1958 & Saint-François-d'Assise \\
177 & 9 & Niagara-Falls & SCA & 1955 & Saint-Antoine-de-Padoue \\
178 & 10 & Oshawa & TOR & 1966 & Assomption-de-Notre-Dame \\
179 & 11 & Port-Colborne & SCA & 1951 & Saint-Jean-de-Brébeuf \\
180 & 12 & Sarnia & LON & 1944 & Saint-Thomas-d'Aquin \\
181 & 13 & Windsor (1) & LON & 1951 & Saint-Paul \\
182 & 14 & Windsor (2) & LON & 1958 & Saint-Jérôme \\
\hline
\end{tabular}

Nombre de paroisses sur la Carte XI: 14.

Au total, 14 paroisses furent fondées dans les diocèses du Centre-Sud-Ouest de la province. Comme cette région disposait déjà d'un dense réseau de paroisses de langue anglaise, la question linguistique ne semble pas avoir soulevé d'objections. En effet, à cette époque, l'immigration modifiait les attitudes. L'ère de la tolérance commençait déjà à transformer la société ontarienne. D'ailleurs, plusieurs groupes ethniques réclamaient des paroisses nationales. Aujourd'hui, l'archidiocèse de Toronto se glorifie du fait que des messes se chantent régulièrement dans des douzaines de langues différentes. Le bilinguisme officiel canadien, instauré en 1969 , et les politiques de multiculturalisme (1971) ont préparé une importante évolution des idées au sein de la population ontarienne. 

(Comtés du sud de l'Ontario)

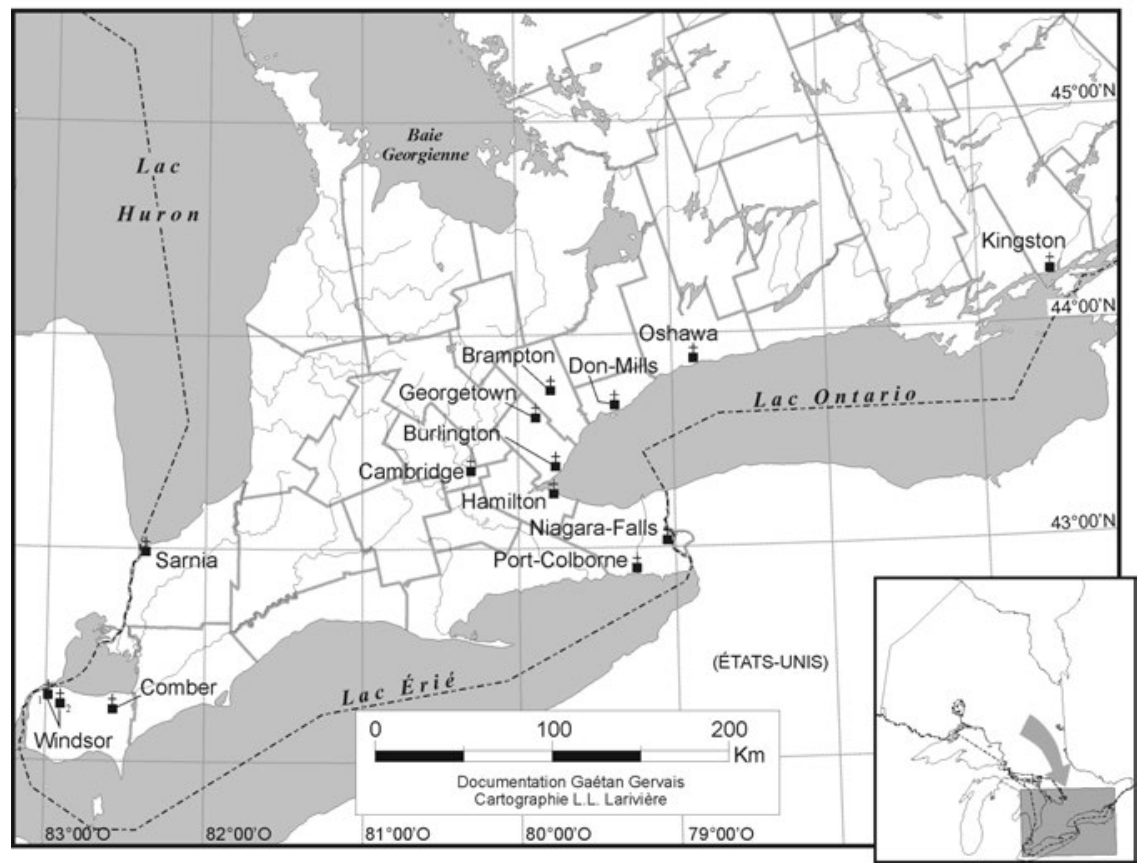

Une paroisse française fut fondée à Kingston (SaintFrançois-d'Assise, 1958), à la sortie du lac Ontario, et une autre à Sarnia (Saint-Thomas-d'Aquin, 1954), à la sortie du lac Huron. Comme Sarnia, Windsor est une importante ville industrielle. Deux autres paroisses furent fondées à Windsor, d'abord la paroisse bilingue de Saint-Paul (1951), mais surtout la paroisse française de Saint-Jérôme (1958). Elle devenait la seule paroisse regroupant la population française de Windsor. C'était la fin des paroisses bilingues dans la ville.

Le développement économique et la croissance démographique de la région de Toronto furent les plus forts au pays. L'industrie et le commerce attirèrent dans cette métropole des personnes de toutes les régions du Canada et de nombreux immigrants. Une partie de ces immigrants 
parlaient le français. Un groupe de neuf paroisses françaises furent fondées dans la région de Toronto: Hamilton (Notre-Dame-du-Perpétuel-Secours, 1951), Port-Colborne (Saint-Jean-de-Brébeuf, 1951), Niagara-Falls (Saint-Antoinede-Padoue, 1955), Georgetown (Sacré-Cour, 1966), Oshawa (Asssomption-de-Notre-Dame, 1966), Toronto (Saint-Louisde-France, 1967), Burlington (Saint-Philippe, 1968), Brampton (Sainte-Famille, 1976) et Cambridge (SaintsMartyrs-Canadiens, 1976).

\section{L'est de l'Ontario après 1940}

Durant la période 1945-1965, 16 nouvelles paroisses furent fondées dans la région d'Ottawa-Carleton. Cette liste (Carte XII) montre à nouveau l'importance de l'urbanisation. Trois paroisses surgirent dans la ville-enclave d'Eastview (Vanier), soit Notre-Dame-du-Saint-Esprit (1953), Bienheureuse-Vierge-Marie-Médiatrice-de-Toutes-lesGrâces (1956), Saint-Louis-Marie-de-Montfort (1964), deux dans le quartier de Côte-de-Sable (Saint-Pie-X, 1954, et la paroisse de rite latin, Saint-Clément, 1993), deux autres dans Overbrook (Notre-Dame-de-la-Présentation, 1946, et Saint-Sébatien, 1959), plus les paroisses de Blossom-Park (Saint-Bernard, 1957), de Britannia (Saint-Rémi, 1963), de Canterbury (Sainte-Geneviève, 1963), du Centre-Ville (Notre-Dame-des-Anges, 1953), de New-Edinburgh (SaintVincent-de-Paul, 1954) et de Riverview-Park (Nativité-deNotre-Seigneur-Jésus-Christ, 1959). On voit aussi la naissance de paroisses dans les villes-dortoirs que sont Beacon-Hill (Saint-Gabriel, 1957), Blackburn-Hamlet (Saint-Claude, 1973) et Orléans (Sainte-Marie, 1987). La création de ces paroisses d'Ottawa-Carleton découle de l'augmentation de la population franco-ontarienne, de son urbanisation et du développement de la région d'Ottawa. 
Au cours de la dernière décennie, l'archevêque a été obligé de fusionner certaines paroisses, d'en obliger d'autres à partager un même curé (de 1980 à 1996, un seul curé s'occupa des trois paroisses de Saint-Charles, de MarieMédiatrice et de Notre-Dame-du-Saint-Esprit); enfin il a parfois dû fermer quelques églises. Par exemple, l'église de Notre-Dame-de-la-Présentation ferma ses portes en 1993, alors que la paroisse de Notre-Dame-des-Anges devint en 1986 une paroisse croate. À Vanier, l'église Notre-Damedu-Saint-Esprit cessa d'exister en 1995. En 1993, SaintPie-X a disparu pour faire place à la paroisse Saint-Clément, qui est de rite latin.

Les Cartes IV et $\mathrm{V}$ ont montré les nombreuses paroisses rurales créées dans l'Est ontarien. Ces paroisses, fondées avant 1940, existaient toujours en 1940, mais les nouvelles étaient surtout urbaines, ce que montre la Carte XIII. Dans les comtés les plus à l'est (Prescott, Russell, Glengarry et Stormont), 15 paroisses furent fondées entre 1940 et 1964.

Dans les comtés de Prescott et de Russell, déjà bien pourvus, seulement quatre paroisses furent créées, deux dans les villes-dortoirs de Russell (Notre-Dame-de-laMédaille-Miraculeuse, 1947) et de Cumberland (SainteMarguerite-Marie, 1954), et deux autres dans la ville de Hawkesbury (Ascension-de-Notre-Seigneur-Jésus-Christ, 1957, et Saint-Dominique, 1964). Outre les 16 paroisses d'Ottawa-Carleton (Carte XII) et les quatre de PrescottRussell, il en reste onze pour les comtés de Glengarry et de Stormont. Cinq de ces onze paroisses se trouvent dans la ville de Cornwall (Saint-Jean-Bosco, 1944, Sainte-Croix, 1954, Sainte-Thérèse-de-Lisieux, 1955, Saints-MartyrsCanadiens, 1962, Christ-Roi, 1964), confirmant l'importance numérique des paroisses urbaines. 


\section{TABLEAU XV \\ MUNICIPALITÉ D'OTTAWA-CARLETON (voir Carte XII) (PARTIE DE L'ARCHIDIOCÈSE D'OTTAWA)}

Paroisses françaises et bilingues fondées depuis 1940

(Comté de Carleton)

\begin{tabular}{cccccc}
\hline \multirow{2}{*}{$N^{\circ}$} & $N^{\circ}$ & & & & \\
Série & Carte & Lieu & Diocèse & Fondée & Paroisse \\
183 & 1 & Beacon-Hill & OTT & 1957 & Saint-Gabriel \\
184 & 2 & Blackburn-Hamlet & OTT & 1973 & Saint-Claude \\
185 & 3 & Blossom-Park & OTT & 1957 & Saint-Bernard \\
186 & 4 & Britannia & OTT & 1963 & Saint-Rémi \\
187 & 5 & Canterbury & OTT & 1963 & Sainte-Geneviève \\
188 & 6 & Centre-Ville (Bayview) & OTT & 1953 & Notre-Dame-des-Anges \\
189 & 7 & Côte-de-Sable (1) & OTT & 1954 & Saint-Pie-X \\
190 & 8 & Côte-de-Sable (2) & OTT & 1993 & Saint-Clément \\
191 & 9 & New-Edinburgh & OTT & 1954 & Saint-Vincent-de-Paul \\
192 & 10 & Orléans & OTT & 1987 & Sainte-Marie \\
193 & 11 & Overbrook (1) & OTT & 1946 & Notre-Dame-de-la-Présentation \\
194 & 12 & Overbrook (2) & OTT & 1959 & Saint-Sébastien \\
195 & 13 & Riverview-Park & OTT & 1960 & Nativité-de-Notre-Seigneur- \\
& & & & \multicolumn{3}{c}{ Jésus-Christ } \\
196 & 14 & Vanier (1) & OTT & 1953 & Notre-Dame-du-Saint-Esprit \\
197 & 15 & Vanier (2) & OTT & 1956 & Bienheureuse-Vierge-Marie- \\
& & & & \multicolumn{3}{c}{ Médiatrice-de-Toutes-les-Grâces } \\
198 & 16 & Vanier (3) & OTT & 1964 & St-Louis-Marie-de-Montfort \\
\hline
\end{tabular}

Nombre de paroisses sur la Carte XII : 16. 




Les six autres se trouvent dans de petits villages (SaintBernard de Finch, 1945, Saint-Jacques de Maxville, 1946, Saint-Paul de Dalkeith, 1947, Sainte-Marie-de-l'Assomption de Green-Valley, 1956, Saint-Guillaume de Martinville, 1949 et Saint-Laurent de Curry-Hill, 1959).

Le diocèse de Pembroke n'ouvre aucune paroisse française nouvelle après 1940. 


\section{TABLEAU XVI \\ EST ONTARIEN (voir Carte XIII) (DIOCÈSE D'ALEXANDRIA-CORNWALL ET PARTIE DE L'ARCHIDIOCÈSE D'OTTAWA)}

Paroisses françaises et bilingues fondées depuis 1940

(Comtés de Russell, de Prescott, de Glengarry et de Stormont)

\begin{tabular}{cccccc}
\hline $\mathrm{N}^{\mathrm{e}}$ & $\mathrm{N}^{\mathrm{o}}$ & & & & \\
Série & Carte & Lieu & Diocèse & Fondée & Paroisse \\
199 & 1 & Cornwall (1) & ALE & 1944 & Saint-Jean-Bosco \\
200 & 2 & Cornwall (2) & ALE & 1954 & Sainte-Croix \\
201 & 3 & Cornwall (3) & ALE & 1955 & Sainte-Thérèse-de-Lisieux \\
202 & 4 & Cornwall (4) & ALE & 1962 & Saints-Martys-Canadiens \\
203 & 5 & Cornwall (5) & ALE & 1964 & Christ-Roi \\
204 & 6 & Curry-Hill & ALE & 1959 & Saint-Laurent \\
205 & 7 & Cumberland & OTT & 1954 & Sainte-Marguerite-Marie \\
206 & 8 & Dalkeith & ALE & 1947 & Saint-Paul \\
207 & 9 & Finch & ALE & 1945 & Saint-Bernnard \\
208 & 10 & Green-Valley & ALE & 1956 & Sainte-Marie-de-l'Assomption \\
209 & 11 & Hawkesbury (1) & OTT & 1957 & Ascension-de-Notre- \\
& & & & & Seigneur-Jésus-Christ \\
210 & 12 & Hawkesbury (2) & OTT & 1964 & Saint-Dominique \\
211 & 13 & Martintown & ALE & 1949 & Saint-Guillaume \\
212 & 14 & Maxville & ALE & 1946 & Saint-Jacques \\
213 & 15 & Russell & OTT & 1947 & Notre-Dame-de-la- \\
& & & & & Médaille-Miraculeuse \\
\hline
\end{tabular}

Nombre de paroisses sur la Carte XIII: 15. 


\section{Carte XIII}

Est ontarien

(Diocèse d'Alexandria-Cornwall et partie de l'archidiocèse d'Ottawa)

Paroisses françaises et bilingues fondées depuis 1940

(Comtés de Russell, de Prescott, de Glengarry et de Stormont)

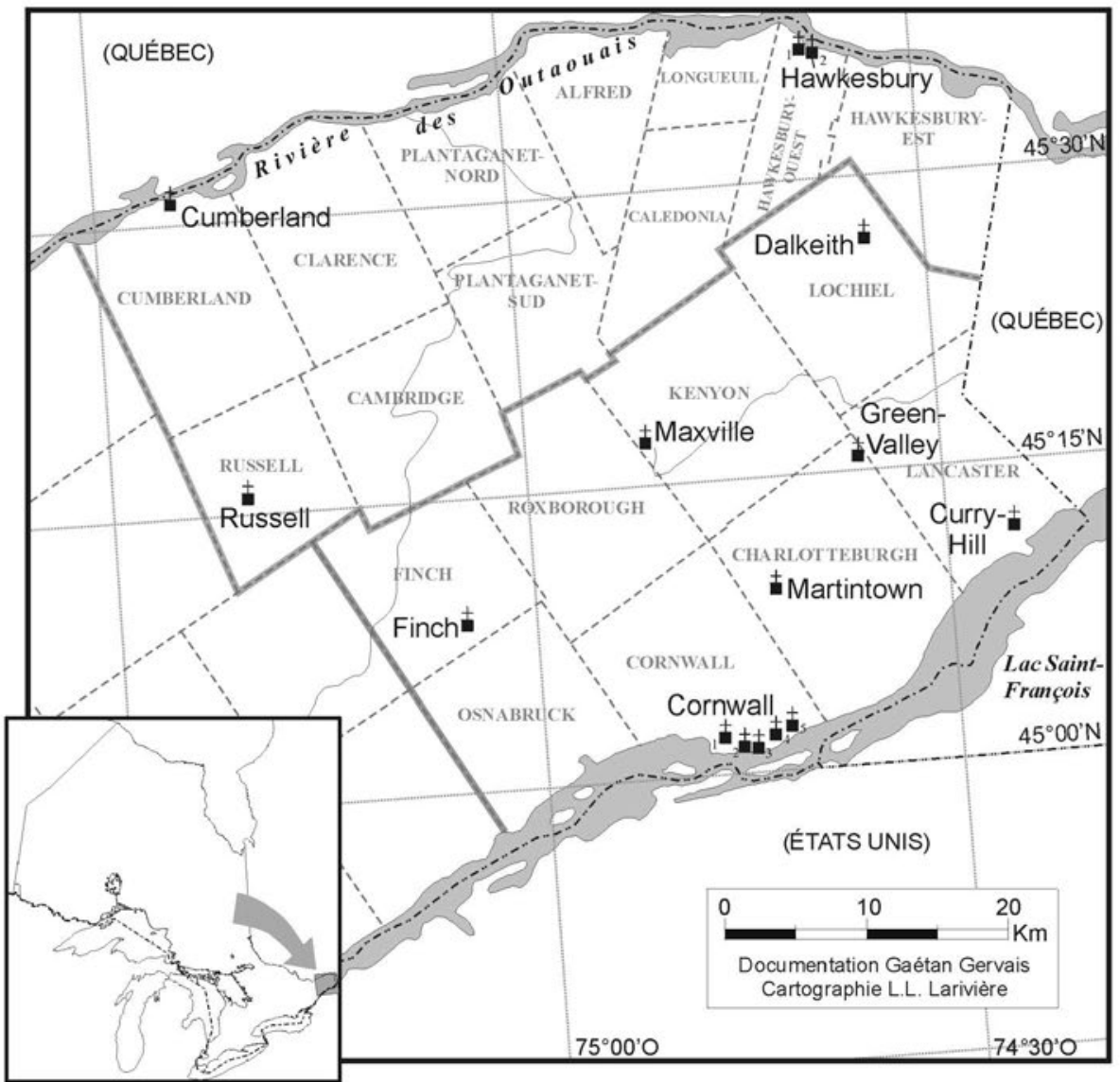


Sault-Sainte-Marie après 1940

L'industrialisation et l'urbanisation ont aussi transformé la région du Nord. Colonisée depuis les dernières décennies du XIX ${ }^{\mathrm{e}}$ siècle, cette région compte de nombreux ruraux, mais peu d'agriculteurs. Presque partout, après 1945, la «déruralisation» se poursuivit. Ce recul agricole avait en contrepartie confirmé la prééminence de l'exploitation

\section{TABLEAU XVII}

DIOCÈSE DE SAULT-SAINTE-MARIE (voir Carte XIV)

Paroisses françaises et bilingues fondées depuis 1940 (Parties des districts d'Algoma, de Sudbury et de Nipissing)

\begin{tabular}{cccccc}
\hline \multirow{2}{*}{$N^{\circ}$} & $N^{\circ}$ & & & & \\
Série & Carte & Lieu & Diocèse & Fondée & Paroisse \\
214 & 1 & Azilda & SSM & 1953 & Sainte-Agnès \\
215 & 2 & Burwash & SSM & 1960 & Notre-Dame-de-la-Confiance \\
216 & 3 & Dowling & SSM & 1963 & Saint-Étienne-Martyr \\
217 & 4 & Dubreuilville & SSM & 1969 & Sainte-Cécile \\
218 & 5 & Elliot-Lake & SSM & 1958 & Sainte-Marie \\
219 & 6 & Espanola & SSM & 1946 & Saint-Louis-de-France \\
220 & 7 & Estaire & SSM & 1941 & Saint-Léon \\
221 & 8 & Garson & SSM & 1954 & Saint-Augustin \\
222 & 9 & North-Bay & SSM & 1954 & Saints-Anges \\
223 & 10 & Sault-Sainte-Marie & SSM & 1964 & Sainte-Croix \\
224 & 11 & Sault-Sainte-Marie & SSM & 1999 & Sainte-Marie-du-Sault \\
225 & 12 & Sturgeon-Falls & SSM & 1947 & La Résurrection \\
226 & 13 & Sudbury (1) & SSM & 1949 & Saint-Eugène \\
227 & 14 & Sudbury (2) & SSM & 1953 & Annonciation \\
228 & 15 & Sudbury (3) & SSM & 1956 & Saint-Dominique \\
229 & 16 & Sudbury (4) & SSM & 1959 & Saint-Mathieu \\
230 & 17 & Sudbury (5) & SSM & 1971 & Saint-Ignace (Universitaire) \\
231 & 18 & Val-Caron & SSM & 1959 & Notre-Dame-de-l'Espérance \\
232 & 19 & Val-Caron & SSM & 1992 & Sainte-Marguerite-d'Youville \\
233 & 20 & Val-Thérèse & SSM & 1961 & Ste-Thérèse-de-l'Enfant-Jésus \\
234 & 21 & Wahnapitae & SSM & 1958 & Notre-Dame-de-la-Rivière \\
\hline
\end{tabular}

Nombre de paroisses sur la Carte XIV: 21 .

forestière et minière. Dans le Moyen-Nord, North-Bay aspira à tenir un rôle de carrefour des voies de transport et de centre gouvernemental. À l'ouest, Sault-Sainte-Marie de- 
vint au début du $\mathrm{XX}^{\mathrm{e}}$ siècle un important centre industriel doté d'une sidérurgie. Au centre de la région du MoyenNord, la ville de Sudbury possède une importante gamme de services divers (éducation, santé, mines, commerce) et elle se proclame la «capitale mondiale du nickel».

Avant la création du diocèse de Thunder-Bay en 1952, le diocèse de Sault-Sainte-Marie s'étendait jusqu'à l'ouest du lac Supérieur. Par la suite, le diocèse correspondit à la région du Moyen-Nord. Après 1940, 21 autres nouvelles paroisses furent créées dans ce diocèse (Carte XIV).

Carte XIV

Diocèse de Sault-Sainte-Marie

Paroisses françaises et bilingues fondées depuis 1940

(Parties des districts d'Algoma, de Sudbury et de Nipissing)

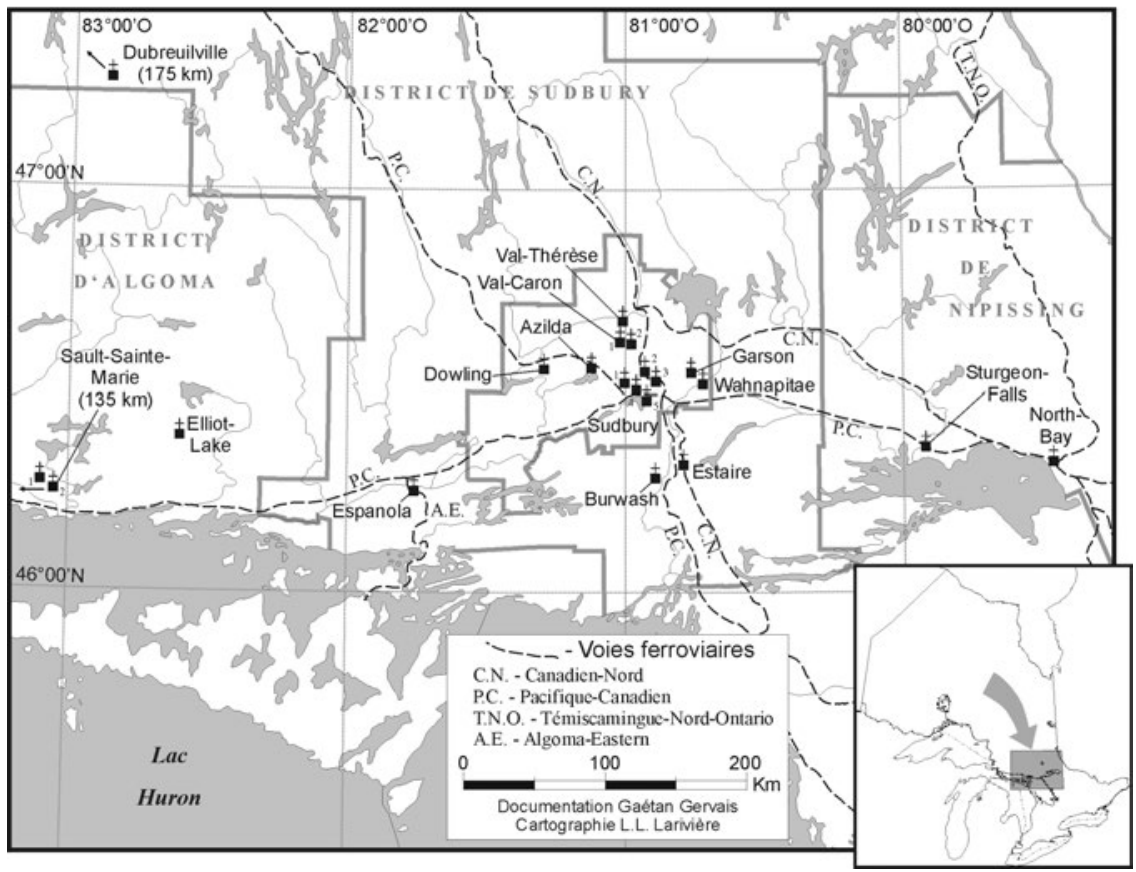


Cinq de ces fondations se produisirent à Sudbury même (Saint-Eugène, 1949, Annonciation, 1953, Saint-Dominique, 1956, Saint-Mathieu, 1959, et la Paroisse Universitaire, 1971, nom qu'elle porta jusqu'en 2003 quand elle devint Saint-Ignace), deux à Sault-Sainte-Marie (Sainte-Croix, 1964, et Sainte-Marie-du-Sault, 1999) et une à North-Bay (Saints-Anges, 1954). Plusieurs autres paroisses virent le jour dans «la Vallée » (Sainte-Agnès d'Azilda, 1953, NotreDame-de-l'Espérance de Val-Caron, 1959, et Sainte-Thérèse-de-l'Enfant-Jésus de Val-Thérèse, 1961, ces deux dernières remplacées par la paroisse de Sainte-Marguerited'Youville de Val-Caron, 1992). Des églises ont aussi desservi quelques villages près de Sudbury, aujourd'hui intégrés à la ville du Grand-Sudbury: Saint-Léon d'Estaire (1941), Notre-Dame-de-la-Confiance de Burwash (1960), SaintÉtienne-Martyr de Dowling (1963), Saint-Augustin de Garson (1954) et Notre-Dame-de-la-Rivière de Wahnapitae (1958).

On fonda d'autres paroisses dans des villes reliées à l'exploitation des richesses naturelles, comme Saint-Louisde-France d'Espanola (1946) et La Résurrection de SturgeonFalls (1947) avec leurs papeteries, comme Sainte-Marie d'Elliot-Lake (1958) avec ses mines d'uranium, comme Sainte-Cécile de Dubreuilville (1969) avec son exploitation forestière. 
Les diocèses de Timmins et de Hearst

Dans les régions du Grand-Nord, où se trouvent les diocèses de Timmins et de Hearst, on créa 14 nouvelles paroisses après 1940 (Carte XV). De ce nombre, trois furent érigées à Kapuskasing (Notre-Dame-des-Victoires, 1954, Notre-Dame-de-la-Paix, 1954, et Saint-Patrick, 1955), trois à Timmins (Saint-Dominique, 1947, Saint-Sauveur, 1957, et Notre-Dame-du-Perpétuel-Secours, 1959) et une à Hearst (Saint-Pie-X, 1955). Les huit autres paroisses se retrouvent dans de plus petits villages: les paroisses du Christ-Roi de Devonshire (1943), du Très-Saint-Sacrement de Holtyre (1955), des Saints-Martyrs-Canadiens d'IroquoisFalls (1949), de Saint-Jean-Baptiste de Long-Lac (1959), de Saint-Jude de Porcupine (1947), du Coeur-Immaculé-deMarie de Thornloe (1947) et de Saint-Pierre-Apôtre de Virginiatown (1948). 


\section{TABLEAU XVIII}

DIOCÈSES DE TIMMINS ET DE HEARST (voir Carte XV)

Paroisses françaises et bilingues fondées depuis 1940

(District de Témiscamingue et des parties des districts

de Cochrane, de Sudbury, d'Algoma et de Thunder-Bay)

\begin{tabular}{cccccc}
\hline \multirow{2}{*}{$\mathrm{N}^{\circ}$} & \multirow{2}{*}{$\mathrm{N}^{\mathrm{o}}$} & & & & \\
Série & Carte & Lieu & Diocèse & Fondée & Paroisse \\
235 & 1 & Devonshire & HEA & 1943 & Christ-Roi \\
236 & 2 & Hearst & HEA & 1955 & Saint-Pie-X \\
237 & 3 & Holtyre & TIM & 1955 & Très-Saint-Rédempteur \\
238 & 4 & Iroquois-Falls & TIM & 1949 & Saints-Martyrs-Canadiens \\
239 & 5 & Kapuskasing (1) & HEA & 1954 & Notre-Dame-des-Victoires \\
240 & 6 & Kapuskasing (2) & HEA & 1954 & Notre-Dame-de-la-Paix \\
241 & 7 & Kapuskasing (3) & HEA & 1955 & Saint-Patrick \\
242 & 8 & Longlac & HEA & 1959 & Saint-Jean-Baptiste \\
243 & 9 & Porcupine & TIM & 1947 & Saint-Jude \\
244 & 10 & Thornloe & TIM & 1947 & Coeur-Immaculé-de-Marie \\
245 & 11 & Timmins (1) & TIM & 1947 & Saint-Dominique \\
246 & 12 & Timmins (2) & TIM & 1957 & Saint-Sauveur \\
247 & 13 & Timmins (3) & TIM & 1959 Notre-Dame-du-Perpétuel-Secours \\
248 & 14 & Virginiatown & TIM & 1948 & Saint-Pierre-Apôtre \\
\hline
\end{tabular}

Nombre de paroisses sur la Carte XV: 14 . 


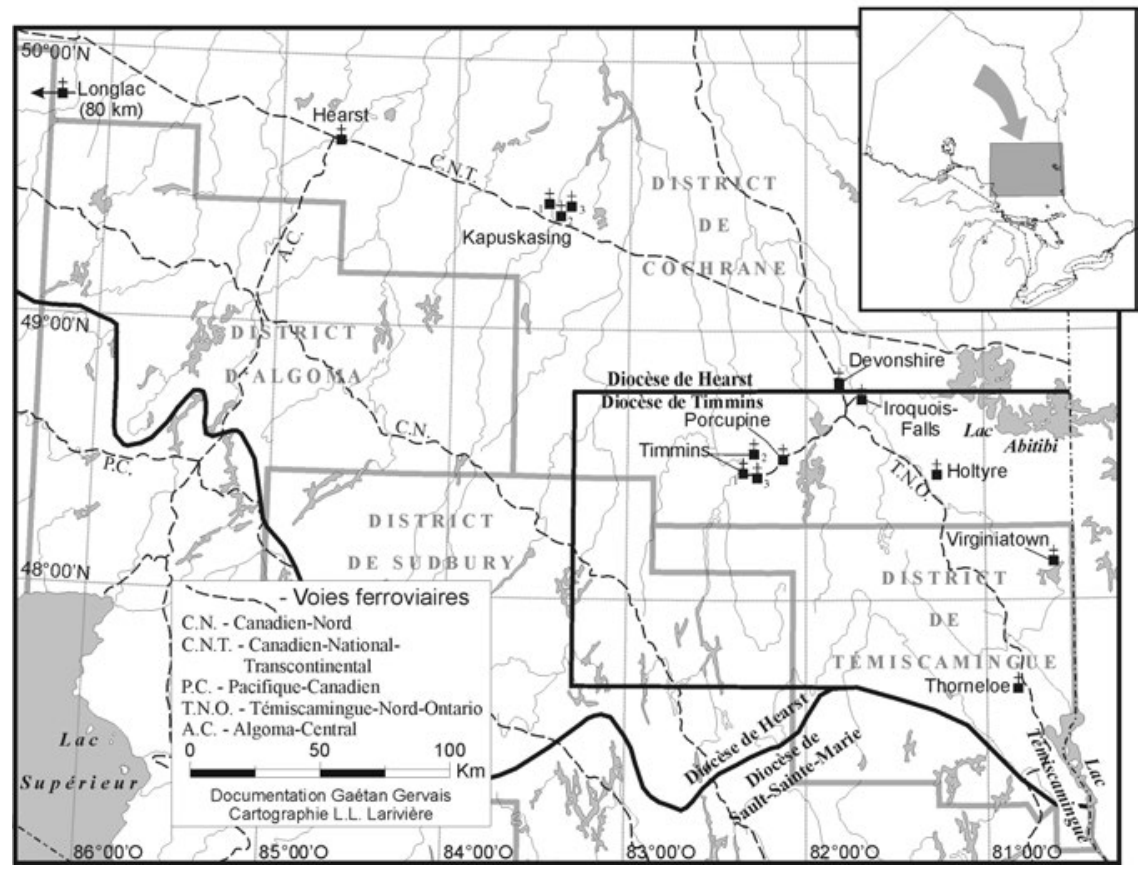

Le diocèse de Thunder-Bay

Le nord-ouest de l'Ontario chevauche deux régions hydrographiques: au sud de la hauteur des terres, on se retrouve dans le bassin du lac Supérieur et donc, après 1904, dans le diocèse de Sault-Sainte-Marie, tandis qu'au nord, c'est un territoire qui, au point de vue ecclésiastique, relevait de l'archidiocèse de Saint-Boniface. Cette deuxième composante explique un phénomène inattendu: la présence dans le Nord-Ouest d'une population anglaise dont le clergé est en grande partie canadien-français. Ainsi, il existe un groupe de dix paroisses qui ont longtemps bénéficié des services d'un clergé canadien-français (des oblats ou des séculiers), mais où la population est de langue anglaise: Atikokan, Dryden, Fort-Frances, Keewatin, 
Kenora, Pinewood, Rainy-River, Sioux-Lookout, plus des dizaines de missions. C'est par exemple le cas de SainteMarguerite de Fort-Frances (1893), dont les curés oblats appartenaient au diocèse de Saint-Boniface et étaient tous canadiens-français jusqu'au milieu du $\mathrm{XX}^{\mathrm{e}}$ siècle.

Aucune paroisse française n'a existé dans le Nord-Ouest de l'Ontario. Aujourd'hui, il existe seulement, à la paroisse St. Elizabeth de Thunder-Bay, une "communauté" de langue française (Carte XVI).

\section{TABLEAU XIX}

DIOCÈSE DE THUNDER-BAY (voir Carte XVI)

Paroisses desservies par le clergé canadien-français avant 1960

(Districts de Thunder-Bay, de Rainy-River et de Kenora)

\begin{tabular}{cccccc}
\hline $\mathrm{N}^{\mathrm{N}}$ & $\mathrm{N}^{\mathrm{o}}$ & & & & \\
Série & Carte & Lieu & Diocèse & Fondée & Paroisse \\
249 & 1 & Atikoken & THU & 1943 & Saint-Patrick \\
250 & 2 & Dryden & THU & 1925 & Saint-Joseph \\
251 & 3 & Fort-Frances & THU & 1893 & Sainte-Marguerite \\
252 & 4 & Fort-William & THU & 1893 & Saint-Patrice \\
253 & 5 & Keewatin & THU & 1904 & Saint-Louis \\
254 & 6 & Kenora & THU & 1881 & Notre-Dame-du-Portage \\
255 & 7 & Pinewood & THU & 1898 & Notre-Dame-du-Chemin \\
256 & 8 & Port-Arthur & THU & 1875 & Saint-André \\
257 & 9 & Rainy-River & THU & 1904 & Notre-Dame-du-Bon-Conseil \\
258 & 10 & Sioux-Lookout & THU & 1913 & Sacré-Coeur \\
\hline
\end{tabular}

Nombre de paroisses sur la Carte XVI: 10. 




G. LES PAROISSES ET LA PRÉSENCE FRANCO-ONTARIENNE

La Carte XVII indique par un point noir chacune des 258 paroisses du réseau franco-ontarien. On constate déjà que ces points sont concentrés dans les zones de peuplement franco-ontarien.

Évidemment, plusieurs découpages du territoire ontarien seraient possibles. La plus simple division distingue le Nord (souvent appelé le Nouvel-Ontario) du Sud (le «Vieil Ontario»). En Ontario français, la géographie mentale renvoie habituellement aux trois grandes régions de l'Est, du Nord et du Sud. Le gouvernement a augmenté, selon ses besoins et selon le domaine d'activités, le nombre de ses divisions administratives. On en trouve cinq, voire sept ou neuf, selon le besoin de chaque secteur.

Mettons de côté ces divers découpages et cherchons plutôt les zones de peuplement franco-ontarien. On peut, à 


\section{GaÉtan GeRVAIS}

la lumière de facteurs historiques et géographiques, en identifier sept (Carte XVIII).

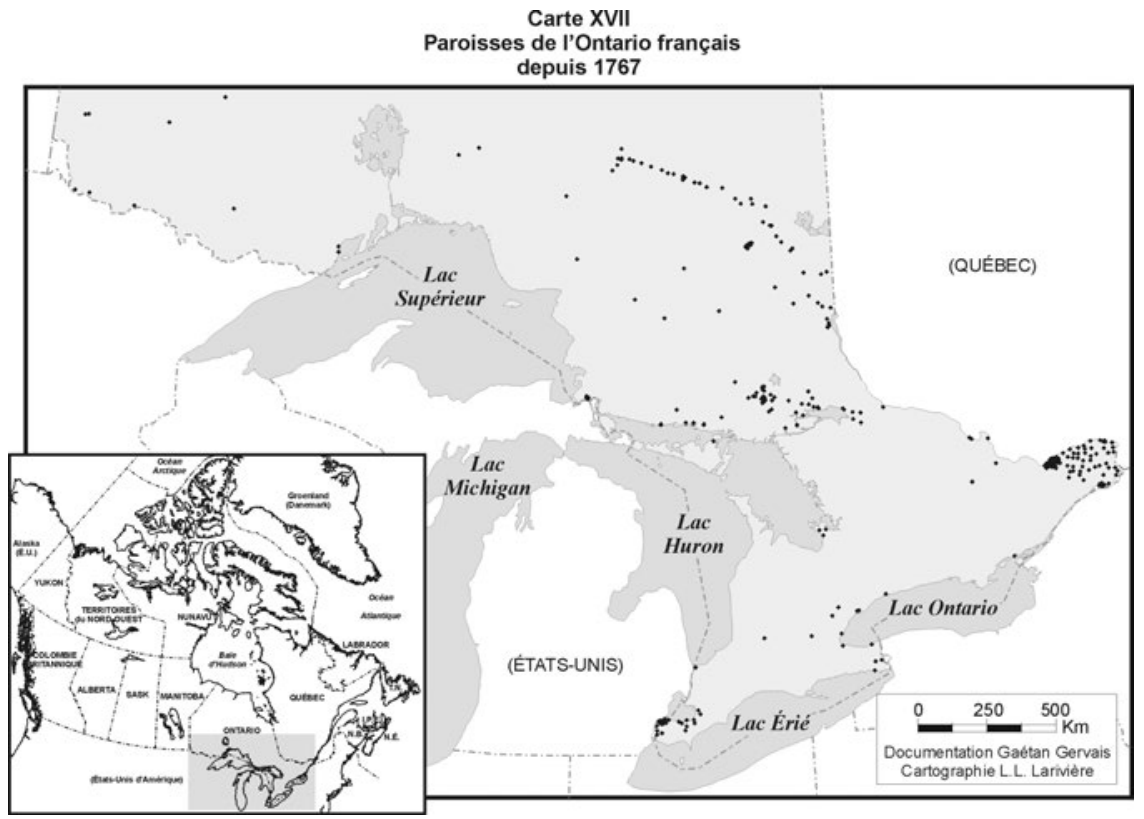

La région des comtés d'Essex et de Kent, dans le SudOuest, est le plus ancien centre de peuplement européen de l'Ontario (1749). Ici naquirent la première paroisse (1767) et la première école (1786) françaises de la province. Au XIX ${ }^{e}$ siècle, le peuplement original de l'Assomption s'étendit vers le sud, le long de la Petite-Côte, mais surtout vers l'est, dans les belles terres situées au sud du lac Sainte-Claire. Le peuplement se poursuivit dans la seconde moitié du XIX ${ }^{\mathrm{e}}$ siècle.

La Huronie constitue la deuxième région de colonisation. Situé au sud de la baie Georgienne, ce peuplement s'amorça en 1828 avec l'arrivée d'un groupe de voyageurs du commerce des fourrures, venus de l'île Drummond. Des colons arrivèrent du Québec pendant les décennies suivantes, s'établissant notamment à Pénétanguishene, à Lafontaine et à Perkinsfield (dans les cantons de Tiny et de Tay). 


\section{Carte XVIII}

Zones de peuplement

franco-ontarien

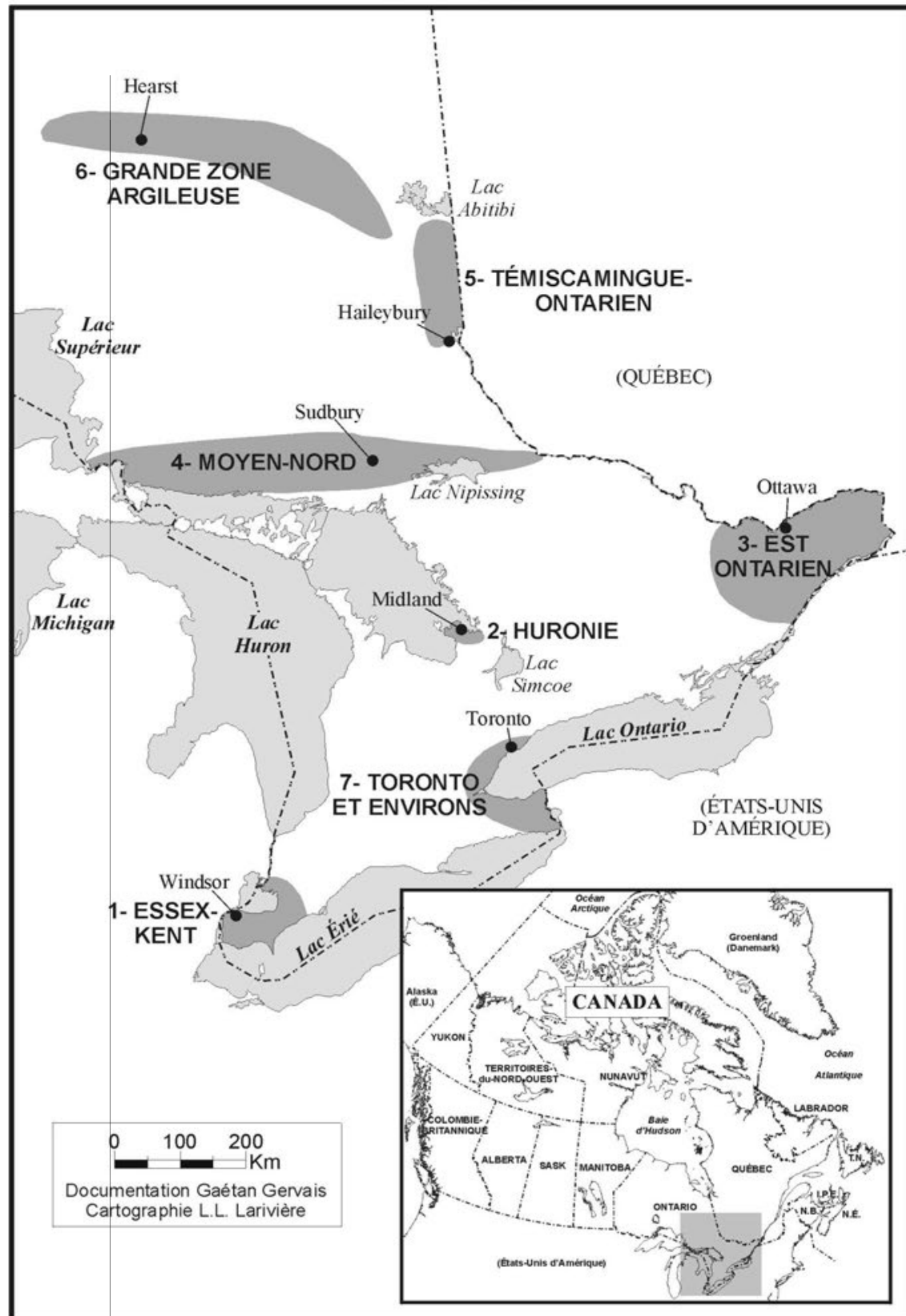


La troisième région de peuplement se situe dans l'est de l'Ontario, le long de la frontière du Québec, dans les comtés de Prescott, de Russell et de Carleton (1840-1900). Renforcée par la proximité de la province de Québec, par la présence du gouvernement fédéral avec ses fonctionnaires canadiens-français, par la disponibilité d'une abondante main-d'œuvre cléricale, la ville d'Ottawa devint la "capitale" de l'Ontario français, le siège de presque toutes les associations franco-ontariennes d'envergure provinciale. D'importantes associations et institutions y furent actives (l'ACFEO, l'Ordre de Jacques-Cartier, l'École normale d'Ottawa, les caisses populaires, l'association des enseignants, l'Université d'Ottawa). Les deux comtés de Prescott et de Russell représentent la région la plus homogène de l'Ontario français.

C'est le chemin de fer Pacifique-Canadien qui ouvrit une quatrième région, le Moyen-Nord, à la colonisation (18801920). Comme ailleurs, c'est un pays où domine le régime agroforestier. L'activité agricole et l'exploitation forestière, importantes dans le Nipissingue à l'est et sur la Rive-Nord à l'ouest, sont complémentaires. Au centre, outre la coupe du bois et l'agriculture, on exploite de grands gisements miniers qui ont assuré l'ascendant de la région de Sudbury au centre du Moyen-Nord.

Une cinquième région comprend l'Outaouais supérieur et les environs du lac Témiscamingue. Après la fourrure et la forêt, l'agriculture prit le relais économique, avec le fort encouragement des missionnaires oblats (1870-1910). Les meilleurs résultats, pourtant modestes, furent atteints à Mattawa et à Ville-Marie. Les découvertes, à partir de 1903, de plusieurs gisements argentifères et aurifères donnèrent à la région une vocation autant minière qu'agricole. Entre 1903 et 1914, de grandes ruées minières se produisirent. Au nord-est se trouve la Petite Zone argileuse.

La Grande Zone argileuse, la sixième zone, fut colonisée à partir de 1907 grâce au passage de la voie ferrée du 
Transcontinental (1910-1940). Cette région comprend l'important centre minier de Porcupine-Timmins, mais aussi des terres agricoles qui, de Cochrane à Hearst, se vidèrent rapidement après la Deuxième Guerre mondiale. La forêt et les mines sont ici la grande activité économique, compte tenu du déclin de l'agriculture.

La septième et dernière zone d'immigration est la grande région industrielle de Toronto et des villes environnantes (Oshawa, Brampton, Cambridge, Burlington et Hamilton). Cette région attire depuis 1945 des travailleurs et des membres des professions libérales, non seulement des autres régions du Canada, mais de toutes les parties du monde. Cette nouvelle population franco-ontarienne affiche souvent un visage multiculturel.

\section{Conclusion}

Il ne faut pas être grand clerc pour savoir que la paroisse a joué un rôle de premier plan en Ontario français. Les témoignages, à ce propos, convergent.

Soucieuses de protéger simultanément la langue et la foi, les élites nationalistes attribuèrent à la paroisse de langue française une double vocation, religieuse et nationale. Cette institution représentait, pour la minorité, un mécanisme de solidarité, alors que l'idée d'un réseau exprimait plutôt, surtout chez les élites cléricales, le sentiment de partager un même destin culturel. La paroisse devint donc, à l'époque du Canada français, un autre outil de la "survivance», au même titre que la famille ou l'école. Elle faisait partie du réseau institutionnel franco-ontarien, apportant à la minorité culturelle un support clérical fortement apprécié.

La plupart des paroisses françaises, et même bilingues, virent le jour sans provoquer de débats linguistiques. Dans les cas ordinaires, l'évêque prenait ses décisions, concernant la création des paroisses, à la lumière de 
considérations financières et selon la disponibilité de prêtres. Ce serait donc déformer l'histoire que de voir des conflits linguistiques partout. En pratique, plusieurs paroisses de langue française ont existé et continuent d'exister: comme les gens heureux, elles n'ont pas, du point de vue de la langue, d'histoire.

Au Canada, avant les années 1960, de nombreux conflits linguistiques se succédèrent, notamment en éducation. Dans l'Église catholique aussi, deux manières de voir l'avenir du français s'affrontaient. Les uns réclamaient des paroisses françaises, alors que les autres préféraient des paroisses territoriales englobant tous les fidèles d'un même secteur. Ainsi, les nationalistes canadiens-français et certains évêques anglo-celtes se retrouvèrent parfois dans des camps opposés.

De fait, la question linguistique ne surgit pas dans le vide. L'école, bilingue ou française, souleva en éducation des débats semblables. Il est d'ailleurs significatif que les mêmes arguments aient servi, de part et d'autre, au sujet des écoles et des paroisses. Le fond de ce débat, ancien, appartient à l'histoire des relations entre les deux groupes linguistiques du Canada. D'ailleurs, le conflit continue, comme le montre la récente lutte pour conserver le caractère français de l'hôpital Montfort d'Ottawa, et comme le manifestent encore les revendications actuelles pour l'université franco-ontarienne.

Quant au réseau des paroisses franco-ontariennes, il existait réellement, mais il ne jouissait d'aucune reconnaissance officielle. Combien de paroisses peut-on inclure dans le réseau? Le présent travail propose une liste provisoire de 258 noms. Il peut s'agir de paroisses homogènes de langue française, de paroisses bilingues ou de paroisses dont le clergé fut de langue française. Il est vrai que la durée de leur participation à ce réseau a pu être brève. Dans ce répertoire, certains noms font difficulté, causant des hésitations sur certaines paroisses, mais cette incerti- 
tude fait aussi partie de la vie minoritaire en Ontario.

Pendant un siècle, le nombre de paroisses créées en Ontario français et la chronologie de leurs dates de fondation ont reflété assez fidèlement l'expansion démographique de la minorité française. En effet, on peut identifier trois temps forts dans l'histoire des fondations: une première période (1875-1890) correspond à la colonisation de l'Est ontarien (29 paroisses sont fondées en quinze ans), une deuxième (1900-1930) répond au peuplement du Nord-Est (91 nouvelles paroisses en trente ans) et la troisième (1945-1965) s'explique par l'urbanisation qui suivit la Deuxième Guerre mondiale (55 érections de paroisses en vingt ans). Parmi les 258 paroisses de l'Ontario français, 177 (soit 68,6\%) furent fondées avant 1940. Peu de paroisses sont créées après 1970 .

Le dossier cartographique montre que ces paroisses se retrouvent, assez évidemment, dans les zones de peuplement canadien-français. Ces cartes et leurs légendes fournissent une liste exhaustive des 258 paroisses identifiées, avec la date de fondation et le diocèse d'attache de chacune. La dernière partie de ce travail brosse, trop sommairement sans doute, un portrait schématique du réseau des paroisses. Ce répertoire permet au moins de confirmer le lien entre l'Ontario français et l'institution paroissiale avant les années 1960.

Tout en reconnaissant le caractère religieux de la paroisse, il faut par ailleurs tenir compte de son rôle social. Pour une minorité culturelle comme l'Ontario français, la paroisse est appelée à intervenir dans plusieurs champs d'activités. Les élites canadiennes-françaises ont longtemps tenu un discours qui en faisait une institution centrale. À leurs yeux, la paroisse exerçait donc deux fonctions complémentaires, tout comme les nationalistes étaient à la fois catholiques et français.

Le prestige dont bénéficiait la paroisse s'estompe dans les années 1960, quand se désagrégea le réseau clérical 
qui avait longtemps supporté les institutions canadiennesfrançaises, notamment dans le domaine de l'enseignement. Pendant que la paroisse retrouvait sa vocation pastorale, d'autres institutions et organismes culturels prirent la relève dans les domaines profanes. Cette transformation s'explique par divers facteurs: l'urbanisation, la mutation du nationalisme canadien-français en nationalisme québécois, le déclin du nombre de vocations, la baisse de la pratique religieuse, les réformes du concile Vatican II. La fermeture d'églises commença dans les années 1970 et se poursuit encore aujourd'hui.

À ce premier inventaire, il manque beaucoup d'éléments. En particulier, il importerait de camper le réseau paroissial dans son milieu ontarien à majorité protestante. Des questions comme les écoles séparées s'y rattachent. De même, il faudrait étudier les modalités d'organisation d'une paroisse: le recrutement et la formation d'un clergé diocésain, ses relations avec la hiérarchie, ses effectifs, y compris dans les communautés religieuses. L'organisation de la paroisse se conforme à un modèle, avec un cheminement délimité et des étapes à franchir: la mission, la vie religieuse, les premiers prêtres et l'érection de la paroisse (la construction de l'église, du presbytère, de l'école, l'aménagement du cimetière, l'organisation de diverses activités, en commençant par la vie religieuse).

La paroisse, au temps du Canada français, joua en Ontario français un rôle central. Elle fait partie du système général des institutions de la minorité franco-ontarienne.

\section{Remerciements}

L'auteur tient à remercier l'Université Laurentienne, notamment les vicerecteurs, Messieurs Harley d'Entremont et Doug Parker, qui ont accordé une subvention généreuse à la préparation des cartes. L'auteur veut aussi remercier le cartographe Léo Larivière qui a dessiné toutes les cartes. Enfin, l'auteur tient à remercier ses collègues de la Société Charlevoix qui ont lu cet article et ont fait des suggestions utiles pour l'améliorer. 